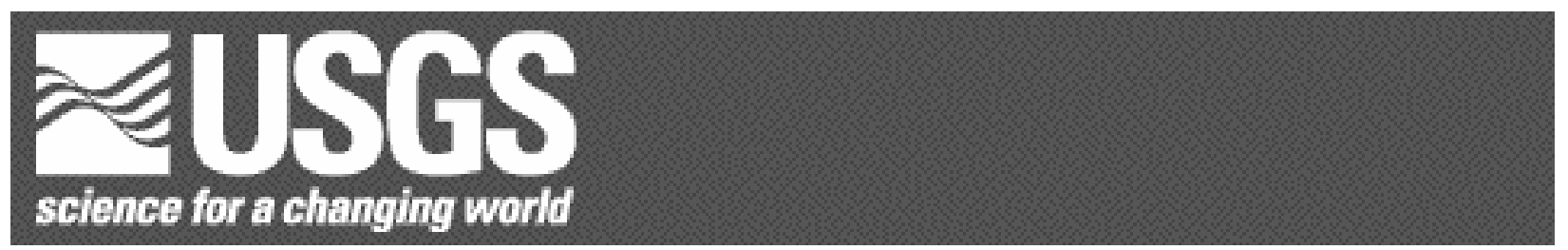

\title{
Abstracts of the Annual Meeting of Planetary Geologic Mappers, Nampa, Idaho 2006
}

Edited By Tracy K.P. Gregg, ${ }^{1}$ Kenneth L. Tanaka, ${ }^{2}$ and R. Stephen Saunders 3 Open-File Report 2006-1263

2006

Any use of trade, firm, or product names is for descriptive purposes only and does not imply endorsement by the U.S. Government.

U.S. DEPARTMENT OF THE INTERIOR

U.S. GEOLOGICAL SURVEY

${ }^{1}$ The State University of New York at Buffalo, Department of Geology, 710 Natural Sciences Complex, Buffalo, NY 14260-3050.

${ }^{2}$ U.S. Geological Survey, 2255 N. Gemini Drive, Flagstaff, AZ 86001.

${ }^{3}$ NASA Headquarters, Office of Space Science, 300 E. Street SW, Washington, DC 20546. 
Report of the Annual Mappers Meeting

Northwest Nazarene University

Nampa, Idaho

June 30 - July 2, 2006

Approximately 18 people attended this year's mappers meeting, and many more submitted abstracts and maps in absentia. The meeting was held on the campus of Northwest Nazarene University (NNU), and was graciously hosted by NNU's School of Health and Science. Planetary mapper Dr. Jim Zimbelman is an alumnus of NNU, and he was pivotal in organizing the meeting at this location. Oral and poster presentations were given on Friday, June 30. Drs. Bill Bonnichsen and Marty Godchaux led field excursions on July 1 and 2.

USGS Astrogeology Team Chief Scientist Lisa Gaddis led the meeting with a brief discussion of the status of the planetary mapping program at USGS, and a more detailed description of the Lunar Mapping Program. She indicated that there is now a functioning website (http://astrogeology.usgs.gov/Projects/PlanetaryMapping/Lunar/) which shows which lunar quadrangles are available to be mapped. Like other USGS-published maps, proposals to complete a lunar geologic map must be submitted to the regular Planetary Geology \& Geophysics (PGG) program for peer review. Jim Skinner (USGS) later presented the progress of the 1:2.5M-scale map of the lunar Copernicus quadrangle, and demonstrated the wide range of data that are available to support these maps. Gaddis and Skinner encouraged the community to submit proposals for generating lunar geologic maps, and reminded us that, as for all planetary maps, the project must be science-driven.

Venus mapper Jim Zimbelman of the Smithsonian Institution (SI) presented the progress for his V-15 and V-16 quadrangles; Vicki Hansen (University of Minnesota Duluth) showed her preliminary work on V-45. Zimbelman addressed an issue that has been plaguing the community: "delinquent Venus mappers." In short, there were a number of Venus maps funded in the early 1990s under the Venus Data Analysis Program (VDAP). Unfortunately, funding for this program was cut before many Venus maps could be completed, resulting in about 10 Venus maps that were initially assigned but have shown little or no progress in many years. Zimbelman announced that he was not going to be able to complete quadrangle V-27 that he was assigned under VDAP, and was therefore returning that quadrangle to the community; he invited people to propose to PGG to map this quadrangle.

Dave Williams of Arizona State University (ASU) reported on the progress of his global Io map. His mapping team recently received the completed, controlled global mosaic (using Voyager and Galileo images) from the USGS; this will be the basemap for their geologic mapping. Furthermore, the three team members (Laszlo Keszthelyi, David Crown and Dave Williams) have calibrated their individual mapping techniques by each mapping the same region for comparison. Thomas Doggett (ASU) showed progress on the global Europa map that was awarded to Ron Greeley. There was some consternation expressed on the methodology for determining relative ages of the lineaments; it was suggested that Vicki Hansen contact Patricio Figueredo (Exxon) directly, because Figueredo is the one who has been developing the lineament mapping techniques. 
Mars remains the most popular planet to map. Kevin Williams (SI) and Corey Fortezzo (SI) presented progress on their 1:500K maps in the Margaritifer Terra region of Mars. Jim Zimbelman described his 1:1M Medusae Fossae map, which is nearing completion. Peter Mouginis-Mark (University of Hawai'i) reported progress on his 1:200K maps of Tooting crater and of the Olympus Mons summit caldera. Jim Skinner discussed the progress of his and Ken Herkenhoff's (USGS) map (1:500K) on the Olympia Cavi region of Mars' north pole, and Eric Kolb (USGS) presented work that he and Ken Tanaka (USGS) are completing on the Martian south pole. David Crown of the Planetary Science Institute (PSI) reported on numerous 1:500K and 1:1M maps in the Hellas and Hesperia regions of Mars. Frank Chuang (PSI) discussed progress on mapping the Deuteronilus Mensae region of Mars with David Crown. Finally, Tracy Gregg (University at Buffalo) presented preliminary results of a 1:2M Hesperia Planum mapping project with David Crown.

During discussion, it was concluded that we will attempt to hold the next mappers meeting in Tucson, at the Planetary Science Institute, during the $2^{\text {nd }}$ or $3^{\text {rd }}$ week in June. David Crown volunteered to coordinate that effort. At Lisa Gaddis' suggestion, we may try to coordinate this with a 1-day digital mapping workshop, sponsored by the USGS. 


\section{CONTENTS}

\section{Venus}

Geologic Mapping of V-11 Shimti Tessera and V-12 Vellamo Planitia, Venus J.C. Aubele

Geologic Mapping of the Beta Regio Quadrangle (V-17), Venus: Constraints on Beta Rise Evolution
A.T. Basilevsky

Preliminary Report on Geologic Mapping of Isabella Quadrangle (V-50) and Helen Planitia, Venus L.F. Bleamaster

Geologic Mapping of the Guinevere Planitia Quadrangle of Venus D.A. Crown and E.R. Stofan

Mapping in the Fredegonde (V-57) Quadrangle, Venus: Preliminary Results M.A. Ivanov and J.W. Head

Geologic History of the Lavinia Planitia/Lada Terra Region, Venus: Results of the Mapping in the V-55, V-61, and V-56 Quadrangles

M.A. Ivanov and J.W. Head

Mapping of the V-7 Quadrangle: Sequence of Events During Formation of Lakshmi Planum, Venus M.A. Ivanov and J.W. Head

Geology of the Juno Chasma Quadrangle (V-47), Venus D.A. Senske

Geology of the Phoebe Regio Quadrangle (V-41), Venus D.A. Senske

Geology of the Tellus Tessera Quadrangle (V-10), Venus D.A. Senske

Mapping of Quadrangle V-53: Themis Regio E.R. Stofan and A.W. Brian

\section{Galilean Satellites}

Global Geologic Map of Europa

T. Doggett, P. Figueredo, R. Greeley, T. Hare, E. Kolb, K. Mullins, D. Senske, K. Tanaka, and S. Weiser

A Global Geologic Map of Ganymede at 1:15M 
G.W. Patterson, J.W. Head, G.C. Collins, R.T. Pappalardo, L.M. Proctor, and

B.K. Lucchitta

Global Geologic Mapping of Io: First Steps

D.A. Williams, L. Keszthelyi, P. Geissler, W. Jaeger, and T. Becker

\section{Moon}

The Lunar Geologic Mapping Program: Summer 2006 Status

L.R. Gaddis, J.A. Skinner, Jr., T. Hare, K. Tanaka, B.R. Hawke, P. Spudis, B. Bussey, C. Pieters, and D. Lawrence

The Comparison and Origin of Copernicus Rays: Implications for the CopernicanEratosthenian Boundary

B.R. Hawke, T.A. Giguere, L.R. Gaddis, B.A. Campbell, D.T. Blewett, J.M. Boyce, J.J. Gillis-Davis, P.G. Lucey, C.A. Peterson, M.S. Robinson, and G.A. Smith

Progress on Mapping the Copernicus 1:2,500,000-Scale Quadrangle on the Moon: Impact Crater Facies and Mineralogies

J.A. Skinner, Jr., L.R. Gaddis, and K.L. Tanaka

\section{Mars}

Geologic Mapping of the Highland/Lowland Boundary Zones: Eastern Hellas Planitia and Deuteronilus Mensae, Mars

D.A. Crown, L.F. Bleamaster, and F.C. Chuang

Mapping Margaritifer Terra: MTMS -15017, -20002, -20007, -20017, -20022, -25002, $-25007$

C.M. Fortezzo, K.K. Williams and J.A. Grant

Geologic Mapping of Olympus Mons Caldera, Mars, at 1:200K

Peter J. Mouginis-Mark

1:200K Geologic Mapping of the Martian Impact Crater Tooting Peter J. Mouginis-Mark

Geologic Mapping Results of the Olympia Cavi Region of Mars (MTM 85200): Units and History

J.A. Skinner, Jr., and K. Herkenhoff

Geologic Mapping and Stratigraphy of North Polar Deposits on Mars: Preliminary Results

K.L. Tanaka, K.F. Mullins, J.A. Skinner, Jr., J.A.P. Rodriguez, and C.M. Fortezzo

Geologic Mapping of the Medusae Fossae Formation on Mars and the Northern Lowland Plains of Venus

\section{J.R. Zimbelman}




\section{GEOLOGIC MAPPING OF V-11 SHIMTI TESSERA AND V-12 VELLAMO PLANITIA, VENUS}

J.C. Aubele, New Mexico Museum of Natural History \& Science, Albuquerque, NM jayne.aubele@ state.nm.us

Plains terrain covers $\sim 80 \%$ of the surface of Venus[1]; however, the mechanism(s) of formation and age(s) represented by the plains continue to be debated. While the plains are assumed to be volcanic in origin, with subsequent modification by tectonism, impact cratering, and aeolian processes [2], there is a paucity of large volcanic centers occurring within the lowland plains [1,3]. The volcanic edifices that do commonly occur are small, predominantly shield-type, volcanoes.

These small volcanoes were first examined in detail using Venera 15/16 data by this author and colleagues [4]. Magellan data enabled this author and colleagues to classify their morphology, to recognize that they frequently occurred in clusters [5], and to first name these clusters "shield fields" [6]. Shield fields were interpreted to be similar to terrestrial volcanic fields, with associated material covering an area beyond the edifices. In many cases the stratigraphic relationships of these fields are uncertain, but some clearly post-date and some pre-date surrounding regional plains.

Questions of plains formation can be tested by detailed mapping using Magellan SAR images and other Magellan data sets [7]. V-11 and V-12 were originally proposed for mapping under VDAP, in order to analyze the relationship of small volcanoes and lowland plains. Four possible stratigraphic models were anticipated to be tested: (1) small volcanoes are the source of local flows that form or resurface the plains; (2) small volcanoes and the plains formed simultaneously, which implies that the edifices are localized point sources within a larger extrusive mechanism; (3) small volcanoes predate most of the plains terrain, which implies an early small edifice building stage and subsequent change in eruption style; or (4) small volcanoes postdate most of the plains terrain, which implies a change in eruption style to late localized centers or regions of volcanism.

Quadrangle V-12 was mapped (Fig.1), and reports were presented in the mid-late 1990s [8]. The reports included the description and interpretation of a new unit in V-12, the "shield plains" or "Akkruva shield plains,” designated as Psh in the preliminary map. The type example of this unit is located at Akkruva Colles, $43 \mathrm{~N}, 131.5 \mathrm{E}$, and consists of an average density of small volcanoes numbering $4500 / 10^{6} \mathrm{~km}^{2}$. Unit Psh exhibits consistent characteristics and stratigraphic relationships within $\mathrm{V}$-12. It was interpreted as a distinctive plains unit erupted by, or in association with, small volcanoes, and a useful local to regional stratigraphic marker. Preliminary mapping of $\mathrm{V}-11$ tested the significance and extent of the unit; it has been mapped over an area of $2.3 \mathrm{X} 10^{6} \mathrm{~km}^{2}$ in $\mathrm{V}-11$ and $\mathrm{V}-12$.

Following the initial reports of the Akkruva shield plains, authors of other Venus quadrangles also identified and mapped similar shield plains or shield terrain [9] units. Some of these units have similar stratigraphic relationships to the Akkruva unit, for example in V-3, 4, 13, 23, 24, 54, 55, and 56 [10]; other mappers have found different stratigraphic relationships, for example in V-8 and V-20 [11]. A shield plains unit is included in the proposed global stratigraphy of Venus [12] and has been suggested to be a globally widespread unit [13]. It has also been described as a thin, discontinuous, mechanically coherent layer (shield paint), with map relations that are inconsistent with a global stratigraphy but, instead, provide evidence for a new model of plains resurfacing $[9,14]$. Others have described the small volcanoes as responsible for a large component of local-scale resurfacing throughout Venus geologic history [15].

$\mathrm{V}-11$ and $\mathrm{V}-12$ provided the original definition and type example of this unit, and although a decade has passed since the initial mapping (due to the abrupt end of the VDAP program and a change in job), it is clearly useful to provide a reviewed and published map interpretation of this unit. While it may not provide the final, definitive answer, it is anticipated that geologic maps of $\mathrm{V}-11$ and V-12 will provide additional data to better understand (1) differences and similarities of shield fields and shield plains, (2) stratigraphic relationships and regional extent of the Akkruva shield plains, and (3) possible significance of the Akkruva shield plains for style of volcanism and resurfacing. The steps needed for completion are: (1) complete detailed mapping of $\mathrm{V}-11$; (2) revise $\mathrm{V}-12$ geologic map as needed based on contact relationships with $\mathrm{V}-11$ and with adjoining published maps; (3) finalize description of units and accompanying text for both maps; and (4) submit both maps for review by the end of the 2006 calendar year.

[1] Guest et al (1992) JGR 97. [2] Squyres et al (1992) JGR 97; Arvidson et al (1992) JGR 97; Greeley et al (1992) JGR 97; Campbell et al (1992) JGR 97. [3] Head et al (1992) JGR 97, 13153; Crumpler et al (1989) Sci 246, 273. [4] Aubele\&Slyuta (1990) EMP, 50/51, 493; Garvin\&Williams (1990), GRL17, 9, 1381. [5] Aubele (1993) LPSC24, 47; Crumpler et al (1997) in Venus II UofA Press; Crumpler\&Aubele (2000) in H. Sigurdsson et al Encyl of Volcanology Academic Press. [6] Aubele\&Crumpler (1992) International Colloquium on Venus, LPI Contrib. 789. [7] Tanaka et al (1993) Venus Geol Mappers Handbk, Open-file 93-516; Tanaka et al (1997) Venus II. [8] Aubele (1997) GSA Abst. 29, no. 6, A-138; Aubele (1996) LPSC 27, 49; Aubele (1995) LPSC 26, 59; Aubele (1994) LPSC 25, 45; Aubele (1993) GSA Abst. 25, A-221. [9] Hansen (2005) GSA Bull 117, no.5/6. [10] Bridges \& Mercer (2002) LPSC 33; Lang\&Hansen (2003) LPSC 34; Young\&Hansen (2003) USGS I-2783; Ivanov\&Head (2006) LPSC 37; Ivanov\&Head (2001) USGS I-2684; Ivanov\&Head (2003) USGS I-2792; Ivanov\&Head (2005) USGS I-2870. [11] Addington (1999) LPSC 30; McGill (2000) USGS I-2637. [12] Basilevsky\&Head (2002) Geology 30, 1015; Basilevsky\&Head (2000) PlanSpSci 48. Basilevsky\&Head (1998) JGR 103, 8531; Head \& Basilevsky (1998) Geology 26, 35. [13] Kortz\&Head (2002) LPSC 31; Ivanov\&Head (2004) JGR 109, E10. [14] Hansen (2003) LPSC 34. [15] Stofan et al (2004) LPSC 35. 


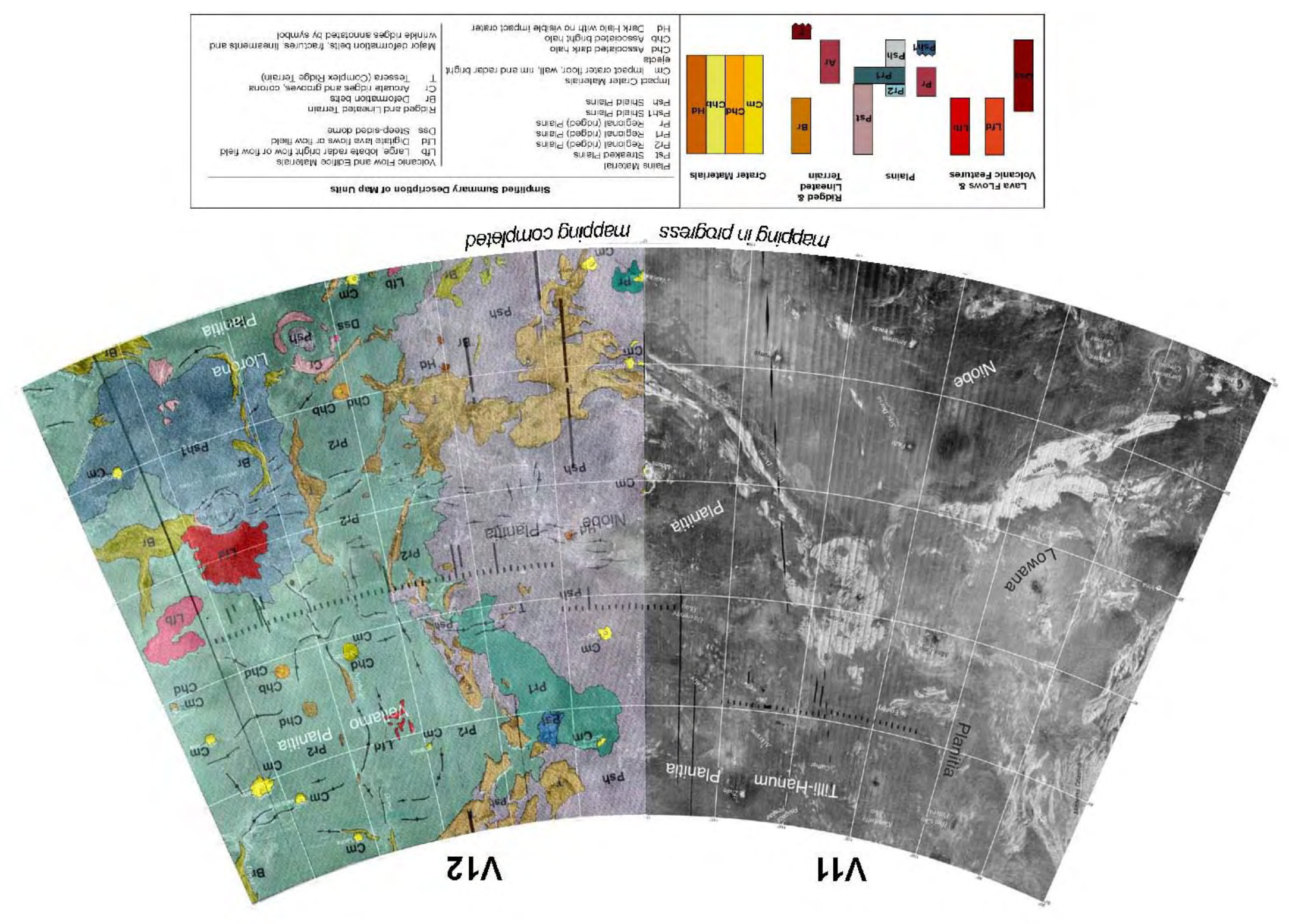


GEOLOGIC MAPPING OF THE BETA REGIO QUADRANGLE (V-17), VENUS: CONSTRAINTS ON BETA RISE EVOLUTION. Alexander T. Basilevsky, Vernadsky Institute of Geochemistry and Analytical Chemistry, Russian Academy of Sciences, 119991 Moscow, Russia and Department of Geological Sciences, Brown University, Providence, RI 02912, USA, atbas@geokhi.ru; Alexander_Basilevsky@Brown.edu.

Summary: Geologic mapping of the V-17 quadrangle, which includes a significant part of the Beta Regio domical topographic rise (considered to be driven by mantle plume) and the analysis of the mapping results revealed the sequence of geologic units and structures and their relations to the rise. We show evidence that the Beta uplift started closely before the emplacement of psh/pwr regional plains whose global mean age is close to the mean surface age of the planet $\mathrm{T}=300 \mathrm{~m}$.y. to $1 \mathrm{~b} . \mathrm{y}$. [11]. The rise was continuing up to the recent time suggesting that the plume was active for several hundreds of millions of years and may be active now.

Introduction: This study is based on the results of the geologic mapping of the V-17 quadrangle (25$50^{\circ} \mathrm{N}, 270-300^{\circ} \mathrm{E}$ ), which includes a significant part of Beta Regio and the adjacent areas. This project used the traditional methods of geologic unit definition and characterization for the Earth [e.g., 1] and planets [e.g., 13] modified for radar data [12]. Presented here are the results of the map revision resubmitted to USGS in May 2006.

The mapped units: In the V-17 quadrangle there were mapped 8 geologic material units, dividing two of them into subunits, and three tectonic units. Their morphology and age sequence are shown in Figure 1.

Tessera material (tt) is the oldest unit in the quadrangle. It is relatively radar bright, characterized by at least two sets of intersecting ridges and grooves resulting from tectonic deformation of some precursor terrain and is embayed by most of the other units.

Densely fractured plains material ( $p d f$ ) has rather flat surfaces, cut by swarms of subparallel lineaments, sometimes resolved as fractures. The general flatness of unit outcrops suggests that it was plains, probably made of mafic lavas [see e.g., 3].

Fractured and ridged plains material (pfr) is medium-bright with a predominantly smooth surface suggesting that it is composed of mafic lavas. The pfr unit is commonly deformed by broad ridges, forming ridge belts.

Shield plains material (psh) is of intermediate radar brightness and characterized by abundant shields interpreted to be of volcanic origin [e.g., 8]. Typically shield plains are embayed by plains with wrinkle ridges and are wrinkle ridged, but in a few places, separate shields and shield clusters are superposed on wrinkle ridges.

Wrinkle ridged plains material ( $p w r$ ) is represented by plains material of intermediate-low to intermediate- high radar brightness complicated by narrow wrinkle ridges. The volcanic (lava) origin of the pwr plains globally and within V-17 is supported by flow-like morphology of one of the subunits of this unit and by presence of the lava channels [8]. The pwr unit was subdivided into four subunits: the age sequence of pwr1, pwr2 and pwr3 plus pwru - undivided. Pwr and psh plains are often called altogether regional plains.

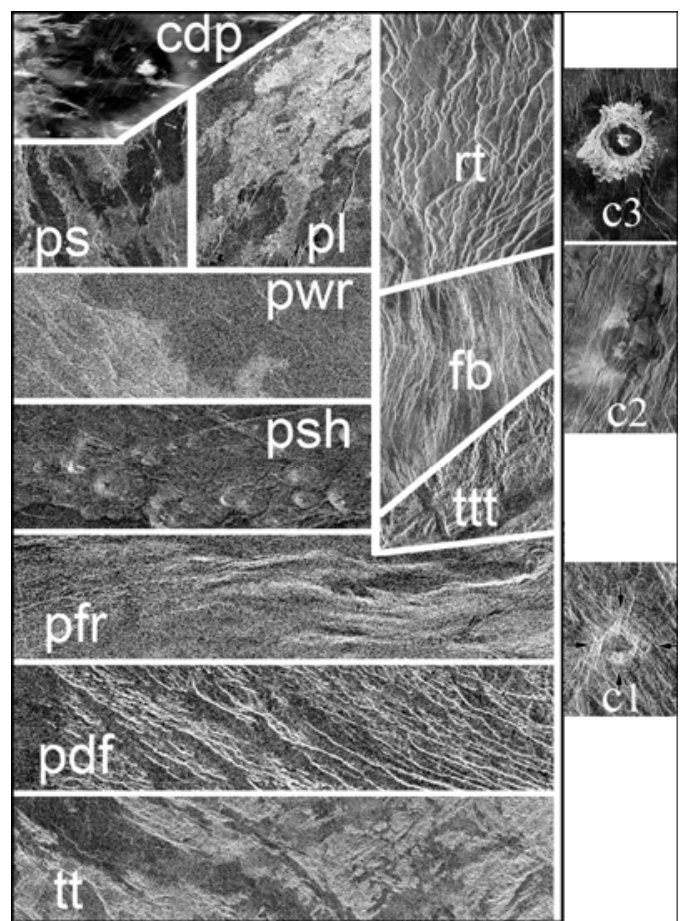

Figure 1. Stratigraphic column for the V-17 Beta Regio quadrangle. Unit cdp (material of dark parabola craters) was not found within the quadrangle but some parts of ps, pl and rt units may be contemporaneous to cdp.

Smooth plains material (ps) is radar dark and morphologically smooth. It is observed in the form of fields typically of irregular outlines and tens of kilometers across. Similar fields have been interpreted by [8] as flows of very liquid lava.

Lobate plains material ( $\mathrm{pl}$ ) is mostly radar bright. Their prominent flow-like texture and association with obvious volcanic constructs prove that unit $\mathrm{pl}$ is composed of lavas [8].

Impact crater material unit (C). Within the V-17 quadrangle there are 25 impact craters. They were subdivided into three age subunits: a lower one (C1) pre-regional plains (pwr+psh) craters (crater Aigul); a middle one (C2) - post-regional plains craters with faint or no associated radar-dark halo (12 craters); and 
an upper one (C3) - post-regional plains craters with clear halo (12 craters).

Within the V-17 quadrangle there were identified three tectonic units. The places saturated with young post-pwr fractures and graben have been mapped as tectonic unit of rifted terrain (rt), mostly in the N-S axial zone of the Beta rise. Fractures and graben of the rt unit deform all materials including the youngest ps and pl units, but locally are flooded by the pl lavas.

Within V-17 there are linear zones saturated with faults distinct from those of rt unit in morphology (Figure 1) and in age. They have been mapped as a tectonic unit of fracture belts $(\mathrm{fb})$ and are considered as close in origin to the rt zones $[6,7]$. The fb faults cut units tt, pdf and pfr and are embayed by units psh and pwr, although some of fb faults cut psh and pwr.

In several places of the $\mathrm{V}-17$ quadrangle, there are areas of terrain resembling tessera in morphology. It is formed at the expense of fracturing of the material units pfr and pdf. In contrast to units rt and fb, this type of terrain typically forms equidimensional areas. Following [9] we mapped these areas as a tectonic unit of tessera transitional terrain (ttt).

Spatial distribution of units and structures: Based on the mapping results, we have analyzed the distribution and trends of different units and structures. It was found that tt, pdf, pfr and ttt structures show no correlation with the Beta rise planimetric geometry but next in time sequence, fb unit forming, in particular, the Agrona Linea belt and its structures do show the alignment. This is considered as the first morphologic signature of the initiation of the Beta uplift. Formed next in time, pwr plains obviously avoid the Beta rise thus confirming that it was already an upland area. However, the wrinkle ridge network, formed next, does not show a clear alignment with the Beta geometry, probably suggesting that the rise at that time was not sufficiently high to form the topographic load which could control the wrinkle ridge orientation.

Dating the Beta activity using the degree of crater dark halo preservation: This was done through analysis of age relations of four impact craters with pl lavas and rt faults. The craters are: 1) crater Sanger $\left(33.8^{\circ} \mathrm{N}, 288.6^{\circ} \mathrm{E}, \mathrm{D}=84 \mathrm{~km}\right)$, has a clear dark halo and its ejecta outflows are cut by faults branching from the Devana Chasma rift; 2) crater Raisa $\left(27.5^{\circ} \mathrm{N}\right.$, $280.3^{\circ} \mathrm{E}, 13.5 \mathrm{~km}$ ), has a faint halo $(\mathrm{FH})$ and is partly flooded by Theia Mons pl lavas; 3 ) the FH crater Olga $\left(26^{\circ} \mathrm{N}, 284^{\circ} \mathrm{E}, 15.5 \mathrm{~km}\right)$, superposed on some rt faults and cut by others; and 4) $\mathrm{FH}$ crater Tako $\left(25^{\circ} \mathrm{N}, 285^{\circ} \mathrm{E}\right.$, $11 \mathrm{~km})$, superposed on pl lavas associated with a branch of Devana Chasma rift. A number of authors $[2,5,6,10]$ showed that craters with faint or no associated dark halo formed within the first part of the post-regional plains time period $\mathrm{T}$, while craters with clear dark halos, within the second part of it, but earlier than 0.1-0.15T ago. So the described relations suggest that the Theia Mons pl volcanism and the Devana Chasma rt rifting were active at least within some period of time between $\mathrm{T}$ and $0.5 \mathrm{~T}$ ago, and that the rifting continued, at least, into the time between 0.5T to 0.1-0.15T ago.

Beta Regio evolution: Analysis of the mapping results permitted the construction of a scenario of Beta Regio evolution shown in Figure 2:

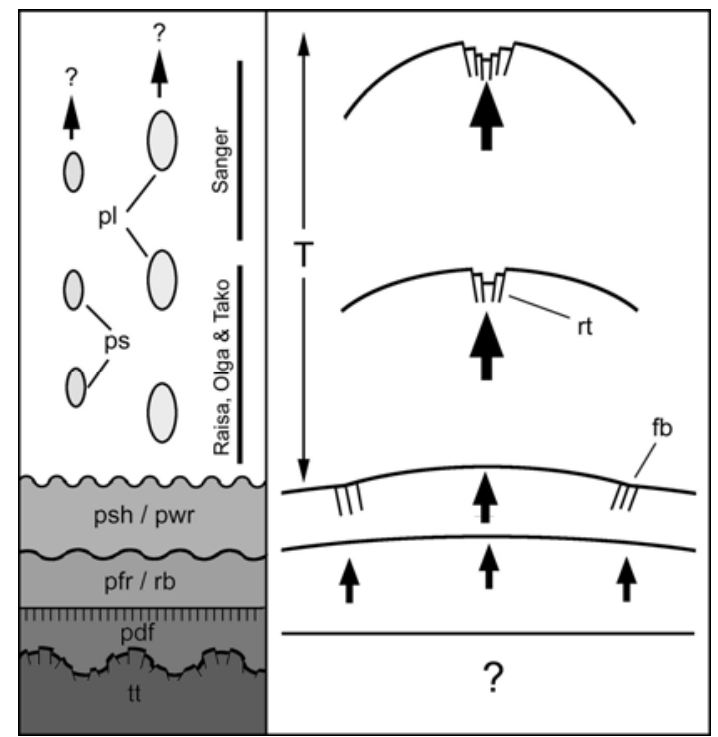

Figure 2. A diagram showing evolution of the Beta Regio rise.

References: [1] American Commission on Stratigraphic Nomenclature, 1961, Amer. Ass. Petrol. Geol. Bull., 45, 645-665. [2] Arvidson, et al., 1992, JGR, 97, 13,303-13,318. [3] Basilevsky \& Head, 2000, PSS, 48, 75-111. [4] Basilevsky \& Head, 2000, JGR, 105, 24,583-24,611. [5] Basilevsky \& Head, 2002, JGR, 107, doi 10.1029/2001JE001584. [6] Basilevsky et al., 2003, JGR doi:1029.2003GL 017504. [7] Hansen et al., 1997, in Venus II, Univ. Arizona Press, p. 797844. [8] Head et al., 1992, JGR, 97, 13,153-13,197. [9] Ivanov \& Head 2001, JGR, 106, p. 17,515-17,566. [10] Izenberg et al., 1994, GRL 21, 289-292. [11] McKinnon et al., 1997, in Venus II, Univ. Arizona Press, p. 969-1014. [12] Tanaka, K.L. (compiler), 1994, Venus geologic mappers' handbook, second edition: U.S. Geological Survey Open-File Report 94438, 50 p. [13] Wilhelms, D.E., 1990, Geologic mapping, in Planetary Mapping: New York, Cambridge University Press, p. 208-260. 
PRELIMINARY REPORT ON GEOLOGIC MAPPING OF ISABELLA QUADRANGLE (V-50) AND HELEN PLANITIA, VENUS. Leslie F. Bleamaster III, Planetary Science Institute, 3635 Mill Meadow Dr., San Antonio, TX 78247, lbleamas@psi.edu.

Introduction: New funding (start 04.15.06) supports geologic mapping efforts of Isabella Quadrangle (1:5M) (Figure 1a.) and Helen Planitia (1:10M) (Figure 2). Data downloads from the USGS are complete for Isabella and continue for Helen Planitia (approximately 30 GB in total). The remainder of year one will build upon completed reconnaissance mapping [1] with the definition and description of map units (DOMU) and construction of the sequence of map units (SOMU) and geologic history. By the end of year two, Isabella Quadrangle will be submitted for review and mapping of Helen Planitia will begin. Year three will be devoted to completing the synthesis map of Helen Planitia.

Geologic areas and motivation: The Isabella Quadrangle $\left(25-50^{\circ} \mathrm{S}, 180-210^{\circ} \mathrm{E}\right)$ lies to the south of the eastern extent of the Diana-Dali Chasmata system and Atla Regio, which contains the volcanoes Sapas, Maat and Ozza Montes. Isabella Quadrangle is host to numerous coronae and small volcanic centers (paterae and shield fields) (Figure 1b.), focused (Aditi and Sirona Dorsa) and distributed (penetrative north-south trending wrinkle ridges) contractional deformation, and radial and linear extensional structures (Figure 1c.), all of which contribute materials to and/or deform the expansive surrounding plains (Nsomeka and Wawalag Planitiae). Specific questions posed for geologic mapping of the $\mathrm{V}-50$ quadrangle include: a) what and where are the source locations for the regionally dominant plains materials (e.g., coronae, paterae, shield fields, rifts and fissures)? b) what is the relationship, if any, between focused (deformation belts) and distributed (wrinkle ridges) contractional strain and local/regional volcanism? c) what role does structural reactivation play in deformation belt and wrinkle ridge development?

The second map to be constructed through this effort is Helen Planitia $\left(0-57^{\circ} \mathrm{S}, 180-300^{\circ} \mathrm{E}\right)$, which encompasses over 70 million square kilometers (including V-50), displays $\sim 10 \mathrm{~km}$ of relief, and potentially spans the entirety of Venus' limited preserved geologic history as determined by Average

$\rightarrow$ Figure 1a. Synthetic aperture radar (SAR) mosaic of Isabella Quadrangle (V-50); 25-50 `S, 180-210 E. Preliminary mapping shows spatial distribution of large- and small-scale volcanic centers (1b) and deformation (1c).
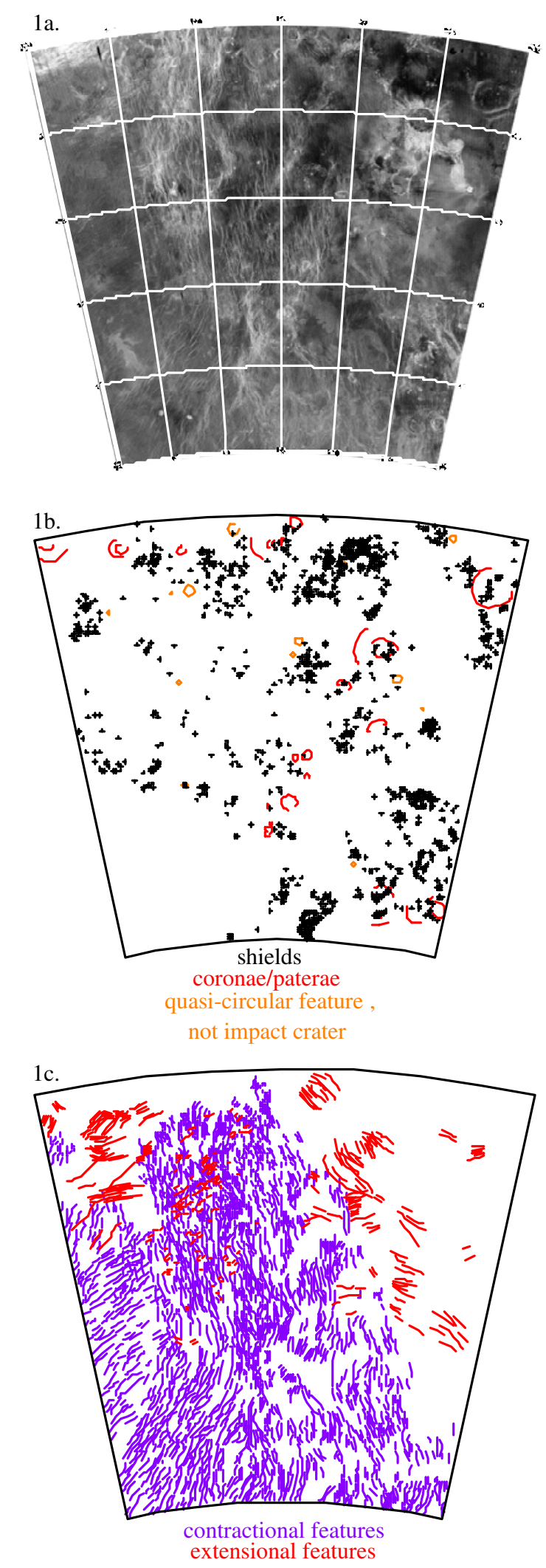
Surface Model Ages (ASMA) [2, 3]. This area affords the opportunity to study local relationships of a series of volcano-tectonic features across several physiographic provinces. Motivation for mapping in Helen Planitia includes assessment of a) resurfacing styles with respect to transitions from the highlands to the lowlands, b) changes in surface morphology of volcano-tectonic features across physiographic regions that may represent crustal/lithospheric heterogeneities, c) local timing relationships and their regional significance, d) the spatial and temporal relationships between craters with outflows and volcanic constructs, and to what extent are crater outflows directly related to impact processes versus post-impact modification, and e) various mapping methodologies and techniques.

Mapping: Preliminary mapping of $\mathrm{V}-50$ has begun with the demarcation of major structural and morphologic features including both primary features (flow fronts, impact craters) and secondary features (wrinkle ridges, fractures) (Figure $1 \mathrm{~b}$ and 1c) in a reconnaissance mode. This approach avoids the often-frustrating task of drawing the first unit contact, and although secondary structures do not define geologic units, they do provide a good first-sense of crosscutting and embayment relationships while one achieves a deeper appreciation of all the datasets. Adobe Illustrator currently serves as the primary mapping environment; datasets have been placed into several georectified layers with varying degrees of transparency. Reconnaissance mapping (please see poster) will soon be followed by the delineation and description of geologic units incorporating topography, reflectivity, and emissivity.

References: [1] Bleamaster, L.F. III, (2006) LPSC XXXVII abstract \#2233. [2] Phillips and Izenberg (1995) Geophys. Res. Lett., 22, 1517-1520. [3] Hansen and Young (in press), GSA special volume in honor of Gary Ernst.

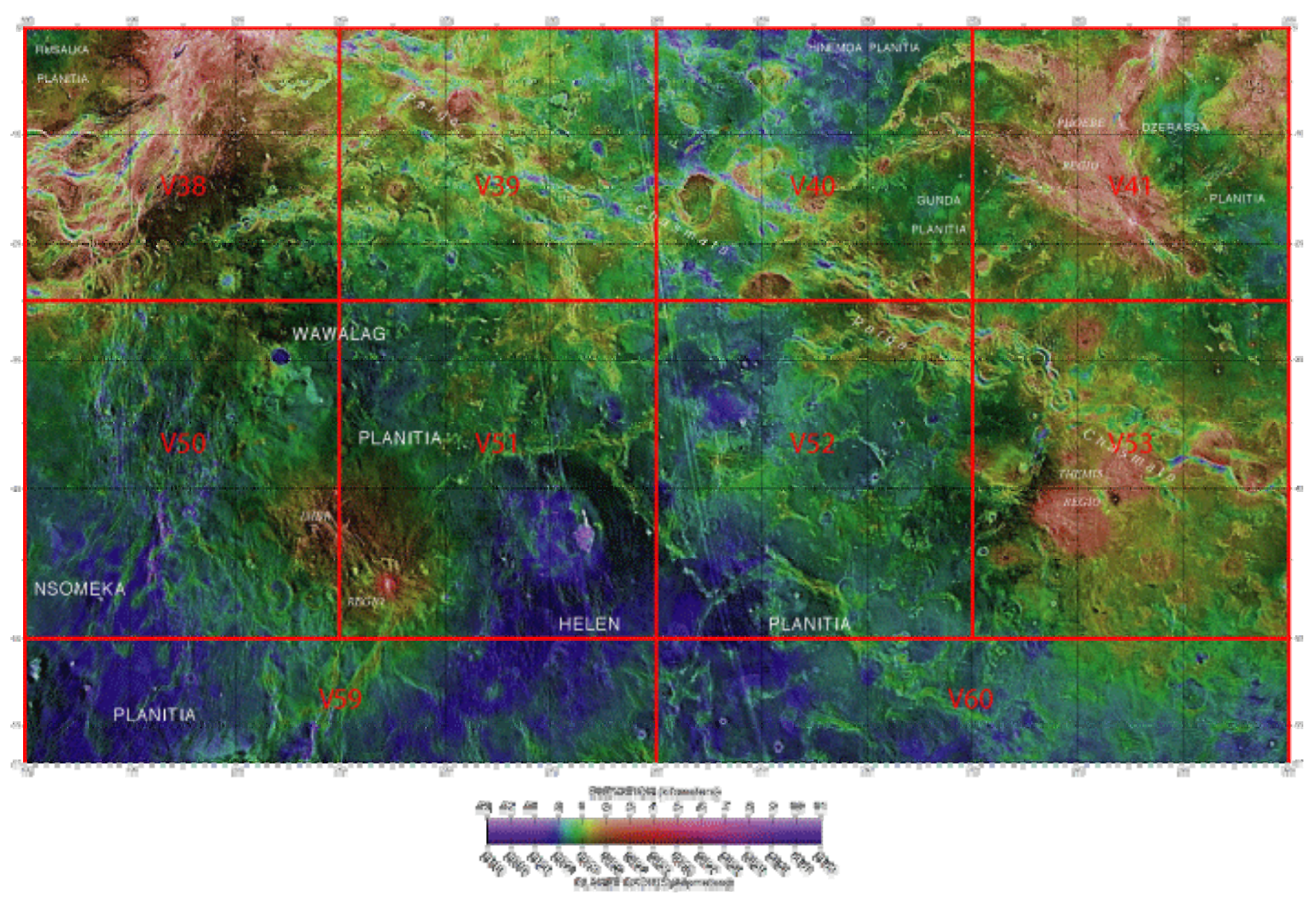

Figure 2. Altimetric radar image map and prominent geographic feature names of the Helen Planitia Regional Study Area (I-2477) to be mapped at 1:10M scale. Red lines demark 1:5M scale quadrangle boundaries. 
GEOLOGIC MAPPING OF THE GUINEVERE PLANITIA QUADRANGLE OF VENUS. David A. Crown ${ }^{1}$ and Ellen R. Stofan ${ }^{2},{ }^{1}$ Planetary Science Institute, 1700 E. Ft. Lowell Rd., Suite 106, Tucson, AZ 85719, ${ }^{2}$ Proxemy Research, P.O. Box 338, Rectortown, VA 20140, crown@psi.edu.

Introduction. The Guinevere Planitia (V-30) quadrangle of Venus $\left(0-25^{\circ} \mathrm{N}, 300-330^{\circ}\right)$ covers a lowland region east of Beta Regio and west of Eistla Regio and includes parts of Guinevere and Undine Planitiae. The V-30 quadrangle is dominated by lowlying plains interpreted to be of volcanic origin and which exhibit numerous wrinkle ridges. Using Pioneer Venus, Goldstone, and Arecibo data, previous investigators have described radar bright, dark, and mottled plains units in the Guinevere Planitia region, as well as arcuate fracture zones and lineament belt segments that define the Beta-Eistla deformation zone [1-5]. Magellan SAR images reveal that volcanic landforms compose the majority of the surface units in the quadrangle [6-7]. The V-30 quadrangle contains parts of four major volcanoes: Atanua $\left(9^{\circ} \mathrm{N}, 307^{\circ}\right)$, Rhpisunt $\left(3^{\circ} \mathrm{N}, 302^{\circ}\right)$, Tuli $\left(13^{\circ} \mathrm{N}, 314^{\circ}\right)$, and $\operatorname{Var}\left(3^{\circ} \mathrm{N}\right.$, $\left.316^{\circ}\right)$ Montes, and three coronae: Hulda $\left(12^{\circ} \mathrm{N}, 308^{\circ}\right)$, Madderakka $\left(9^{\circ} \mathrm{N}, 316^{\circ}\right)$, and Pölöznitsa $\left(1^{\circ} \mathrm{N}, 303^{\circ}\right)$. Seymour crater, located at $18^{\circ} \mathrm{N}, 327^{\circ}$, is associated with extensive crater outflow deposits.

Project Overview. Preparation of the geologic map of the V-30 quadrangle includes analysis of Magellan data, including synthetic aperture radar (SAR) images and altimetry, roughness, reflectivity, and emissivity data sets. Full-resolution Magellan image mosaics (FMAPs) and synthetic parallax stereo images produced by the U.S. Geological Survey are key mapping products for unit characterization and determination of stratigraphic relationships.

Initial support for production of the geologic map was provided by a NASA Venus Data Analysis Program (VDAP) grant (1993-1994), which also included morphologic and radar remote sensing analyses of venusian steep-sided domes and terrestrial silicic domes as potential analogues [8-10]. Subsequent analyses of the morphologic and radar backscatter properties of lava flows associated with volcanoes in Guinevere Planitia have also been conducted [11].

Mapping work completed under VDAP support included completion of a preliminary geologic map of the entire quadrangle [6-7]. This map was prepared by hand on an early SAR base of incorrect scale. Current tasks include compilation of the map in digital form on the $1: 5 \mathrm{M}$ base, and, during the digitization process, a reassessment of unit contacts using synthetic stereo data, which was not available when the original draft of the map was prepared.

Scientific objectives for mapping the Guinevere Planitia quadrangle include: 1) documenting the evolutionary stages of shield volcanoes, 2) evaluating the geologic context for steep-sided dome formation, and 3) assessing spatial and temporal relationships between volcanic and tectonic features. Mapping will provide a synthesis of the geologic and volcanic histories of Guinevere Planitia and assess their implications for the evolution of venusian lowland plains and styles of venusian volcanism.

Mapping Results. Mapping completed to date has defined four main types of geologic units in the V-30 quadrangle: flow materials, plains materials, tesserae and other highly tectonized units, and crater materials. Scattered throughout the map area are embayed remnants of intensely deformed materials; some of these show two or more tectonic fabrics (tesserae) and others show one dominant orientation of lineaments. The extensive volcanic plains evident across the quadrangle have been divided into two units. Mottled, lineated plains are generally large expanses containing a variety of small volcanic domes, cones, shields and flows. Zones of tectonic disruption are common. Smooth plains are low-lying regions that exhibit uniform radar brightness over large distances. Flow margins can be identified, but small volcanic edifices are not abundant. Fractures and ridges are common. Typically, volcanic flows are superposed on the plains; locally plains may embay the flanks of the major volcanoes in the map area.

Volcanic flow materials in the V-30 quadrangle have been divided into two major morphologic types. Plains-forming flow materials are extensive, radar bright or dark, relatively flat-lying sheets and can extend for hundreds of kilometers from their apparent source vents. Lobate flow materials are narrow, sinuous, overlapping radar bright and dark deposits with lobate margins that form radial patterns around their source vents; lobate flow materials have accumulated to form the surfaces of the major volcanoes in the map area. Numerous small domes, cones, and shields are observed in association with lobate flow materials on these large volcanoes.

Structural features observed in Guinevere Planitia include wrinkle ridges, fractures, and lineaments found primarily in plains units, coronae and corona-like structures, and tesserae and other highly tectonized units. In the plains, structures exhibit a diversity of orientations and occur in sets of features with similar trends. Prominent E-W and SE-NW trends are observed in the smooth plains at the eastern margin of the V-30 quadrangle.

References: [1] Campbell, D.B. et al. (1989), Science, 246, 373-377. [2] Arvidson, R.E. et al. (1990), in Proc. Lunar Planet. Sci. Conf., 20 ${ }^{\text {th }}$, 557-572. [3] Senske, D.A. (1990), Earth, Mons, and Planets, 50/51, 305-327. [4] Senske, D.A. et al. (1991), Earth, Moon, and Planets, 55, 163-214. [5] Stofan, E.R. et al. (1990), Lunar Planet. Sci. Conf., XXI, 1208-1209. [6] Crown, D.A. et al. (1993), Lunar Planet. Sci. Conf., XXIV, 355-356. [7] Crown, D.A. et al. (1994), Lunar Planet. Sci. Conf., XXV, 301-302. [8] Anderson, S.W. et al. (1998), Geol. Soc. Am. Bull., 110, 1258-1267. [9] Stofan, E.R. et al. (2000), J. Geophys. Res., 105, 26,757-26,771. [10] Plaut, J.J. et al. (2004), J. Geophys. Res., 109 E03001, doi:10.1029/2002JE002017. [11] Byrnes, J.M. and D.A. Crown (2002), J. Geophys. Res., 107 (E10), 5079, doi:10.1029/2001JE001828. 
MAPPING IN THE FREDEGONDE (V-57) QUADRANGLE, VENUS: PRELIMINARY RESULTS. M.A. Ivanov $^{1,2}$ and J.W. Head ${ }^{2},{ }^{1}$ Vernadsky Institute, RAS, Moscow, Russia, mikhail_ivanov@brown.edu, ${ }^{2}$ Brown University, Providence, RI, USA, james_head @brown.edu.

Introduction: Midlands $(0-2 \mathrm{~km}$ above MPR, $[1,2])$ constitute the most significant topographic province on Venus ( $\sim 80 \%)$ and host the richest variety of terrains, units, and structures. The character of transition from the midlands to both the lowlands and highlands and the distribution and sequence of units and structures in the midlands are crucially important in understanding of modes and timing of formation of this topographic province. Many workers have documented the wide range of features that are seen in the midlands [3-12].

The Fredegonde (V-57) quadrangle in the southern hemisphere of Venus is a typical region of midlands that exposes abundant features characterizing this province and contacts with the upland of Lada Terra to the west and the lowland of Aino Planitia to the northeast. Here we report on the preliminary results of geologic mapping in the V-57 quadrangle and describe major features, units, and structures exposed in the map area, and outline the main episodes of the geologic history of this region.

Regional setting and major geologic and topographic features: The area of the Fredegonde quadrangle $\left(50-75^{\circ} \mathrm{S}, 60-120^{\circ} \mathrm{E}\right.$, Fig. 1$)$ covers the eastern midland portion of Lada Terra. The most prominent features in the map area are linear deformational zones consisting of large coronae interconnected by swarms of grooves and graben. There are two such zones. The largest is in the central portion of the quadrangle. It is several thousands of $\mathrm{km}$ long, oriented in the northern direction, and includes four coronae. The second zone is in the northwestern corner of the map area. It is oriented in NE direction, consists of Geyaguga and Xaratanga Chasmata, and includes two coronae. Less abundant are fragments of belts of ridges that have a general NW trend and occur in the central longitudinal area of the quadrangle. Topographically, both the corona-groove chains and belts of ridges represent broad (up to $100 \mathrm{~s} \mathrm{~km}$ wide) ridges $100 \mathrm{~s} \mathrm{~m}$ (up to a kilometer) high. Relatively small (100s km across, 100s m deep) equidimensional basins of Mugazo, Alma-Merghen, and Laimdota Planitiae occur between the coronagroove-chains in the west and border the central chain from the east. The corona-groove chains resemble in many aspects the corona-rift zones at the margins of large equidimensional basins such as Lavinia (V-55) and Atalanta (V-4) Planitiae [13,14].

Material and structural units and their relationships: During our reconnaissance mapping we have defined three groups of material and structural units (Fig.2). (I) The oldest units: densely lineated plains (pdl), ridged plains (pr), and groove belts (gb). Unit pdl occurs as small outliers in the central area of the quadrangle. Ridged plains are exposed in fragments of the belts of ridges. Groove belts consist of dense swarms of fractures and graben and form the corona-groove chains. All units of this group form either local (pdl) or regionally important highs (pr and gb) and are embayed by vast plains units of group II. (II) Units of the middle stratigraphic level, shield plains (psh) and regional plains (rp), cover the major portion of the quadrangle. Shield plains are characterized by abundant small shield- and cone-like features (small volcanoes [15-17]) that give the unit a distinctly hilly texture. The volcanoes appear to be sources of the adjacent plains material. Regional plains have a morphologically smooth surface and uniform radar backscatter. Sources of the plains are not obvious. Wrinkle ridges deform both units of this group and sometimes occur in the older units. Shield plains and regional plains occur at relatively low topographic levels and fill the equidimensional basins. (III) Units that form the top of the regional stratigraphic column: smooth plains (ps), and lobate plains (pl). Smooth plains have uniform and preferentially low radar albedo and lobate plains are characterized by lobate and digitate boundaries. Both units are tectonically undeformed and embay most tectonic structures including wrinkle ridges. Lobate plains are spatially associated with some coronae of the corona-groove chains, flow down the regional slopes and partly fill the basin-like topographic lows.

Summary: The results of preliminary mapping in the V-57 quadrangle allow us to outline the major episodes of the geologic history of this region. Tectonics apparently played the most important role in the beginning of the history. The majority of tectonic deformation occurred early on and was related to the formation of linear deformational belts, the most prominent of which are the corona-groove chains. During this period, the most important topographic features (broad linear ridges and equidimensional basins) of the midland portion of Lada Terra were formed. During the middle and late periods, volcanism was more important and vast plains moderately deformed by tectonic structures were emplaced. There is a little evidence suggesting a continued development of the major topographic features during the middle stages of the geologic history of the region. The flow direction of lobate plains (from the broad ridged toward the floor of the basins) suggests that the overall topographic configuration of the midlands within the map area was established prior to emplacement of the youngest volcanic plains. The main topographic and structural elements of coronae in the region were formed before 
emplacement of both shield plains and regional plains. The youngest lobate plains, however, typically are associated with some coronae. This means that the corona structures were either reactivated late in the geologic history or volcanic activity at coronae was delayed until the late stages of history.

References: 1) Masursky, H., et al., JGR, 85, 8232, 1980, 2) Pettengill, G.H., et al., JGR, 85, 8261, 1980, 3) Ford, P.G. and G.H. Petttengill, JGR, 97, 13103, 1992, 4) Barsukov, V.L., et al., JGR, 91, D399, 1986, 5) Frank, S.L. and J.W. Head, EMP, 50/51, 421, 1990 6) Basilevsky, A.T. and J.W. Head, PSS, 48, 75, 2000, 7) Basilevsky, A.T. and J.W. Head,
JGR, 105, 24583, 2000, 8) Stofan, E.R., et al., Icarus, 152, 75, 2001, 9) Bleamaster, L.F. and V.L. Hansen, JGR, 109, doi: 10.1029/2003JE002193, 2004, 10) Nunes, D.C., et al., JGR, 109, doi: 10.1029/2003JE002119, 2004, 11) Young, D.A. and V.L. Hansen, $J G R, 110$, doi: 10.1029/2004JE001965, 2005, 12) Herrick, R.R., et al., JGR, 110, doi: 10.1029/2004JE002283, 2005, 13) Ivanov, M.A. and J.W. Head, USGS Map I-2684, 2001, 14) Ivanov, M.A. and J.W. Head, USGS Map I-2792, 2004, 15) Aubele J.C., LPSC XXVI, 59, 1995, 16) Addington, E.A., Icarus, 149, 16, 2001, 17) Ivanov, M.A. and J.W. Head, JGR, 109, doi: 10.1029/2004JE002252, 2004.

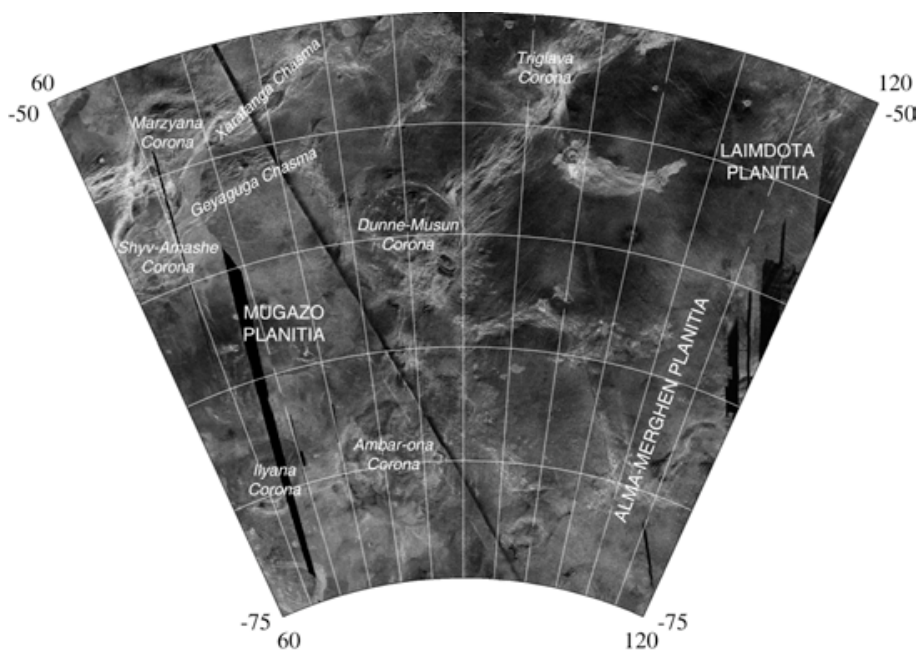

Figure 1. Major features in the V-57 quadrangle.

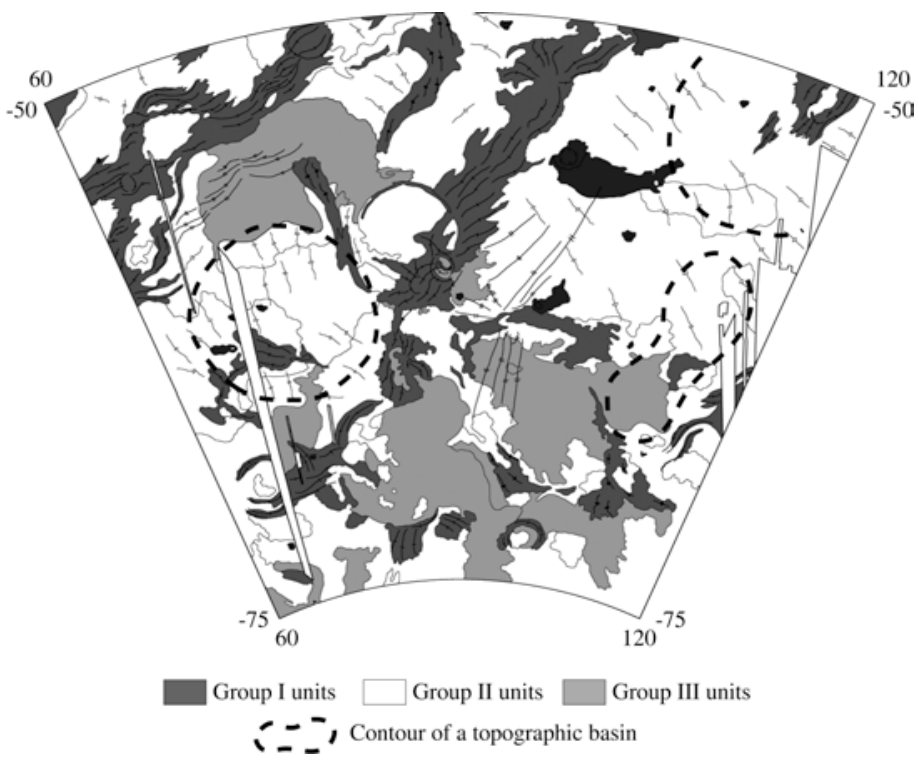

Figure 2. Preliminary sketch map of the V-57 quadrangle. 
Geologic history of the LAVinia Planitia / LADA TerRa REgion, VenUs: Results Of THE MAPPING IN

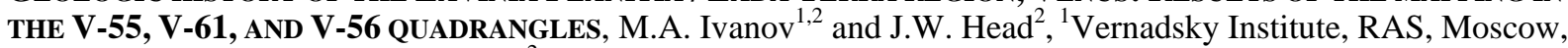
Russia, mikhail_ivanov@brown.edu; ${ }^{2}$ Brown University, Providence, RI, USA, james_head@brown.edu

1. Introduction: Lada Terra is a region of midlands (0$2 \mathrm{~km}$ above mean planetary radius, MPR) at high southern latitudes $\left(\sim 300-90^{\circ} \mathrm{E}, 55-80^{\circ} \mathrm{S}\right.$, covered by the V-61 and V-56 quadrangles). It is characterized by a large dome-shaped structure, a swell. Lada Terra hosts numerous coronae, including Quetzalpetlatl ( 800 km across) and Boala Coronae [1,2], and large complexes of lava flows, fluctūs, emanating from several distinct centers $[3,4]$. Belts of fractures and graben interconnect many coronae in Lada Terra [5]. The vast lowland of Lavinia Planitia ( $330-0^{\circ} \mathrm{E}, 25-55^{\circ} \mathrm{S}, \mathrm{V}-55$ quadrangle) is adjacent to Lada Terra to the north. Deformational belts of ridges and grooves and vast moderately deformed plains characterize the floor of Lavinia Planitia $[6,7]$. The pattern of deformation, topography, and gravity signature are consistent with mantle downwelling under Lavinia Planitia [8] and with mantle upwelling in the region of Lada Terra $[9,10]$. Thus, Lada Terra and Lavinia Planitia appear to represent contrasting geodynamic provinces. Their close proximity suggest a genetically linked history [4]. We studied these regions in detail during geological mapping at 1:5 $\mathrm{M}$ scale under the USGS planetary mapping program (combined area of the quadrangles V-55 [11], V-56, mapping in progress, and V-61, map in edit). The major goal of our study was to reconstruct the major episodes of geologic history of Lada and Lavinia and establish the timing and sequence of events during formation and evolution of these regions.

2. Topographic configuration of Lavinia Planitia and Lada Terra: Lavinia Planitia is a large lowland (a basin) a few thousands of km across, which is as deep as $\sim 1.5 \mathrm{~km}$ below MPR. The general distribution of topography in Lavinia Planitia is asymmetric. The deepest portion of the basin is shifted toward its southern edge. Toward the north and northwest, the elevation changes $\sim 1 \mathrm{~km}$ over a distance of $\sim 1800 \mathrm{~km}$ while at the southern and eastern margins the same change in elevation occurs over a distance of $\sim 500 \mathrm{~km}$. Deformational belts on the floor of the basin form a radial pattern and topographically represent elevated zones several hundred meters high. The most prominent belts are concentrated in the deepest area of Lavinia Planitia. The major portion of Lada Terra is within the $0-2 \mathrm{~km}$ interval (midlands). The largest topographic feature of Lada Terra is a broad ( 1000 km across) symmetric swell, the summit of which reaches an elevation of $\sim 3.5 \mathrm{~km}$. The overall topographic shape of the Lada swell resembles that of the other dome-shaped rises on Venus such as Beta Regio or Eistla Regio. In contrast to these areas, which are topped by large volcanoes, the Lada swell hosts the nested Quetzalpetlatl and Boala Coronae and lacks large volcanoes. Two regional-scale topographic features (thousands of $\mathrm{km}$ long, hundreds of $\mathrm{km}$ wide, a couple of $\mathrm{km}$ in amplitude), an elongated depression, and a topographic ridge, concentrically outline the swell of Lada from the north and east.

3. Regional geology: Units, structures, and their stratigraphic relationships: In our mapping, we used traditional methods of unit definition $[12,13]$ appropriately modified for radar data [14]. We defined units and mapped relations between them and tectonic structures using F- and C1-MIDR images and altimetry data. The background for our mapping approach is described in [14-18].

3.1. Units All three mapped quadrangles display a similar set of material and tectonic units. Outcrop continuity and consistent age relationships among them allow stratigraphic correlations of the units in the broad mapped region. The oldest unit is Tessera. It has a unique pattern of deformation consisting of intersecting ridges and grooves [19-22, 7] and is consistently embayed by less deformed materials. The major occurrences of tessera in the area of our mapping are Alpha Regio (to the east of Lavinia Planitia) and Cocomama Tessera (to the east of the Lada swell). Densely lineated plains (pdl) form the oldest plains unit. Its surface is cut by densely packed lineaments (some of them are fractures). Material of densely lineated plains embays tessera where these units are in contact. Ridged plains (pr) are commonly deformed by broad (5-10 km wide) ridges tens of kilometers long. The ridges are arranged in linear belts and predominantly occur on the floor of Lavinia Planitia. Both emplacement and deformation of ridged plains postdate deformation of the unit pdl. Abundant small (a few km) shield-like features characterize Shield plains (psh). The unit occurs preferentially within Lavinia Planitia where it embays ridged plains. Psh is significantly less widespread within the elevated portion of Lada Terra where shield plains appear to be almost completely buried by younger plains. Regional plains (rp) form the most widespread unit with a morphologically smooth and homogeneous surface, which is typically cut by wrinkle ridges. Sources of the plains are not obvious. There are two units of regional plains. The lower unit $\left(\mathrm{rp}_{1}\right)$ has relatively low radar backscatter and usually makes up the floor of the lowlands surrounding Lada Terra. Sometimes it occurs in stratigraphic windows on the slopes of the Lada swell. The upper unit $\left(\mathrm{rp}_{2}\right)$ has a higher radar albedo and, sometimes, lobate boundaries. The unit occurs on the western slope of the Lada swell. Both units of regional plains embay shields plains. Lobate and digitate boundaries (Lobate plains, pl), morphologically smooth surfaces (Smooth plains, ps), and clusters of small shields (Shield clusters, sc) similar to those of shield plains characterize units that are younger than regional plains. 
We also defined two tectonic units: Groove belts (gb) and Rift zones (rt). These are elongated belts of extensional structures thousands of $\mathrm{km}$ long and hundreds of $\mathrm{km}$ wide. Groove belts preferentially occur on the floor of Lavinia Planitia where they cut ridges of the unit $\mathrm{pr}$ and are embayed by shield plains and regional plains. Rift zones are concentrated in Lada Terra and appear to be contemporaneous with the youngest plains units (pl, ps, and sc).

3.2. Structures There are two types, scales, and ages of contractional features in the map area. The older are ridges and arches that deform ridged plains (unit pr). Regional plains embay these structures. The northern rim of Quetzalpetlatl Corona is morphologically similar to a typical ridge belt, although it is unclear whether it is a fragment of regionally developed belts or it is related to the evolution of the corona. Regional plains embay the rim at its southern end. Thus, formation of the rim predates emplacement of regional plains. The younger contractional features are wrinkle ridges that form a regional network that deforms regional plains and other older units and are embayed by smooth and lobate plains.

Numerous fractures and graben in the studied region are typically collected in zones of extensional structures (groove belts and rift zones). The largest of them is the rift-like zone of Kalaipahoa Linea (V-61) that outlines the Lada swell from the north. Another riftlike zone is within the V-56 quadrangle. It consists of a chain of coronae interconnected by graben and outlines the swell from the east. Within both zones there are prominent sources (coronae) from which emanate the youngest volcanic flows (e.g. Mylitta Fluctus).

4. Discussion and conclusions: The V-55, V-61, and V-56 quadrangles cover a region that consists of two provinces, Lavinia Planitia and Lada Terra, contrasting in topography, gravity, and overall geologic history. Deformational zones of ridge and groove belts that form the bottom of the general stratigraphic column populate the floor of Lavinia Planitia. The most prominent belts preferentially occur at the deepest portion of the Lavinia basin and are embayed by units of intermediate stratigraphic position (psh and rp). An important characteristic of the basin is the absence of both young deformation and volcanic materials postdating formation of wrinkle ridges. The general topographic configuration of Lavinia Planitia and the radial pattern and topographic position of the deformational belts on its floor are consistent with the subsidence of the surface and formation of the Lavinia basin [8]. The stratigraphic position of the belts implies that the subsidence largely occurred relatively early on in the geologic history and the topographic asymmetry of Lavinia suggests that the locus of the subsidence was near the southern and eastern edges of the basin. The vast plains units of the intermediate stratigraphic position were emplaced on the floor of the already existing lowland.
Lada Terra is in sharp contrast to Lavinia Planitia. It is an elevated region, which is dominated by the Lada swell and characterized by abundant young volcanism (lobate plains) and young extensional deformation (rift zones). The summit area of the swell (Quetzalpetlatl and Boala Coronae) and the Tarbell/Jord Coronae complex within the rift of Kalaipahoa Linea are the most important sources of young volcanism. Young lava flows flow down the regional slopes of the swell and the steeper southern and eastern edges of the Lavinia basin [11,23]. Magellan gravity data [24,25] show that the eastern half of the quadrangle, which corresponds to the Lada swell, is characterized by high values of both vertical gravity acceleration (up to $120 \mathrm{mGal}$ ) and height of geoid (up to $40 \mathrm{~m}$ ). These features collectively strongly suggest that the central portion of Lada Terra represents a region of mantle upwelling. The stratigraphic position of the most abundant units in Lada Terra means that the upwelling largely postdates the subsidence in Lavinia Planitia.

Thus, the geologic history of the region of Lavinia Planitia and Lada Terra appears to consist of two major episodes. The earlier episode corresponds to formation of a vast basin in Lavinia. During a distinctly later episode a broad updoming, massive volcanism, and extensional tectonics occurred in Lada Terra. The close geographic position of Lavinia and Lada, their overall topographic configuration, and general sequence of events are consistent with a genetically linked evolution of these provinces. In this model, the downwelling in Lavinia may have provoked the upwelling under Lada and led to younger geologic activity in this region.

References: [1] Stofan, E. R. et al. (1997) JGR, 97, 13347. [2] Crumpler, L. S. and J. Aubele, Volcanism on Venus, in: Encycl. of Volcanoes, 727, 2000, 3) Roberts, K.M., et al., JGR, 97, 15991, 1992, 4) Magee, K.P. and J.W. Head, JGR, 100, 1527, 1995, 5) Baer, G. et al., JGR, 99, 8355, 1994, 6) Squyres, S.W. et al., JGR, 97, 13579, 1992, 7) Solomon, S.C.et al., JGR, 97, 13199, 1992, 8) Bindschadler, D.L. et al., $J G R, 97,13495,1992,9)$ Kiefer, W.S. and B.H. Hager, JGR, 96, 20947, 1991, 10) Simons, M., et al., GJI, 131, 24, 1997, 11) Ivanov, M. A. and J. W. Head, USGS Geol. Inv. Ser., Map I-2684, 2001, 12) Code of Stratigraphic Nomenclature, AAPGB, 45, 645, 1961, 13) Wilhelms, D. E. Geologic mapping in: Planetary Mapping, 208, 1990, 14) Tanaka, K.L., Venus geologic mappers' handbook, USGS OFR 94-438, 50, 1994, 15) Basilevsky, A. T. and J.W. Head, EMP, 66, 285, 1995, 16) Basilevsky, A. T. and J.W. Head, PPS, 43, 1523, 1995, 17) Basilevsky, A. T.et al., The resurfacing history of Venus in: Venus II 1047-1086, 1997, 18) Ivanov, M. A. and J. W. Head, JGR, 106, 17515, 2001, 19) Barsukov, V.L. et al., JGR, 91, D399, 1986, 20) Basilevsky, A. T., et al., JGR, 91, D399, 1986, 21) Bindschadler, D.L. and J.W. Head, JGR, 96, 5889, 1991, 22) Sukhanov, A.L. In: Venus Geology, Geochemistry, and Geophysics, 82, 1992, 23) Bridges, N. T. and G. E. McGill, USGS Geol. Inv. Ser., Map I-2747, 2002, 24) Konopliv, A.S., et al., GRL, 20, 2403, 1993, 25) Konopliv, A.S. and W.L. Sjogren, Icarus, 112, 42, 1994. 
MAPPING OF THE V-7 QUADRANGLE: SEQUENCE OF EVENTS DURING FORMATION OF LAKSHMI PLANUM, VENUS, M.A. Ivanov ${ }^{1,2}$ and J.W. Head ${ }^{2},{ }^{1}$ Vernadsky Institute, RAS, Moscow, Russia, mikhail_ivanov@brown.edu; ${ }^{2}$ Brown University, Providence, RI, USA, james_head@brown.edu

1. Introduction: The key feature of the Lakshmi Planum quadrangle $\left(\mathrm{V}-7,50-75^{\circ} \mathrm{N}, 300-360^{\circ} \mathrm{E}\right)$ is the volcanic plateau of Lakshmi Planum, which represents a unique class of highlands on Venus. The surface of Lakshmi Planum stands 3-4 km above mean planetary radius, MPR, and is surrounded by the highest Venusian mountain ranges that are $7-10 \mathrm{~km}$ high. Lakshmi Planum and its mountain surroundings are among the most intriguing features on Venus [1-7]. There are two alternative models of formation of the complex of Lakshmi Planum. In the first, this feature is considered as a result of mantle upwelling, formation, and collapse of a large dome $[8,6,9,10]$. In the second model, formation of Lakshmi Planum is explained by a mantle downwelling and collision of terrains against a foreland of the core region of Lakshmi [11-16]. The sequence of events during formation of Lakshmi plays a crucial role in the assessment of both models. For example, the collapse of a large dome would result in formation of chaotically oriented contractional structures in the interior of the plateau, suppressed volcanism there, and a general lateral progression of events in the direction from inside out. The alternative model would be consistent with the opposite direction of geologic activity, the older relative age of the mountain ranges, and younger volcanic activity in the central area of the plateau.

In our mapping, we used traditional methods of unit definition $[17,18]$ appropriately modified for radar data [19]. We defined units and mapped relations between them and tectonic structures using F- and C1-MIDR images and altimetry data. The background for our mapping approach is described in [19-23]. In this paper we describe the set of mapped units and structures and outline the apparent sequence of events during formation of Lakshmi Planum.

2. Material units and structures: Although we have mapped tectonic structures independently of geologic units, sometimes the structures become a part of the definition of a unit. For example, tessera is analogous to Aureole member 4 of the Olympus Mons Formation on Mars [24]. In recently published Venus maps, the same approach was successfully applied in the mapping of several quadrangles [25-28]. Here we summarize the stratigraphic units and structures and their relations.

2.1. Units. Tessera (t) appears to be the oldest material because it is embayed by most of the other units in the map area. Tessera is deformed by at least two sets of intersecting ridges and grooves, and is a result of tectonic deformation of some precursor terrain $[3,4,29,30]$. In the V-7 quadrangle, tessera is exposed inside and outside Lakshmi Planum. Densely lineated plains (pdl) postdate tessera and form one of the oldest units. It has relatively flat surfaces and is cut by dense swarms of lineaments (fractures). Typically small patches of pdl occur outside Lakshmi Planum. Ridged plains (pr) are commonly deformed by relatively broad (2-5 km wide) ridges tens of kilometers long. In the V-7 quadrangle this unit is not abundant and occurs in the southern portion of the map area outside Lakshmi. Shield plains (psh) are characterized by abundant small shield-shaped features $(2-20 \mathrm{~km})$ interpreted to be small volcanoes. The unit is widely distributed in the quadrangle but occurs predominantly within the lowlands around Lakshmi Planum and is absent inside the plateau. Material of psh embays all previous units. Pitted and grooved material (pgm) is cut by narrow, wide, and shallow grooves with scalloped edges. In places, isolated pits and low shieldlike features are seen. The unit pgm occurs in four small areas at the periphery of the interior of Lakshmi in spatial association with the mountain ranges. Regional plains (rp) form the most widespread unit. The surface of it is smooth, homogeneous, and typically cut by wrinkle ridges. The sources of the unit are unknown. Regional plains occur both inside and outside Lakshmi Planum and cover the majority of the quadrangle. Lower unit of lobate plains $\left(\mathrm{pl}_{1}\right)$ is also deformed by wrinkle ridges but has lobate boundaries and higher radar albedo than regional plains. The largest area of this unit is outside Lakshmi and a smaller occurrence of it is on the northern flank of Colette Patera inside the plateau. Smooth plains (ps) are characterized by uniform and preferentially low albedo. Material of unit ps embays wrinkle ridges. Small patches of ps are scattered throughout the map area. The largest occurrence of the unit is in the southern portion of Lakshmi Planum. Upper unit of lobate plains $\left(\mathrm{pl}_{2}\right)$ is characterized by lobate flows that embay most tectonic structures including wrinkle ridges. There are three major occurrences of the unit: Neago Fluctūs and Djata Fluctus outside Lakshmi and Colette and Sacajawea Paterae inside the plateau. Impact craters (c) and crater outflow deposits (cf) are peppered throughout the quadrangle without any preferential concentrations.

2.2. Structures. Extensional structures. In many places, extensional structures are closely spaced and obscure underlying terrain. These concentrations consist of numerous fractures and graben and form linear belts (groove belts, gb) that are many hundreds of kilometers long and a few hundreds of kilometers wide. Groove belts are concentrated within the southern regional slope of Lakshmi Planum where they cut the units pdl and pr and are embayed by shield plains and regional plains. Contractional structures. Several types and scales of contractional features are observed within the quadrangle. Narrow and sinuous wrinkle ridges are seen throughout the quadrangle but are more abundant in vast 
areas of regional plains. Broader and more linear ridges dominate ridged plains (pr), which are largely equivalent to the ridge belts of [31-32].

The most important occurrences of contractional structures in the map area are mountain belts (unit mt) surrounding the interior of Lakshmi Planum. Densely packed ridges that are 5-15 km wide and tens to a few hundreds of kilometers long characterize all belts. There are four such belts. Danu Montes ( 100 km wide, $\sim 1000-1200 \mathrm{~km}$ long, and $\sim 4-5 \mathrm{~km}$ high) border the southern edge of Lakshmi. Regional plains embay the ridges of Danu Montes on both sides of the mountain range. Akna Montes to the $\mathrm{W}$ of Lakshmi is a shorter ( 800-900 km), wider ( 200 km), and higher $(\sim 6-7 \mathrm{~km})$ mountain range, which is slightly bent inside, toward the plateau of Lakshmi. Regional plains of the Lakshmi interior embay the innermost ridges of Akna Montes. At the outer side, ridges of Akna Montes deform the surface of pdl. Freyja Montes border Lakshmi Planum from the $\mathrm{N}$ and NE. This belt is wide $(\sim 300 \mathrm{~km})$ and high ( 6-7 km) and is characterized by complicated structure consisting of several domains with their own pattern of deformation. The massif of Freyja Montes appears to be embayed by regional plains of the Lakshmi interior. The northern edge of the belt is outside of the map area. Maxwell Montes are at the eastern edge of Lakshmi Planum. Within the map area, only the westernmost extensions of Maxwell are seen. Relationships of structures of Maxwell with the plains inside Lakshmi appear to be ambiguous and do not provide strong evidence suggesting relative ages of these units.

3. Discussion and conclusions: The major goal of our mapping in the V-7 quadrangle was to establish the sequence of events during formation and evolution of Lakshmi. The main issues that we addressed in our study were: When were the mountain ranges formed? What is the nature of the Lakshmi interior? How do the interior and exterior regions of Lakshmi compare to each other? What is the general sequence of events during formation and evolution of Lakshmi Planum? There are three major physiographic provinces in the map area: the interior of Lakshmi Planum, the surrounding mountain ranges, and the exterior of Lakshmi. The sets of units and structures and their stratigraphic relationships are similar within the interior and exterior. This implies that similar processes in similar sequences have operated there and allows broad temporal correlations among mapped features.

There is no compelling evidence suggesting when the mountain ranges formed relative to each other. It is possible, however, to establish the range of stratigraphic ages for the mountain belts as a class of features. The youngest unit deformed by structures of the mountain belts (Akna Montes) is pdl of Atropos Tessera. This unit establishes the lower stratigraphic limit of the belt formation. The oldest unit embaying structures of the ranges are regional plains inside and outside Lakshmi.
Thus, the mountain crown of Lakshmi was formed relatively early on in the geologic history of the region.

The interior of Lakshmi has a relatively simple stratigraphic record. The oldest unit exposed there is tessera, which is heavily embayed by regional plains. Large and small outliers of tessera are seen in many places of the interior suggesting that the thickness of regional plains is small. An important feature of the interior is the absence of ridge belts that indicates a virtual lack of contractional deformation there. Thus, the interior of Lakshmi appears to represent initially a tessera-like plateau that was geologically stable during formation of the mountain ranges. The youngest activity within the interior is related to volcanism and formation of the young plains $\mathrm{ps}, \mathrm{pl}_{1}$, and $\mathrm{pl}_{2}$ sourced by Colette and Sacajawea Paterae.

The exterior of Lakshmi displays abundant units and structures that predate regional plains (t, pdl, gb, pr, psh) suggesting that both volcanism and tectonics were concentrated predominantly outside the plateau during the earlier stages of the geologic history of the region. After formation of regional plains, volcanism through a few centers to the southeast and west of Lakshmi played the major role in the geologic history.

The sequence of events during formation of the Lakshmi Planum and its surroundings suggests that these features began near the beginning of the observable geologic record. The general lateral progression of events appears to be oriented from outside in rather than in the opposite direction, which is consistent with the formation of the complex of Lakshmi Planum and the mountain ranges due to large-scale horizontal convergence, underthrusting, imbrication, and folding $[13,14,16,33]$.

References: 1) Masursky, H., et al., JGR, 85, 8232, 1980, 2) Pettengill, G.H., et al., JGR, 85, 8261, 1980, 3) Basilevsky, A.T., et al., JGR., 91, D399, 1986, 4) Barsukov, V.L. et al., JGR, 91, D399, 1986, 5) Sukhanov, A.L., et al., USGS Map I-2059, 1989, 6) Pronin, A.A. In: Venus Geology, Geochemistry, and Geophysics, 68-81, 1992. 7) Kaula, W.M., et al., JGR., 97, 16085, 1992, 8) Pronin, A.A., Geotectonics, 20, 271, 1986, 9) Grimm, R.E. and R.J. Phillips, GRL, 17, 1349, 1990, 10) Grimm, R.E. and R.J. Phillips, JGR, 96, 8305, 1991, 11) Vorder Bruegge, R.W. and J.W. Head, GRL, 16, 699, 1989, 12) Vorder Bruegge, R.W. and J.W. Head, Geology, 19, 885, 1991, 13) Head, J.W., Geology, 18, 99, 1990, 14) Roberts, K.M. and J.W., GRL, 17, 1341, 1990, 15) Bindschadler, D.L., et al., GRL, 17, 1345, 1990, 16) Keep, M. and V.L. Hansen, JGR., 99, 26015, 1994, 17) Code of Stratigraphic Nomenclature, AAPGB, 45, 645, 1961, 18) Wilhelms, D. E. Geologic mapping in: Planetary Mapping, 208, 1990, 19) Tanaka, K.L., Venus geologic mappers' handbook, USGS OFR 94-438, 50, 1994, 20) Basilevsky, A. T. and J.W. Head, EMP, 66, 285, 1995, 21) Basilevsky, A. T. and J.W. Head, PPS, 43, 1523, 1995, 22) Basilevsky, A. T., et al., In: Venus II 1047-1086, 1997, 23) Ivanov, M. A. and J. W. Head, JGR, 106, 17515, 2001, 24) Scott, D.H., and Tanaka, K.L., USGS Map I1802-A, 1986, 25) Rosenberg, E. and McGill, G. E., USGS Map I-2721, 2001, 26) Bridges, N. T., and McGill, G. E., USGS Map I-2747, 2002, 27) Campbell, B.A., and Campbell, P.G., USGS Map I-2743, 2002, 28) Hansen, V. L., and DeShon, H. R., 2002, USGS Map I-2752, 2002, 29) Bindschadler, D.L. and J.W. Head, JGR., 96, 5889, 1991, 30) Sukhanov, A.L. In: Venus Geology, Geochemistry, and Geophysics, 82, 1992, 31) Solomon, S.C., et al., JGR, 97, 13199, 1992, 32) Squyres, S.W. , et al., JGR, 97, 13579, 1992, 33) Vorder Bruegge, R.W. and J.W. Head, EMP, 50/51, 251, 1990. 
GEOLOGY OF THE JUNO CHASMA QUADRANGLE (V-47), VENUS, D. A. Senske, Jet Propulsion Laboratory/California Institute of Technology, Pasadena, CA, 91109.

Introduction. To understand how extension and volcanism are related both spatially and temporally, the region between latitudes $25^{\circ} \mathrm{S}$ and $50^{\circ} \mathrm{S}$ and longitudes $90^{\circ} \mathrm{E}$ and $120^{\circ} \mathrm{E}$ (Quadrangle V-47, Juno Chasma), is mapped [1,2] (Figure 1). In terms of large-scale structure and topography, the Juno region contains two distinct physiographic provinces: (1) the rolling lowlands of Aino Planitia that are located in the southern and western part of the map area and (2) the elevated linear topographic rise which runs approximately from east to west along the northern part of the quadrangle. Altimetry measurements show this area to reach an elevation of $1.0 \mathrm{~km}$ above the surrounding plains. Located along the crest of the highest topography is a 60 - to $90-\mathrm{km}$ wide, 1.0 - to $2.5-\mathrm{km}$ deep, graben, Juno Chasma.

Geologic Units. Within the Juno Chasma region, nine geologic material units are identified and mapped [3] (Figure 1). The definition of each unit is based on an evaluation of relative variations and patterns of radar backscatter and the presence of crosscutting and on-lapping relations. The units are divided into four main classes, (1) those that form relatively localized systems of lava flows, (2) regional-scale plains forming materials, (3) tectonic units and (4) impact related materials. Along with the time sequence of events resulting in the emplacement of geologic units, a number of episodes of tectonic activity have acted to shape the surface of this part of Venus. The relative sequence of tectonic activity, crustal stretching and extension forming normal faults, fractures and grabens along with compression forming sets of wrinkle ridges, is identified.

Lava Flow Materials (fa, fb). Volcanic activity within the Juno region has produced a wide variety of structures that range from small shields (several to $10 \mathrm{~s}$ of $\mathrm{km}$ in diameter), steep sided domes and channels to large constructs such as coronae, calderas, and regional-scale, greater than $100-\mathrm{km}$ in diameter, edifices. The characteristics of units placed in the category of lava flow materials are distinguished by (1) lobate sets of deposits whose lengths exceed their width, (2) the presence of distinct flow lobes both at the toe and along the margins of the flows, (3) a range of backscatter characteristics for different flows, producing a local mottled texture. It is generally possible to identify the constructional features that have produced these lava deposits, although in most cases specific vents cannot be distinguished.

Tectonic Units $(t)$. Located on the distal flanks of the Juno rift, but still associated with the elevated topography of the ridge are three areally extensive ele- vated outcrops of material identified as tessera. The first, made up of two occurrences centered at $27^{\circ} \mathrm{S}$, $100^{\circ}$ and $27.5^{\circ} \mathrm{S}, 107.2^{\circ}$ respectively corresponds to Husbishag Tesserae, and the second, Sudice Tessera, is located at $36.4^{\circ} \mathrm{S}, 113.2^{\circ}$. Both parts of Husbishag Tesserae and Sudice Tessera rise to an elevation of $\sim 1.0$-km relative to the adjacent plains.

Plains Forming units (pha, phb, pm, pr, pl). Regional plains forming units make up a majority of the quadrangle. These units generally have a homogeneous texture and are interpreted to be extensive lava flood deposits. Their emplacement covers a major portion of the history of the region. The association of the $p l$ unit with outcrops of $t$ suggests that some of the tessera forming tectonic events also coincided with plains formation. The association of $p h b$ with the Juno rift and the history of subsequent deformation of this unit suggests that its emplacement is related to early rift formation.

Impact Crater Materials (c). Although the density of impact craters is not sufficient to provide reliable ages for individual map units, impact events have influenced the surface and their associated deposits have acted to modify a number of the units. Within the Juno quadrangle, sixteen craters that are interpreted to be of impact origin are identified. These structures range in size from just under three kilometers to over $73 \mathrm{~km}$ in diameter (Boulanger). Mappable crater related materials correspond primarily to the continuous ejecta blanket. In addition, extensive surficial deposits are identified which include low emissivity parabolas (e.g. area of low radar backscatter extending to the south and west of Boulanger) and bright and dark halos/annuli. In some places, windblown material is identified while in others modification of the surface due to the impact blast is observed.

References. [1] Senske, D. A., et al., LPSC XXV, 1245-1246, 1994; [2] Senske, D. A., LPSC XXVII, 1171-1172, 1996; [3] Senske, D. A., Geologic Map of the Juno Chasma Quadrangle (V-47), Venus, in prep. for submittal to USGS, 2006. 

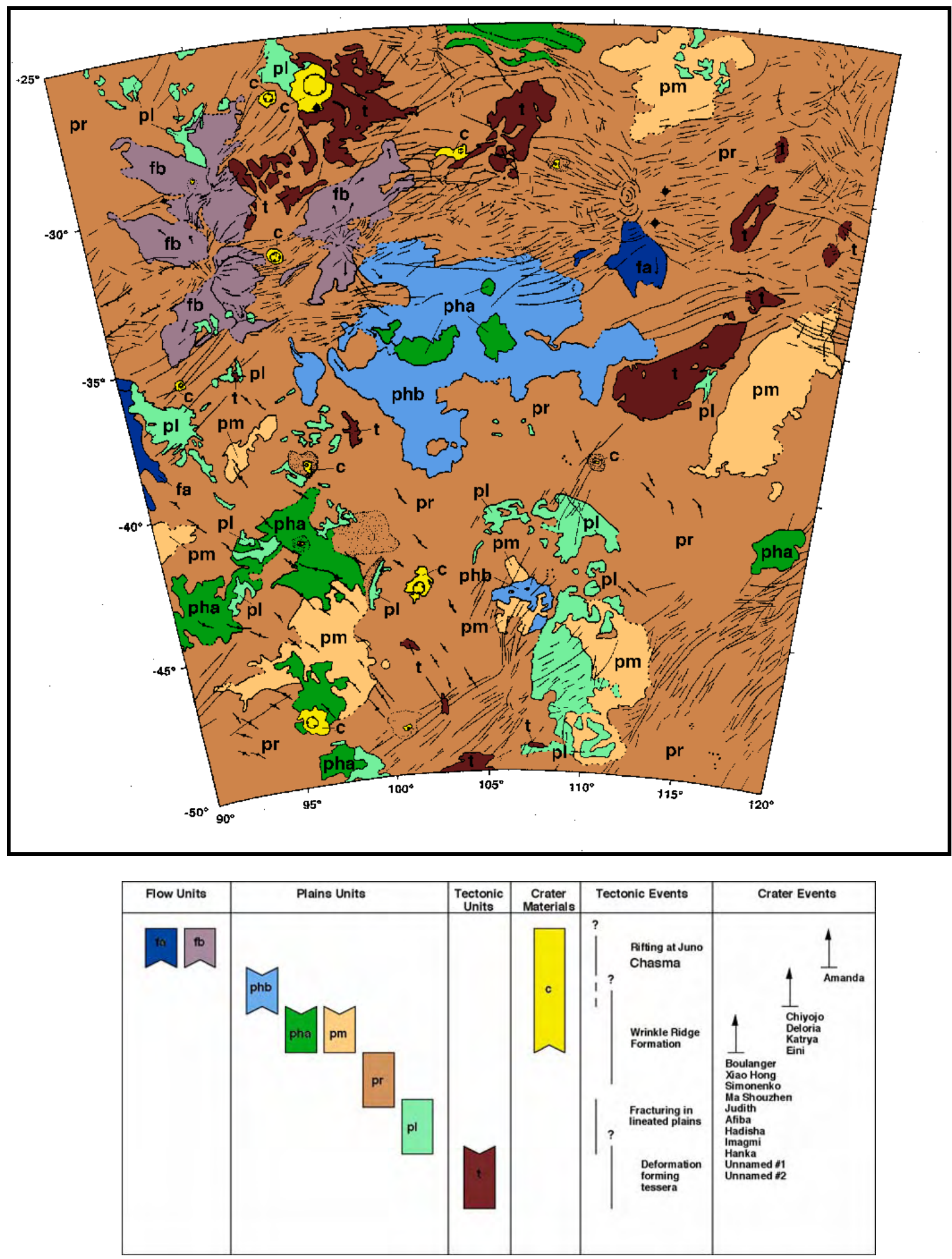

Figure 1 Regional-scale geologic map and correlation chart for the Juno Chasma Quadrangle (V-47). Units are defined on the basis of patterns in radar backscatter and cross-cutting and on-lapping relations. 
GEOLOGY OF THE PHOEBE REGIO QUADRANGLE (V-41), VENUS, D. A. Senske, Jet Propulsion Laboratory/California Institute of Technology, Pasadena, CA, 91109.

Introduction. Tessera covers approximately $9 \%$ of the surface of Venus [1]. The sequence of events and the processes involved in the formation of this type of landform are currently being examined through the geologic mapping of the Tellus Tessera [2] and Phoebe Regio Quadrangles. Results from previous analyses show that the outcrops of tessera in these areas contain distinctly different sets of structural elements $[3,4]$. By evaluating the timing relations between geologic units and structural features, a means is provided to better determine how these terrains formed.

Geology of Phoebe Regio. A total of eleven units are identified for the Phoebe region (Figure 1). Unit definition and characterization is based on an assessment of variations in surface texture, identification of coherent patterns of radar backscatter and the presence of cross-cutting and on-lapping relations.

Surface materials mapped as tessera (t) typically correspond to the 1.5- to 2.5-km high rise of Phoebe Regio and are generally the oldest in the stratigraphic sequence. In comparison to Tellus Tessera where the tessera fabric is composed primarily of ridges and valleys, that at Phoebe is made up of intersecting horsts and grabens, indicating that extension has been the dominant form of deformation [3,4]. In several places, extensive embayment by regional plains (pr) has produced concentrations of isolated, high-standing outcrops of tessera. This is most readily observed along the western part of Phoebe (near $9^{\circ} \mathrm{S}, 280^{\circ}$ ) and in the northeastern part of the quadrangle (near $10^{\circ} \mathrm{S}, 295^{\circ}$ ).

Much of the eastern part and southern margin of Pheobe has been cross cut by later faulting associated with major rift valleys such as the southern extension of Devana Chasma $\left(2^{\circ} \mathrm{S}, 289^{\circ}\right)$. These deformation $\underline{\text { belts }}(\mathrm{db1})$ are most likely composed of regional plains material that has been extensively deformed and modified. Because the high degree of surface alteration has resulted in radar properties that are different than other regional plains materials, these have been mapped as a separate unit.

A variety of lava flow units are identified. The earliest eruption events are associated with the emplacement of lineated plains ( $p l$ ). This unit possesses characteristics similar to units mapped in Tellus, but differs in that its abundance here is very limited. Subsequent to the formation of the lineated plains, volcanic activity associated with the regional plains occurred. More recent volcanism has been more localized, forming mottled (pm), homogeneous (ph) and shield (ps) plains. Source regions for mottled plains are often associated with rift related faults, suggesting that extension has produced zones along which magma has been allowed to migrate to the surface. Units of homogeneous plains are typically associated with large volcanic edifices and coronae. Superposition relations indicate that this unit is associated with early stage eruptions and lava flooding. Later events correspond to the emplacement of digitate plains (pd1) that are typically arrayed radial to a summit caldera. Additional occurrences of digitate plains $(p d 2)$ correspond to sites of early rift related activity. In most cases, the source regions for these flows cannot be identified due to later faulting and fracturing.

In a several areas, crater (c) materials including airfall parabolae and halo deposits blanket many of the other map units. These relations suggest that impact cratering has produced some of the most recent surface deposits.

Volcanic structures located in the Phoebe region include an array of features that range from small shields (several to 10's of $\mathrm{km}$ in diameter) to large edifices and coronae ( $>100 \mathrm{~km}$ in diameter). To understand better the events in the history of the formation of volcanic features, detailed mapping of two coronae located in the southwest part of the quadrangle $\left(22^{\circ} \mathrm{S}\right.$, $271^{\circ}$ and $20.5^{\circ} \mathrm{S}, 273^{\circ}$ ) has been performed. For both features, similar assemblages of units are identified. The early history of each corona is characterized by the emplacement of laterally extensive homogeneous lava flow units that cover 100's of $\mathrm{km}^{2}$. The uniform texture and lack of identifiable sets of flow lobes within the unit suggests that they were most likely emplaced by lava flooding. More recent activity has been concentrated along the flanks and summit region of each corona. Unlike the more distal homogeneous deposits, these are made up of long, digitate systems of flows, indicating a change in the style of eruption activity over time. All the volcanic units are cut by systems of faults and fractures, indicating that extension has been a late stage process.

References. [1] Ivanov, M. A. and J. W. Head, JGR, 101,14861-14908, 1996. [2] Senske, D. A., LPSC XXX, 1999 [3] Hansen, V. L. and J. J. Willis, Icarus, 123, 296-312, 1996. [4] Bindschadler, D. L., et al., JGR, 97, 13495-13532. 


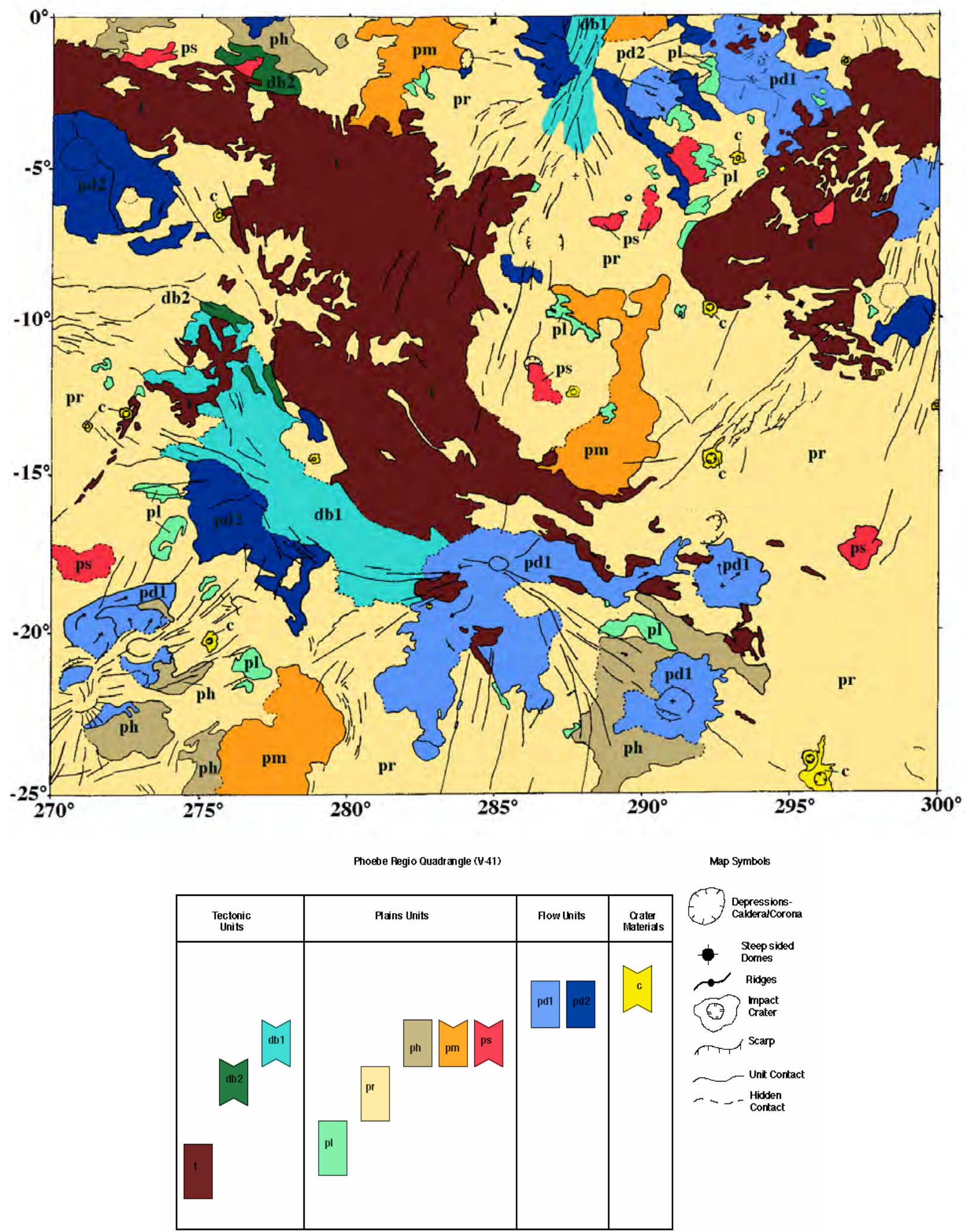

Figure 1 Regional-scale geologic map and correlation chart for the Phoebe Regio Quadrangle (V-41). Units are defined on the basis of patterns in radar backscatter and cross-cutting and on-lapping relations. 
GEOLOGY OF THE TELLUS TESSERA QUADRANGLE (V-10), VENUS, D. A. Senske, Jet Propulsion Laboratory/California Institute of Technology, Pasadena, CA 91109.

Introduction. The processes associated with the formation of tessera terrain on Venus are being examined by a number of investigators [1-5]. To understand better the geologic history of individual occurrences of tessera, mapping of the Tellus Tessera Quadrangle $(\mathrm{V}-10)$ is being performed. The results from this analysis are used to constrain the sequence of events in tessera formation along with evaluating the relations between tessera and adjacent plains.

Geology of the Tellus Tessera Region. Based on the identification of coherent patterns of radar backscatter along with cross-cutting and on-lapping relations, a total of eight surface material units are identified for the Tellus region (Figure 1). Detailed characterization of these units is based on an assessment of variations in surface texture and a quantitative evaluation of their radar properties.

The tessera ( $t$ ) material that makes up Tellus is generally mapped stratigraphically as the oldest. Study of the three dimensional relations along the western margin of this upland, however, indicates that the adjacent plains often lie on a surface that slopes away from Tellus [2, 6], suggesting that post emplacement adjustment has occurred, possibly due to isostatic uplift or later tessera formation related activity. A goal of this analysis is to establish the degree to which subunits and different deformational episodes within the overall context of Tellus can be determined. In several locations, the identification of distinct sets of structural elements has allowed the mapping of a number of domains (tessera units $t 1$ to $t 4$ ). The central part of Tellus, $t 3$, contains an array of intersecting ridges and troughs. Outcrops of $t 3$ located along the northern boundary are embayed by regional plains, producing a number of isolated, high standing "islands" of tessera. Along the northern margin of Tellus are eight caldera/corona-like structures that are interpreted to be source regions for some of the surrounding plains material. The subunits $t 1, t 2$, and $t 4$ lie along the southern and eastern edges of the main outcrop of tessera ( $t 3$ ). Ridges within the $t 4$ subunit appear to reflect tectonic activity associated with adjacent deformation belts (db1). In comparison, compressional deformation associated with the interaction between subunits $t 1, t 2$, and $t 3$ appears to have resulted in the formation of ridges in deformation belt $d b 2$.

Volcanic activity has occurred throughout the Tellus region, being manifested in a variety of plains deposits and edifices. The oldest plains unit, lineated plains $(p l)$ is primarily a boundary forming unit with Tellus. Additional outcrops are preserved as isolated occurrences within the regional plains. In many locations the structure within the lineated plains cross-cuts both this unit and adjacent tessera, suggesting that some of the events that resulted in the formation of the tessera fabric continued after plains emplacement.

A second episode of plains forming activity is associated with regional plains ( $p r$ ). These plains embay tessera, lineated plains and in some places deformation belts (NE-SW trending belts located in the SW part of the quadrangle). In most locations, faults and fractures within the lineated plains are truncated at the boundary with the regional plains, suggesting that the latter are younger and that either (1) the rate of tectonic activity decreased over time (unlike the lineated plains where systems of faults and fractures are pervasive, while those in the regional plains are only localized) or (2) that the emplacement of the two units was separated by a large amount of time, allowing the lineated plains to record numerous tectonic events. Superposition relations show that the deformation belts both predate and postdate the regional plains, indicating that multiple deformation episodes have occurred.

The youngest units within the Tellus quadrangle are local lava flows and crater (c) materials. Based on the absence of multiple flow lobes and their uniform texture, homogeneous plains ( $p h$ ) are interpreted to be sites of lava flooding. The remaining two volcanic units, digitate plains $(p d)$ and shield plains ( $p s)$ are associated with volcanic constructs that range from several to up to $200 \mathrm{~km}$ in diameter. Digitate plains are found exclusively in the SW part of the map area on the flanks of a $200-\mathrm{km}$ diameter volcano $\left(28^{\circ} \mathrm{N}\right.$, $64^{\circ}$ ). A nested summit caldera indicates that multiple eruption events have occurred. Shield plains, consisting of small volcanic shields and their associated deposits, are found mainly in the eastern part of the quadrangle where they are superposed on the regional plains. In some locations, individual shields are both superposed and cross cut by background structure, indicating that within each field, volcanic activity has covered a range of time. Crater materials correspond to impact structures and their associated ejecta. Extensive, up to 1000 's of $\mathrm{km}^{2}$, halo deposits generally blanket most units, indicating that impact craters are often some of the most recent features.

References. [1] Binschadler, D. L. and J. W. Head, JGR, 96, 5889-5907, 1991. [2] Ivanov, M. A. and J. W. Head, JGR, 101, 14861-14908, 1996. [3] Hansen V. L. and J. J. Willis, Icarus, 123, 296-312, 1996. [4] Hansen V. L. and J. J. Willis, Icarus, 132, 321-343, 1998. [5] Gilmore, M. S., et al., JGR, 103, 16813-16840, 1998. [6] Senske, D. A., LPSC XXIX, 1745-1746, 1997. 

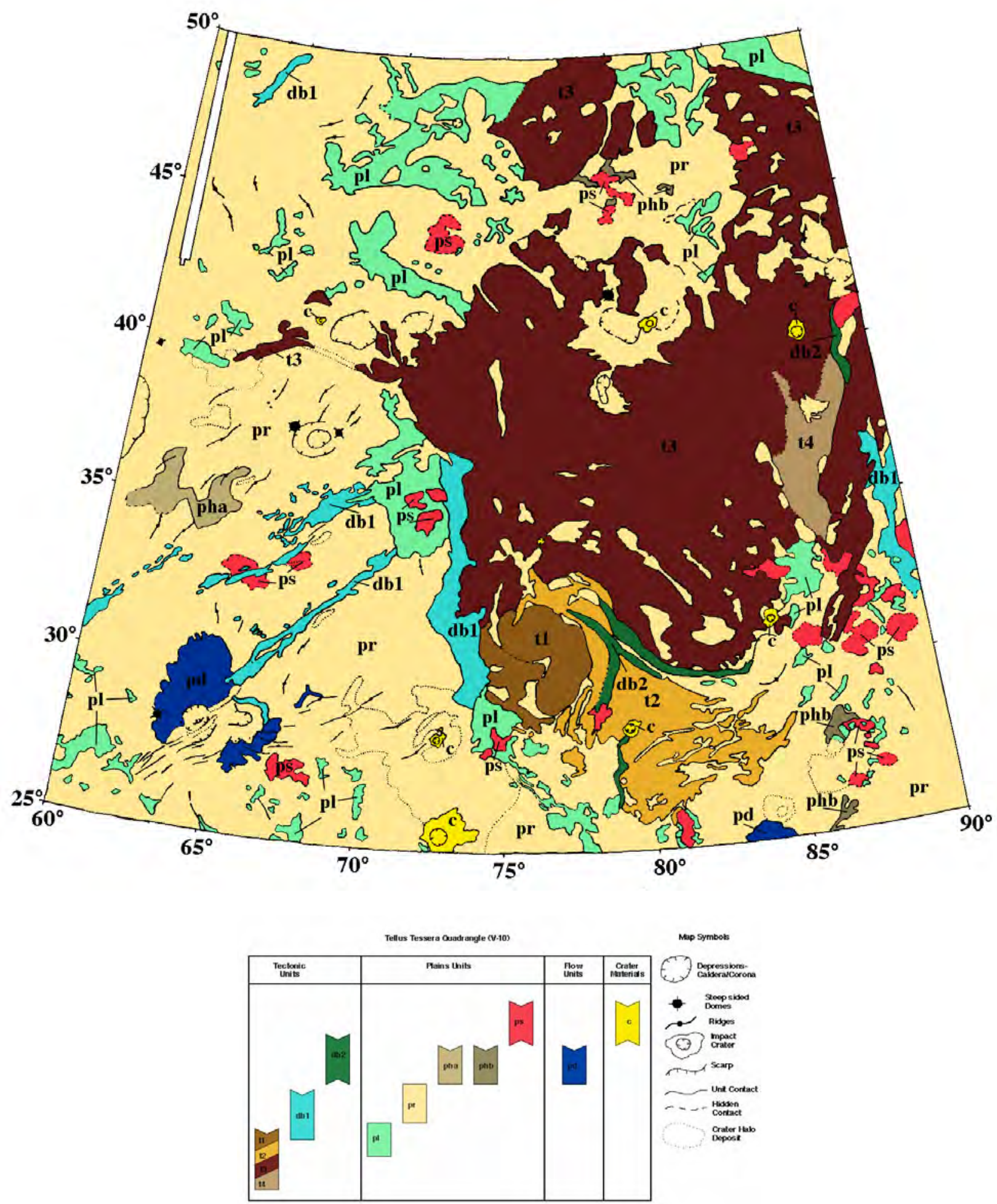

Figure 1. Regional-scale geologic map and correlation chart of the Tellus Tessera Quadrangle (V-10). Units are defined on the basis of patterns in radar backscatter and cross-cutting and on-lapping relations. Although tessera is identified as the oldest unit, an upper bound on the timing of activity in its formation is not clearly defined. Recent activity associated with the formation of plains and flow units is focused at sites of digitate plains, shield plains and homogeneous plains. 
MAPPING OF QUADRANGLE V-53: THEMIS REGIO. E. R. Stofan ${ }^{1,2}$ and A. W. Brian ${ }^{2}$ ${ }^{1}$ Proxemy Research, 20528 Farcroft Lane, Laytonsville, MD 20882, (ellen@ proxemy.com), ${ }^{2}$ Department of Earth Sciences, University College London, WC1E 6BT UK.

Introduction: A geologic map of the Themis Regio (V-53) quadrangle has been completed at 1:5,000,000 scale as part of the NASA Planetary Geologic Mapping Program. The quadrangle covers a portion of the Parga Chasmata system, and has extensive rifting, numerous coronae, and abundant volcanism. We mapped this region to better define the relationship between corona formation and rifting, to study the relationship between rifting and volcanism, including coronae, and to determine the stratigraphic relationship of plains-forming units [e.g., 1, 2].

Quadrangle Overview: The Themis Regio Quadrangle (V-53) extends from $25^{\circ}$ $50^{\circ}$ S. latitude, $270^{\circ}-300^{\circ}$ E. longitude, and includes the Themis Regio highland, surrounding plains, and the southernmost portion of Parga Chasmata. V-53 consists of lowlying plains lying slightly below Mean Planetary Radius (MPR, 6051.84, [3]). The topographically lowest points in the quadrangle (about $2 \mathrm{~km}$ below MPR) are within the Parga rift and in the troughs around several coronae.

We have identified seven plains materials units within the V-53 quadrangle: uniform plains materials (unit pu), smooth plains materials (unit ps), mottled plains material (unit pm), Themis Regio lobate plains material (unit pTl), Themis Regio fractured plains material (unit pTf), Helen Planitia composite plains (unit $\mathrm{pHc}$ ) and densely fractured plains material (unit pdf). None of the plains units within this quadrangle are analogous to regional-scale plains units mapped in other quadrangles, such as the Aino composite plains in quadrangle V-46 [4]. This is largely due to the fact that much of the region has been resurfaced by flows associated with coronae and volcanoes. The Themis Regio lobate plains unit is mapped on the Themis Regio volcanic rise (Figure 1), and is characterized by flows from an unknown source. These units are likely to not be of the same age; some may be volcanic flows that have originated from rift fractures, while others have come from unknown edifices or coronae. The Themis Regio fractured plains unit is composed of multiple occurrences of heavily fractured plains on the Themis volcanic rise. They may represent plains units off the rise that were elevated and deformed (such as unit pu or unit ps), or they may represent earlier corona or volcano flows that have been subsequently deformed.

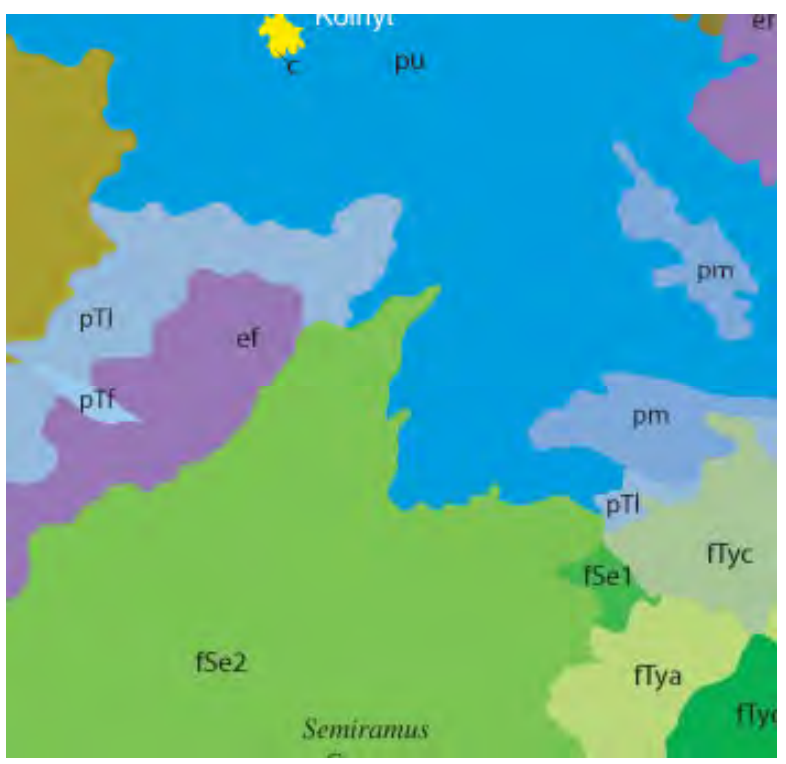

Figure 1. West-central portion of the Themis Regio quadrangle, showing corona flows (unit fSe, unit fTy) overlapping onto plains units, including the Themis lobate plains (unit $\mathrm{pTl}$ ) and the uniform plains (unit pu).

Eleven units associated with specific named volcanic edifices have been mapped, including those associated with the large volcanoes Chloris Mons (Figure 2), Mielikki Mons and Tefnut Mons. Multiple materials 
units associated with unnamed or unknown sources have also been mapped and combined into a single unit. These include a volcanic center unit (unit vc), and edifice field unit (unit ef) and an unnamed volcano unit (unit fvu). Although these units have similar morphologies, the different occurrences have differing relationships with surrounding units, indicating that they did not form at the same time. Most of the volcanic flow units are not in contact with each other, or with consistent plains or corona units, making an overall volcanic stratigraphy difficult to determine.

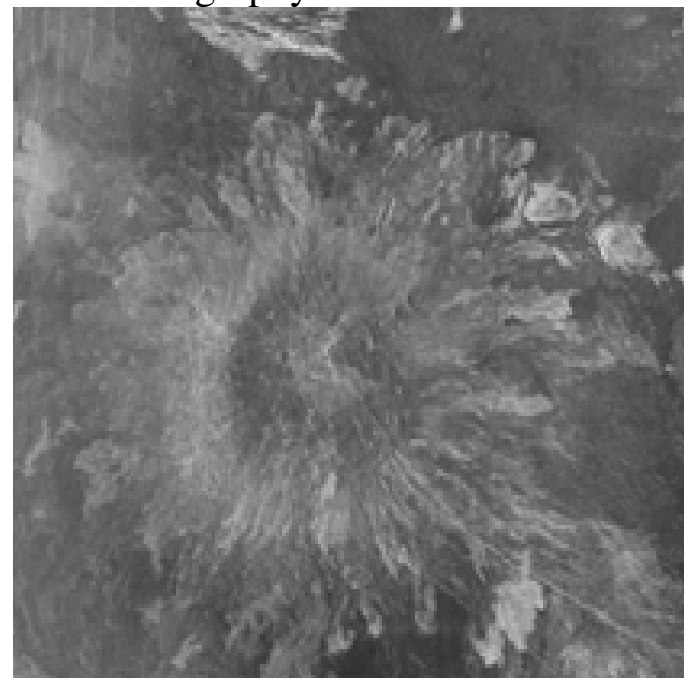

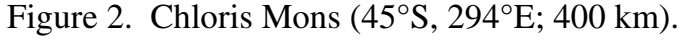

Eighteen named coronae have mapped flow materials units in the V-53 quadrangle, along with units associated with two unnamed coronae. Some of the coronae have multiple associated flow units, including Ukemochi Corona, with five associated units, and Tamiyo Corona, with four associated flow materials units. Where coronae have multiple units, the flow units are interfingered with units from adjacent coronae, suggesting that corona formation overlapped over some likely significant period of time. Coronae with abundant associated flows are located both on and off the rift, and on and off the volcanic rise. Recent work by Martin et al. [2] indicates that coronae on the Themis vol- canic rise have more associated volcanism than other coronae in the Parga region.

There are 12 impact craters within the quadrangle. Most postdate the units upon which they lie, but subtle embayment relationships with surrounding units are possible.

Some age relationships can be determined between some of the coronae and volcanic edifices, with no clear pattern observed. Some coronae predate rifting, some postdate it, while most are interpreted to have formed largely synchronously with rifting.

Conclusions: Unlike many other Venus quadrangles, V-53 lacks regional-scale plains units. In V-53, the scale of plains units tends to be on the order of 100's of kms rather than 1000 's of kms and much of the region has been resurfaced from flows from volcanoes and coronae. We have chosen to lump plains units of relatively similar morphology into units (examples: unit pTl, unit pm) that are unlikely to have originated from the same source or have formed at the same time.

Along Parga Chasmata, coronae are located along the rift, as well as to the north and the south of the rift [2], similar to the situation along Hecate Chasma [5]. Coronae in this quadrangle exhibit all forms of corona topographic shapes, including depressions, rimmed depressions, plateaus and domes. Most of the coronae formed synchronously with the rifting, although some clearly predate the rifts and others postdate extensional deformation [2].

A strong association between volcanism and coronae along rifts has been noted elsewhere on the planet [6]. In V-28 [5] and V53 , some coronae along the rift do not have much associated volcanism; coronae with the most associated volcanism in these quadrangles are located at least $500 \mathrm{~km}$ off the rifts or on the Themis Regio highland. While extension clearly plays a role in volcanism at coronae [6], it is not the only contributing factor. Coronae at Themis Regio may have greater 
than average associated volcanism owing to the possible mantle plume beneath the rise.

The large number of plains units, coronae and volcanoes in this quadrangle results in a very horizontal stratigraphic column, as few units are in direct contact. The scale of resurfacing in this quadrangle is on the scale of 100's of kilometers, consistent with the fact that it lies in the most volcanic region of Venus.

Map Timeline. The map of V-53 has been completed and a copy has been sent along with this abstract. The text, DOMU and stratigraphic column are being finalized, and the map will be submitted by mid- July, 2006.

References: [1] Stofan, E.R. and S.E. Smrekar, Proceedings of Mantle Plume IV Penrose Conf., GSA Special Paper 388, 841-861, 2005. [2] Martin, P., E. Stofan, L. Glaze and S.E. Smrekar, in review, JGR, 2006. [3] Ford, P. G., and Pettengill, G. H. (1992) JGR, v. 97, 3,103-13,114. [4] Stofan, E.R. and J.E. Guest, Geologic Map of the Aino Planitia Quadrangle (V-46), Venus, USGS Geologic Investigations Series Map I2779, 2003. [5] Stofan, E.R., J.E. Guest and A.W. Brian, Geologic Map of the V-28 Hecate Chasma Quadrangle, in review, U.S. Geological Survey, 2005. [6] Magee, K.P. and J.W. Head (1995) JGR 100, 15271552 . 
GLOBAL GEOLOGIC MAP OF EUROPA. T. Doggett ${ }^{1}$, P. Figueredo ${ }^{1, *}$, R. Greeley ${ }^{1}$, T. Hare ${ }^{2}$, E. Kolb ${ }^{1}$, K. Mullins $^{2}$, D. Senske ${ }^{3}$, K. Tanaka ${ }^{2}$, S. Weiser ${ }^{1},{ }^{1}$ Department of Geological Sciences, Arizona State University (tcd@asu.edu), ${ }^{2}$ U.S. Geological Survey, Flagstaff, AZ, ${ }^{3}$ Jet Propulsion Laboratory, California Institute of Technology, Pasadena, CA., (*currently at the ExxonMobil Research Company, Houston, TX).

Introduction: Europa, with its indications of a sub-ice ocean, is of keen interest to astrobiology and planetary geology. Knowledge of the global distribution and timing of Europan geologic units is a key step for the synthesis of data from the Galileo mission, and for the planning of future missions to the satellite.

The first geologic map of Europa [1] was produced at a hemispheric scale with low resolution Voyager data. Following the acquisition of higher resolution data by the Galileo mission, researchers have identified surface units and determined sequences of events in relatively small areas of Europa through geologic mapping [2-6] of images at various resolutions acquired by Galileo's Solid State Imaging (SSI) camera [7]. These works [2-6] provided a local to sub-regional perspective and employed different criteria for the determination and naming of units. Unified guidelines for the identification, mapping and naming of Europan geologic units were put forth by [8] and employed in regional-to-hemispheric scale mapping $[9,10]$ which is now being expanded into a global geologic map.

Methodology: A global photomosaic [11] of Galileo and Voyager data was used as a basemap for mapping in ArcGIS, following suggested methodology of allo-stratigraphy for planetary mapping [12]. Due caution was exercised given that the mosaic has a resolution varying from 12.6 to $0.23 \mathrm{~km}$ per pixel, as well as variations in illumination and viewing geometry, to avoid making distinctions between units that are artifacts of these variations.

\section{Geologic History:}

Background Plains Material (unit $p_{1}$ ). This unit forms globally extensive plains that appear smooth at regional or global resolution (Figure 1), but are intensely ridged at higher resolution. It is characterized by cross-cutting ridges and troughs at multiple scales, with various geometries including arcuate, sinuous and anastomosing. It is disrupted in some localities by pits and domes and is sparsely cratered. It is older than all other units, acting as a background for all other stratigraphic units and structures and is equivalent to the ridged plains material (unit pr) defined in [8].

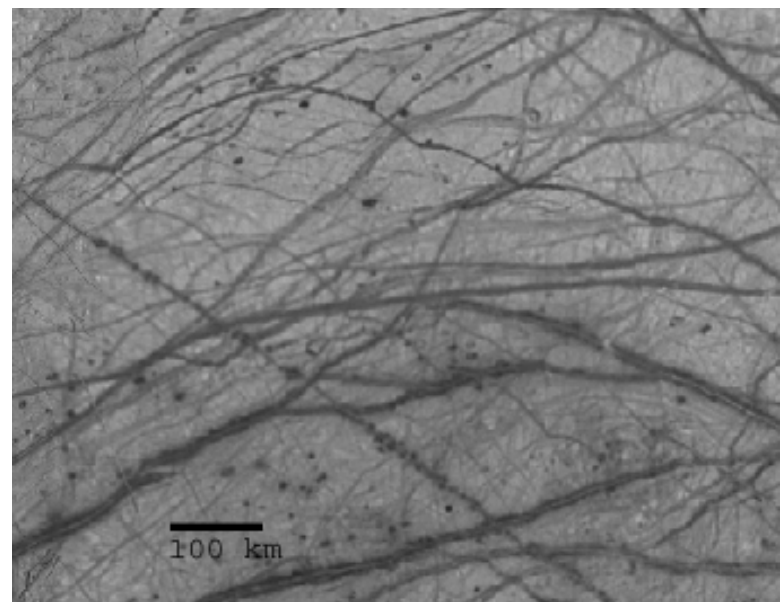

Figure 1: Unit $\mathrm{p}_{1}$ in the northern hemisphere, at $1.57 \mathrm{~km} / \mathrm{pixel}$.

Unit $\mathrm{p}_{1}$ is interpreted to represent tectonic resurfacing of Europa during a period of more intense and denser lineament formation. As indicated by the relative lack of cratering, this occurred relatively recently compared to the age of the solar system.

Initial mapping separated unit $\mathrm{p}_{1}$ into two units, with a more knobby or mottled plains in portions of the polar regions that also had an apparent difference in the cross-cutting lineaments being both wider in size and spacing. However, except for an albedo contrast in some low-resolution $(12.6 \mathrm{~km} / \mathrm{pixel})$ data, only a gradational contact could be drawn, which provided no definitive evidence of their relative ages, although intuitively the more lenticulated plains might seem to be younger. This distinction was discarded as too tenuous for a consensus geologic map, and may be attributed to regional differences in the degree of lenticulation, and possibly thermal inertia (Spencer, pers. comm.), within the same unit.

Argadnel Regio Unit $\left(p_{2}\right)$. In Argadnel Regio the background plains unit is disrupted by wide cycloid lineaments to a degree that warrants a definition as a separate, younger plains unit (Figure 2). This is interpreted to be tectonic disruption, probably by tidal stress forces, of the older plains unit. It is partially equivalent to the dark plains unit in Voyager mapping [1]

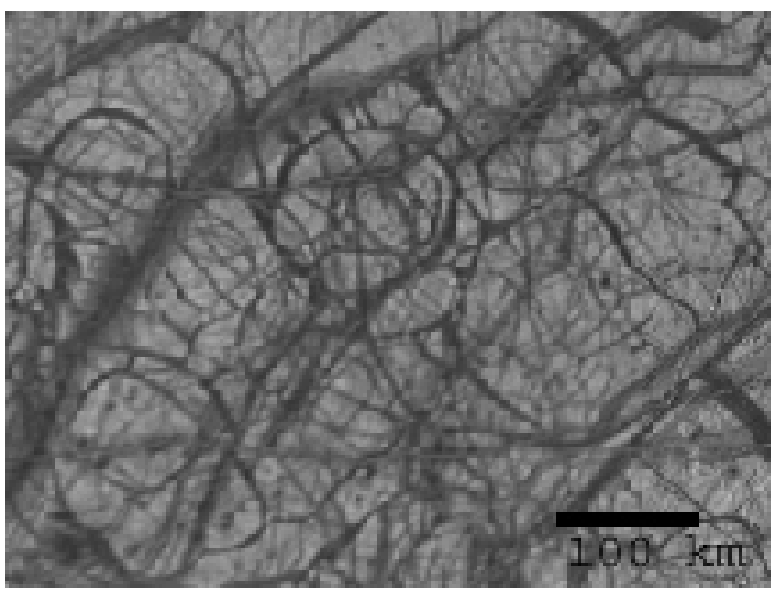

Figure 2: $\mathrm{p}_{2}$ unit in Argadnel Regio, at $0.23 \mathrm{~km} / \mathrm{pixel}$.

Antipodal Dark Plains Material (unit $p_{3}$ ). This unit forms equatorial plains, in two occurrences, centered on the sub-Jovian and antiJovian points respectively, which are darker than surrounding plains. It has a speckling of domes and sharp contacts with surrounding brighter plains, giving the overall resemblance of a scab on skin. The unit contains occasional impact craters, like Cilix, which are readily apparent because of the contrast between bright ejecta and dark plains. It embays surrounding plains $\left(\mathrm{p}_{1}, \mathrm{p}_{2}\right)$ units, but is crosscut by numerous lineaments continuing on from adjacent units. In some cases the boundaries of unit $\mathrm{p}_{3}$ conform to the ridges or abut against cycloids from unit $\mathrm{p}_{2}$.

Unit $\mathrm{p}_{3}$ is interpreted as the modification of pre-existing plains unit by some form of endogenic activity, which floods inter-ridge topographic lows with dark, viscous material that erupted from lenticulae within the unit, and is thus somewhat of an intermediate between ridged plains and chaos. The geographic association with the sub-Jovian and anti-Jovian points is intriguing, suggesting the possibility of the global stress field controlling the occurrence of this unit, or the particle field environment having an effect on the coloring of the unit, but it could also be coincidental. The occurrence of this unit centered on the 180 longitude line is equivalent to the gray mottled terrain unit in the Voyager map [1].

Lineaments. Distinct from the densely spaced ridges in the background plains are the widely spaced lineaments that consistently cross-cut younger plains units $\left(\mathrm{p}_{1}, \mathrm{p}_{2}\right.$ and $\left.\mathrm{p}_{3}\right)$. These lineaments appear to represent a middle period of the geologic time represented by Europa's current surface, with some lineaments being overprinted 
by younger chaos and plains units, and all but two craters (the exceptions being Tyre and Callanish, which have some superimposed lineaments).

A manuscript in preparation for submission to Icarus [13] details the global mapping and sequencing of all major lineaments $(>100 \mathrm{~km}$ in length) into seven sparsely connected regional networks that are broken up by intervening areas of chaos and/or low image resolution. These networks define regional stratigraphic frameworks that allow temporal correlation of features on a hemispheric scale.

Disrupted Plains Material (unit $p_{4}$ ). This unit forms a hummocky terrain which is cross-cut by narrow lineaments, mostly troughs. The craters Avagddu, Tegid and Morvran are superimposed on this unit, forming distinct raised circular rims, and in the case of Tegid, a trough-like annulus. It has a sharp contact with surrounding plains units $\left(\mathrm{p}_{1}\right.$ and $\left.\mathrm{p}_{3}\right)$, which it embays, and a sharp contact with the chaos unit that in turn embays it. Triple bands coming from surrounding plains become obscured within the unit, transitioning to narrow troughs or fading altogether.

This unit is interpreted to be the result of endogenic activity that severely disrupted the pre-existing plains unit, fragmenting it into hummocks and massifs, a transitional form between plains and chaos. The surface expression of lineaments was altered into negative relief, or obscured altogether.

Lenticulated Plains Material (unit $p_{l}$ ). This unit forms regions where a plains unit $\left(\mathrm{p}_{1}\right.$ or $\left.\mathrm{p}_{2}\right)$ acts as a matrix upon which lenticulae have been emplaced. No craters are observed within the lenticulated plains, which is consistent with a young age, or simply too little areal coverage. It is either younger or contemporaneous with $\mathrm{p}_{3}, \mathrm{p}_{4}$ and chaos units. It is cross-cut by most, but not all, lineaments.

It is interpreted to be the result of endogenic activity that disrupted pre-existing plains, in a manner possibly analogous to a volcanic field, where the lenticulae have not yet reached sufficient density to form a knobby chaos unit, and the plains unit has not been disrupted enough to fragment or become discontinuous. They can either be younger or contemporary to more continuous chaos units, and were called micro-chaos in some regional mapping [3].

Chaos Material (unit ch). This unit is composed of disrupted terrain which forms dark albedo features in global or regional resolution, having sharp embaying contacts with brighter, smoother plains units (Figure 3). In low resolution this unit can also have transitional areas of dark albedo spots in a light albedo matrix, but this could also be equivalent to what has been mapped as lenticulated plains in high resolution (Figure 4). At higher resolution the chaos is seen to be hummocky plains, with plates of younger plains units in a matrix of dark, knobby material. There are several separated occurrences globally, with different appearances, but nothing that could not be explained by differences in photometry and resolution within the base mosaic. Chaos is younger than all surrounding material units, with some cross-cutting lineaments. A sub-type is elevated or knobby chaos that is younger than other chaos units $[9,10]$. They are interpreted to be located where pre-existing plains units have been disrupted by an endogenic process that fractures the ice into plates and rafts them in a matrix of material brought to the surface from the interior, overturned plates, or both.

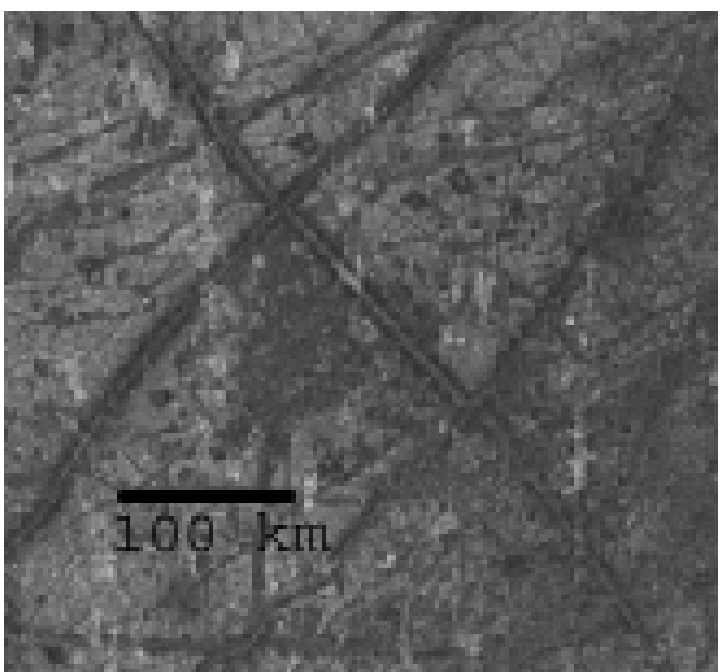

Figure 3: Conamara Chaos, type locality for chaos unit [8]

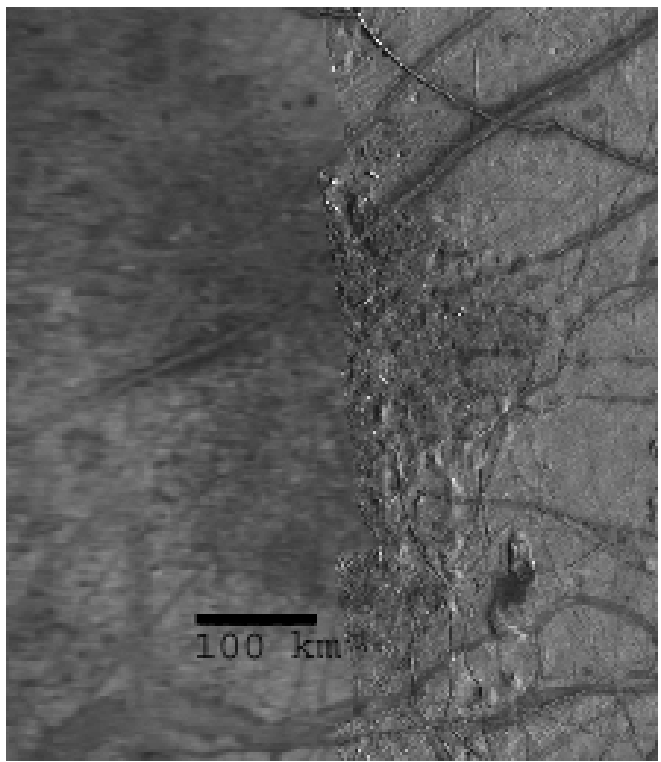

Figure 4: Example of apparent textural difference in chaos unit across resolution boundary.

References: [1] Lucchitta and Soderblom, in The Satellites of Jupiter: 521, 1982. [2] Senske et al., LPSC XXIX, \#1743, 1998. [3] Prockter et al., JGR., 104, 16531-16540, 1999. [4] Kadel et al., JGR, 105, 22657-22669, 2000. [5] Figueredo et al., JGR, 107, 10.1029/2001JE001591, 2002. [6] Kattenhorn, Icarus, 157, 490-506, 2002. [7] Belton et al., Space Science Reviews, 60, 413-455, 1992. [8] Greeley et al., JGR, 105, 22559, 2000. [9] Figueredo and Greeley, JGR, 22629-22646, 2000. [10] Figueredo and Greeley, Icarus, 167, 287-312, 2004. [11] USGS, I-2757, 2003. [12] Skinner and Tanaka, LPSC XXXIV, \#2100, 2003. [13] Figueredo, Weiser and Hare, Icarus, in prep., 2006. 
A GLOBAL GEOLOGIC MAP OF GANYMEDE AT 1:15M. G. Wesley Patterson ${ }^{1}$, James W. Head ${ }^{1}$, Geoffrey C. Collins ${ }^{2}$, Robert T. Pappalardo ${ }^{3}$, Louise M. Prockter ${ }^{4}$, and Baerbel K. Lucchitta ${ }^{5},{ }^{1}$ Department of Geological Sciences, Brown University, Providence, RI, 02912 (Gerald_Patterson@brown.edu), ${ }^{2}$ Wheaton College, Norton, MA, 02766, ${ }^{3}$ LASP, University of Colorado, Boulder, CO, 80309, ${ }^{4}$ Applied Physics Laboratory, Laurel, MD, 20723, ${ }^{5}$ USGS, Flagstaff, AZ, 86001.

Introduction: The Galilean satellites represent a series of bodies that all formed from the same protoJovian nebula but are distinctly different in their physical properties, surface geology, and thermal evolution [1-4]. The explanation for many of these disparate characteristics is likely related to the radially varying conditions of the nebula during the earliest period of their formation [5-6]. However, an explanation for the differences in the geological evolution of Ganymede and Callisto, given their similar size, density, and bulk composition, remains one of the most fundamental questions in comparative planetology [6, 7]. Understanding the global distribution of geologic units on Ganymede in space and time can offer constraints on our ideas of how and why this icy satellite evolved to its present state.

The Voyager mission provided important information about the nature of the surface of Ganymede at moderate resolution and these data were used to produce a series of geologic maps covering the imaged surface at the 1:5M scale [e.g., 8-10]. The Galileo mission provided a host of new data (high-resolution monochromatic, color, and stereo imagery, polarimetry, near-infrared spectral imagery, etc.) and we are compiling a global geologic map of Ganymede (at the $1: 15 \mathrm{M}$ scale) that will represent the most recent understanding of the satellite on the basis of this data. This contribution builds on important previous accomplishments in the study of Ganymede [11-15] and here we summarize our progress toward the completion of this global mapping project.

Unit definitions: Based on a reassessment of the units identified at Voyager resolution using Galileo resolution data $[16,17]$, we have developed a Description of Map Units (DOMU) that divides the surface of Ganymede into five terrain types: 1) light, 2) dark, 3) reticulate, 4) palimpsest, and 5) crater material. The following is a summary of those definitions.

Light material: This material has been subdivided into four units: grooved, subdued, irregular, and undivided. The grooved unit (Ig) is arranged in domains characterized by parallel, approximately evenly spaced grooves and ridges oriented in a single dominant direction. The subdued unit (Is) is similar to the grooved unit but appears smooth or finely grooved at Galileo and/or Voyager resolution except where secondary craters and crater chains are superposed. The irregular unit (li) is similar to the subdued unit but contains isolated grooves with no preferred orientation. The undivided unit (l) represents all materials of sufficiently low resolution for which morphological properties and/or age relationships cannot be determined.
Dark material: This material has been subdivided into four units: cratered, lineated, irregular, and undivided. The cratered unit (dc) represents large areas of low albedo material with moderate to high crater density commonly occurring as polygons bounded by bright units. The lineated unit(dl) is similar in character to the bright grooved unit but with lower albedo and depressions tending to be more sinuous and shallower. The dark irregular unit (di) is characterized by isolated grooves with no preferred orientation similar to the light irregular unit but having an albedo characteristic of dark materials. The undivided unit (d) represents all materials of sufficiently low resolution that their material properties cannot be determined. This also may include irregularly shaped large patches and small slivers of low albedo material interspersed within light terrain of indistinct morphology or areas too small to be identified by morphologic criteria other than albedo.

Reticulate material (r): This terrain consists of a single unit. It is often associated with and surrounded by bright grooved, bright subdued, and/or dark lineated units but can be distinguished from them by its variable albedo and presence of grooves with two dominant directions (typically orthogonal to each other).

Palimpsest material: This material consists of two units: palimpsests and palimpsest interior plains. The palimpsest unit (p) is characterized by flat, generally circular to elliptical structures occurring predominately (but not exclusively) on dark terrain units. These structures lack rims but can have internal, concentric ridges. The palimpsest interior plains unit (pi) is characterized by smooth, circular to subcircular patches of high albedo material commonly found at or near the center of palimpsests.

Crater material: This terrain consists of seven units: bright craters, partly degraded craters, degraded craters, secondary craters, dark crater material, basin rugged material, and basin smooth material. The first three units separate craters into a stratigraphic sequence $\left(\mathbf{c}_{1}, \mathbf{c}_{2}\right.$, and $\mathbf{c}_{3}$ from oldest to youngest respectively) based on degradation state, which we feel can be more clearly determined than for palimpsests. The secondary crater unit (cs) is characterized by fields of uniform, small pits surrounding large bright craters, partly degraded craters, and some palimpsests. Dark crater material (cd) appears to be predominately associated with bright craters and forms dark patches on their floors or rims. The basin rugged material (br) and basin smooth material (bs) units are used to define the prominent Gilgamesh basin.

Mapping strategy: Using the DOMU presented here, we are completing the compilation of a global geologic map of the surface of Ganymede. In accom- 
A GLOBAL GEOLOGIC MAPPING OF GANYMEDE AT 1:15M. G. W. Patterson et al.

plishing this task we have 1) broadly mapped the boundaries of terrain types (i.e., dark and light materials, craters, palimpsests, reticulate) and superimposed structures (i.e. furrows) across the surface of Ganymede and 2) compiled detailed maps of geologic units (e.g., light grooved, dark cratered, palimpsest interior plains, etc.) in $60^{\circ} \mathrm{x} 60^{\circ}$ quadrangles. The assigned unit boundaries have been reviewed and modified as necessary within each quadrangle before proceeding to the next. The minimum dimension we have established for mapping a feature as a unit is $30 \mathrm{~km}$ (2 $\mathrm{mm}$ on the map). This map (Fig. 1) is being produced entirely in GIS format for analysis and combination with other datasets.

Status: We have completed the detailed mapping of light materials, dark materials, reticulate materials, palimpsests, and furrows for the entire surface of Ganymede (Fig. 1). We have also broadly mapped all craters $>30 \mathrm{~km}$. Our remaining tasks are to map the extent of the Gilgamesh basin and finalize the remaining issues in the stratigraphic sequence for the material units we have mapped. Specifically, for light materials, we will be relying on an automated time-sequencesorting of grooves technique we have developed [18] and, for crater materials, we will be relying on the presence of bright rays to separate craters into two units.

References: [1] R. Greeley (1999) The New Solar System, 253-262. [2] R.T. Pappalardo (1999) The New Solar System, 263-276. [3] W.B. McKinnon and E.M. Parmentier (1986) Satellites, 718-763. [4] G. Schubert et al. (1986) Satellites, 224-292. [5] D.J. Stevenson et al. (1986) Satellites, 39-88 [6] T.V. Johnson (2004) Physics Today, 57, 77-83. [7] D.J. Stevenson (2004) Physics Today, 57, 43-48. [8] J.E. Guest et al. (1988) USGS Map I-1934. [9] D.E. Wilhelms (1997) USGS Map I-2242. [10] B.K. Lucchitta et al. (1992) USGS Map I2289. [11] B.K. Lucchitta (1980) Icarus, 44, 481-501. [12] E. M. Shoemaker et al. (1982) Sats. of Jupiter, 435. [13] S. Murchie et al. (1986) JGR, 91, E222-E238. [14] R.T. Pappalardo et al. (1998) Icarus, 135, 276-302. [15] L.M. Prockter et al. (1998) Icarus, 135, 317. [16] G.C. Collins et al. (2003) PGG Planetary Mappers Meeting. [17] G.W. Patterson et al. (2003) PGG Planetary Mappers Meeting [18] E.S. Martin et al. (2006) LPSC \#1204.

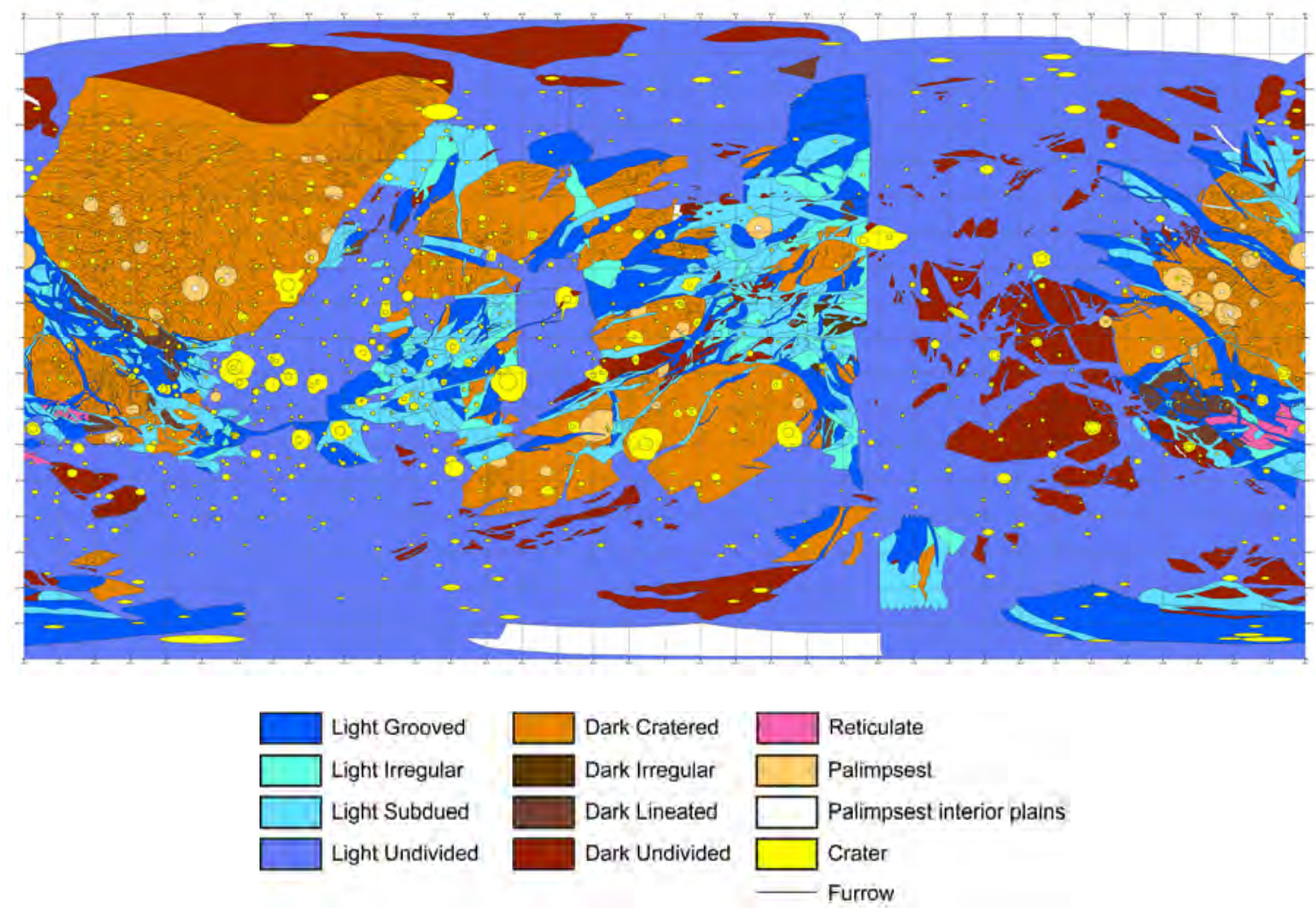

Figure 1. Global geologic map of Ganymede compiled utilizing the DOMU presented here. 
GLOBAL GEOLOGIC MAPPING OF IO: FIRST STEPS. David A. Williams, Department of Geological Sciences, Arizona State University, Box 871404, Tempe, Arizona, 85287 (David.Williams@asu.edu); Laszlo Keszthelyi, Paul Geissler, Windy Jaeger, and Tammy Becker, Astrogeology Team, U.S. Geological Survey, Flagstaff, Arizona; David Crown, Planetary Science Institute, Tucson, Arizona.

Introduction: The objective of this work is to discuss mapping methodology for producing a new global geologic map of Io using the new global Io mosaics. These mosaics, produced by the USGS at a nominal resolution of $1 \mathrm{~km} /$ pixel, combine the best images from the Galileo and Voyager missions. To develop a mapping methodology we have studied the preliminary mosaics, all previous Voyager- and Galileo-based geologic maps of Io, and new maps of the Amirani-Gish Bar region that we recently produced from a $\sim 500$ $\mathrm{m} / \mathrm{pxl}$ regional mosaic. In this abstract we present an overview of the classes of geologic material units and structures that can be identified from existing images, and we discuss our conclusions about the best mapping approach to produce a new global map of Io.

Background: Io, the innermost Galilean satellite of Jupiter, is the most volcanically active body in the Solar System. Tidal heating within Io produces magma that feeds 300 active volcanic centers [1-3]. The 1979 Voyager flybys observed $\sim 25 \%$ of the moon at resolutions of $<2 \mathrm{~km} /$ pixel (the rest at $2-20 \mathrm{~km} /$ pixel: [4]), covering mostly the subjovian hemisphere. The recently completed Galileo mission (1996-2003) included five close flybys of Io, focused mostly on the antijovian hemisphere [5-7], with resolutions between $\sim 10 \mathrm{~m} /$ pixel to $20 \mathrm{~km} /$ pixel. This complementary coverage of Io has enabled the production of a series of high quality grayscale (high-sun and low-sun) and color global mosaics (1 km/pixel nominal resolution). These recently-completed mosaics, produced by the USGS, are now the definitive global compilation of image products for Io.

Our goal is to complement the new mosaics with a corresponding global compilation of geologic understanding at the end of the Galileo era. Geologic mapping is a tool that enables the definition and characterization of surface features into process-related material units and structures and places them within their stratigraphic context, allowing recognition of the geologic evolution of an area, region, or planet (depending upon the scale of the mapping). Before global mapping begins on the new Io mosaics, it is prudent to identify the optimal mapping methodology. Such an activity was done prior to global mapping of Europa [8].

Overview of Ionian Materials \& Structures: Io displays five primary types of material units: plains, patera floors, flows, mountains, and diffuse deposits. Plains cover $>70 \%$ of Io's surface [9], and appear as yellow (S-dominated), gray-white ( $\mathrm{SO}_{2}$-dominated), and red to red-brown (radiation-altered, short-chain sulfur-dominated) color units in Galileo images. Plains are thought to consist of the silicate crust of Io, mantled by dark silicate and bright sulfurous volcanic deposits [10-11]. Eroded plateaus, or layered plains, have also been detected in low-sun images and are mappable at global scales.

Patera floors have a range of albedos and colors, and these materials sometimes extend outside these volcano-tectonic depressions. Patera floors range from bright white to yellow-orange to dark black in Galileo images, in which the colors suggest various compositions, including mixes of silicates, sulfurous compounds, and relatively pure sulfur dioxide in some cases $[3,11]$. Three broad subunits of patera floor materials are characterized for mapping: Bright (presumably sulfur-dominated), Dark (presumably silicatedominated), and Undivided.

Lava flow units are also characterized by their albedo and color: Bright flows (sulfur-dominated), Dark flows (silicate-dominated), and Undivided Flows (units with intermediate albedos and colors). Two subunits are used for both bright and dark flows based on their inferred "freshness"; i.e., the youngest bright flows are very bright (high albedo), the youngest dark flows are very dark (low albedo). Flow materials are typified by their sharp contacts with the other units and generally elongated morphology (lengths >> widths: [10-12]). Correlation between Galileo Near Infrared Mapping Spectrometer and Solid State Imager data also shows that the darkest flow materials are associated with active hot spots [3, 13]. Lithologically, patera floor materials and lava flow units are probably identical. However, their distinctive geologic settings justifies separating them in the global map.

We recognize three types of mountain materials in regional images: Lineated, Mottled [12], and Undivided [13], although for the global mapping we map only massifs and layered plains. Lineated materials are associated with topographically-distinct ridges, grooves, graben, scarps, and lineaments on positiverelief edifices. This unit is interpreted as tectonicallydisrupted sections of crust containing planar structural features, possibly faults involved in uplift and/or collapse during mountain formation. Mottled materials contain lobes or domical mounds that are lacking in lineations. This unit is interpreted as sections of mountains that show evidence of mass wasting processes, most likely involving flow with or without rotational 
sliding $[2,12,16]$. Mountain material whose morphology does not fall within either of these two units is classified as Undivided. Volcanic mountains on Io are rare; the few edifices that have been found are mapped as Tholus materials.

Diffuse deposits are diverse on Io's surface, which was recognized because of the higher resolution color imaging of the Galileo camera. White Diffuse deposits are thought to be dominated by $\mathrm{SO}_{2}$-rich frosts. Yellow Diffuse deposits are likely composed of some combination of sulfur-rich materials and $\mathrm{SO}_{2}$, albeit less $\mathrm{SO}_{2}$, than white deposits. Red Diffuse deposits occur as ephemeral mantles around active vents. They have been interpreted as pyroclastic deposits rich in metastable, $S_{3}$ and $S_{4}$ allotropes, which are red when quenched from magmatic $S_{2}$ gas $[6,14]$, possibly also containing Cl-bearing materials at some vents [15]. Dark Diffuse deposits are interpreted as pyroclastic deposits derived from silicate lavas; Geissler et al. [9] performed a spectral analysis on the dark diffuse deposits from Babbar and Pillan Paterae, and found a spectral signature consistent with Mg-rich silicates. Finally, Green Diffuse deposits occur around active vents and underneath or near active plumes, where dark, fresh silicate flows also underlie the green material. This observation led to the suggestion that the green color results from alteration of cold sulfurous gases interacting with still warm silicate flows.

A wide range of structural features can be identified on Io, including scarps, ridges, graben, lineaments, faults, and circular depressions (pits and patera rims). The additional low-sun observations and higher resolution of the Galileo camera has enabled recognition of these and other structural features over a wider part of Io's surface than was previously possible.

Strategies for Global Mapping: After analysis of our new regional maps of the Amirani-Gish Bar region, analysis of previous geologic maps, and study of early versions of the new global Io mosaics, we have developed the following strategy for global mapping on the new mosaics with ArcGIS by ESRI.

1) Map diffuse deposits using Galileo global color data: The first mapping step will be to map diffuse deposits as a separate layer using the color mosaics. Typically various hachure patterns are used to delineate different types of diffuse deposits, and this approach will be used here. The wide variety of diffuse deposits on Io (black, yellow, white, red, green), which are thought to represent distinct compositions (silicates, sulfurous materials, $\mathrm{SO}_{2}$-dominated materials, short-chain sulfur allotropes, products of silicate/sulfur interaction, respectively), cannot always be discerned in grayscale images. The color images are required to map their diversity. Based on analysis of the preliminary global color mosaic, all five types of diffuse deposits are resolvable (1 km/pixel) and mappable.
2) Map mountains, surrounding plateaus, and structural features using the low-sun mosaic: The second mapping step will be to map mountains, layered plateaus, and other materials delineated by scarps and other structural features using the low-sun mosaic. Because mountains and plateaus have nearly the same color and texture as background plains, it is difficult to reliably identify them except from images taken during low solar incidence angles, resulting in shadows that delineate the rugged topography of ridges, grooves, and scarps. We anticipate having one unit, Mountain Material, for the global (paper) map, with the potential of defining additional subunits (e.g., Lineated vs. Mottled, massifs, mesa/plateaus, volcanic edifices) depending on their resolvability in the final mosaics. One option might be to create a separate structural map showing identified and inferred structural features (e.g., thrust faults).

3) Map vents and paterae: The third mapping step will be to map vents and paterae using the grayscale and high-sun color mosaics. These image products provide the greatest albedo and color (respectively) contrasts available to identify these features. Active vents are usually visible as dark spots in the bright plains or within the floors of larger paterae. We anticipate having one unit, Patera Floor Material, for the global (paper) map, with the potential of defining additional subunits (e.g., bright, dark, undivided and/or intermediate) depending on their detectability and scale in the final mosaics.

4) Map lava flow fields: The fourth mapping step will be to map flow fields using the grayscale and high-sun color mosaics. We will first map the outermost boundaries of each flow field around a vent, followed by the addition of more detail (lobate flow margins or fresher interior flows) as the available resolution permits. Active or recently active flows are identified by the following criteria: 1) observed surface changes in images obtained at different times; 2) thermal anomalies detected in NIMS data; and/or 3) an observed plume source at or near the flow margins. Based on analysis of the preliminary global color mosaic, we anticipate having three primary Lava Flow Material units (bright, dark, undivided) that are resolvable (1 km/pixel) and mappable.

5) Map plains: The final mapping step will be to map the bright plains. This should include everything not mapped in the previous categories. The primary Interpatera Plains Material has three subunits based on color (Yellow, White, and Red-Brown), as well as a Layered Plains unit composed of plateaus separated from surrounding plains by scarps and thought to be produced by degradational processes [16].

References: [1] Radebaugh et al., 2001, JGR 106, 33,00533,020; [2] Schenk et al., 2001, JGR 106, 33,201-33,222; [3] Lopes et al., 2004, Icarus 169/1, 140-174; [4] Smith et al., 1979a,b, Science 204, 951-972, \& Science 206, 927-950; [5] McEwen et al., 2000, Science 288, 1193-1198; [6] Keszthelyi et al., 2001, JGR 106, 33,025-33,052; [7] Turtle et al., 2004, Icarus, 169/1, 3-28; [8] 
Greeley et al., 2000, JGR 105, 22,559-22,578; [9] Geissler et al., 1999, Icarus 140, 265-282; [10] Williams et al., 2002, JGR 107, 5068, doi:10.1029/2001JE001821; [11] Williams et al., 2004, Icarus, 169/1, 80-97; [12] Williams et al., 2005, Icarus, 177, 69-88; [13]
Lopes et al., 2001, JGR 106, 33,053-33,078; [14] Spencer et al., 2000, Science 288, 1208-1210; [15] Schmidt and Rodriguez, 2003, JGR 108, 5104, doi: 10.1029/2002JE001988; [16] Moore et al., 2001, JGR 106(E12), 33,223-33,240. 
THE LUNAR GEOLOGIC MAPPING PROGRAM: SUMMER 2006 STATUS. L.R. Gaddis ${ }^{1}$, J.A. Skinner, Jr. ${ }^{1}$, T. Hare ${ }^{1}$, K. Tanaka ${ }^{1}$, B.R. Hawke ${ }^{2}$, P. Spudis ${ }^{3}$, B. Bussey ${ }^{3}$, C. Pieters ${ }^{4}$, and D. Lawrence ${ }^{5}$, ${ }^{1}$ U.S. Geological Survey, Astrogeology Program, 2255 N. Gemini Drive, Flagstaff, AZ (lgaddis@usgs.gov), ${ }^{2}$ PGD/SOEST, Univ. Hawaii, Honolulu, HI; ${ }^{3}$ Johns Hopkins Univ., Baltimore, MD; ${ }^{4}$ Dept. Geological Sciences, Brown Univ., Providence, RI; ${ }^{5}$ Los Alamos National Laboratory, Los Alamos, NM.

Introduction: A pilot lunar geologic mapping program is underway [1-3] with funding from the NASA Planetary Geology and Geophysics (PGG) Program. As part of this project, we are mapping a quadrangle at 1:2.5 M scale centered on Copernicus crater [4-8]. A major science emphasis of this work is the characterization of crater rays and their implications for the identification of the Copernican/Eratosthenian boundary [9, 10]. The goals of this pilot are to (1) demonstrate integrated use of digital remote sensing data for lunar geologic unit mapping and (2) develop a renewed systematic mapping program for the Moon as a core element of lunar science investigations. Scientists interested in participating in this program should propose a topical lunar science investigation, with a geologic mapping component, to the PGG Program.

Lunar Geologic Mapping Web Site: Information about lunar geologic mapping can be found at: http://astrogeology.usgs.gov/Projects/PlanetaryMap ping/Lunar/. Included there is information on the mapping scheme (Figure 1) and quadrangle layout (Figure 2), map projections, digital basemap materials (to be provided by USGS), and useful links and references. Digital basemaps will include Lunar Orbiter (LO) photomosaics and/or frames at full and reduced resolution [11], and Clementine UVVIS (5 bands 400 to $1000 \mathrm{~nm}$; [12]) and NIR (6 bands, 1100 to $2780 \mathrm{~nm}$; [13]) mosaics. Additional optional digital bases include Clementine colorratio images and derived parameters $(\mathrm{FeO}, \mathrm{TiO} 2$, optical maturity; [e.g., 14, 15]), Lunar Prospector elemental maps (Fe, Ti, Th, H, etc.; [e.g., 16]), and new lunar topographic data [e.g., 17]. Other topical basemaps and derived data may be included as needed to support the science goals of the mapping project.

Mapping Scheme and Scale: Use of digital map bases means that identification of map scale and layout scheme for global mapping is less restrictive than in the past. A uniform scale is required for global systematic mapping, and that scale must take into account differences in available image resolution and quality for various regions. For example, LO frames are $\sim 60 \mathrm{~m} /$ pixel or better for the near side and up to $400 \mathrm{~m} /$ pixel for the far side. If one assumes an 'average' pixel resolution of $200 \mathrm{~m} /$ pixel for the upcoming $\mathrm{LO}$ global mosaic, then a common mapping 'rule of thumb' suggests $\sim 10$ pixels $/ \mathrm{mm}$ as the optimal resolution for mapping with digital data. At the $1: 2.5 \mathrm{M}$ scale of this lunar mapping program, such a mapping resolution translates to 12.5 pixels $/ \mathrm{mm}$, or slightly higher than optimal.

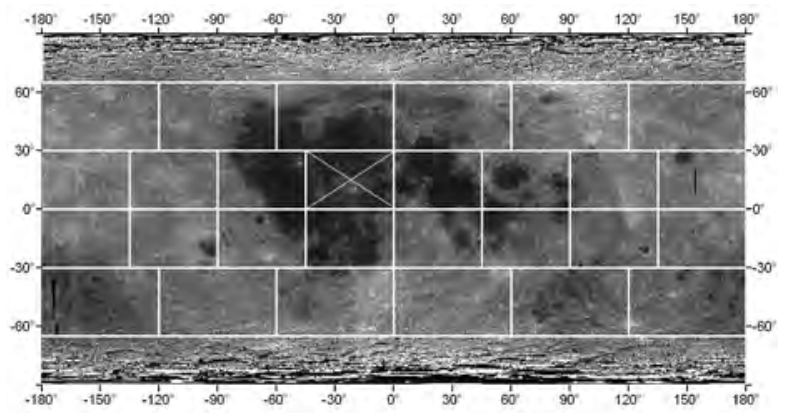

Figure 1. Mapping scheme for lunar geologic maps at 1:2.5 $M$ scale. The Copernicus quadrangle is marked with an $X$. The image base is Clementine 750-nm albedo.

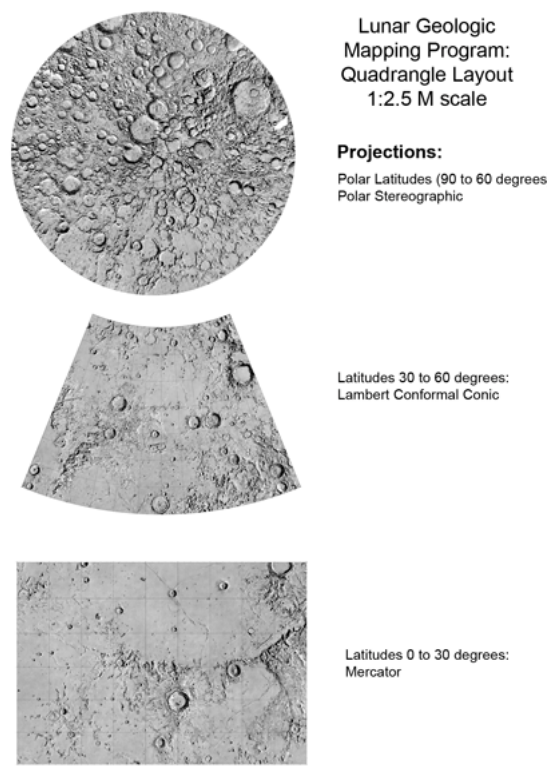

Figure 2. Map projections for lunar quadrangles at 1:2.5 M scale as defined in this program.

The 1:2.5 M scale was considered 'ideal' for lunar geologic mapping [18], and the Moon is thus divided into 30 mapping quadrangles (Figure 1). Polar regions are mapped in Polar Stereographic, latitudes between $30^{\circ}$ and $60^{\circ}$ in Lambert Conformal Conic, and equatorial quadrangles in Mercator projections. At this scale mappers can survey major geologic units, refine unit boundaries and types, 
apply new unit names and contact types where necessary, and map major structures. Quadrangle maps at this scale also print at the relatively convenient size of 21.5”x15” without text.

Digital Geologic Mapping: Digital mapping methods are used in this project, and they are recommended for future lunar mappers as well. Use of digital data readily supports image manipulation and enhancement, as well as derivation of products such as spectral band-depth maps, slope maps from topography data, image texture maps, densitysliced albedo and color, etc. Digital mapping methods using common drafting and analysis tools such as the Geographic Information System (GIS) and 'plug-ins' by ESRI ArcView are being tested and recommendations for their usage will be provided to other mappers.

Lunar Geologic Mappers' Handbook: An additional product of this pilot program is a handbook for future lunar geologic mappers. Currently in preparation, this manuscript will include: (1) a summary of major lunar geologic units, stratigraphic correlation [e.g., 19, 20, 21], and processes; (2) a history of lunar geologic mapping including a summary of current USGS standards (e.g., symbology, contact and structure types); (3) an overview of relevant lunar missions and their scientific objectives, instrumentation, and digital data products; (4) methods and rationales for lunar geologic mapping with available digital data; (5) detailed information on the digital map bases and ancillary data, and how to use both for lunar geologic mapping; (6) specific examples of 1:2.5 M-scale mapping, including definition and correlation of map units as well as identification and characterization of common lunar geologic units and structural features; and (7) recommendations for standardized geologic unit symbols and nomenclature. This manuscript will be published as a USGS Open-File Report (online only) and will also be made available on the Lunar Geologic Mapping Web site noted above.

Summary: The ongoing Copernicus quadrangle mapping project marks the initiation of a new lunar geologic mapping program that takes advantage of new data and methods to advance our understanding of lunar geology. Results of this project include (1) a systematic lunar mapping scheme, (2) a tested method for formatting and releasing digital lunar map bases, (3) a geologic map of the Copernicus quadrangle for publication as a USGS SIMmap, and (4) a lunar geologic mappers' handbook with recommendations on the integration of spectral color, chemistry, mineralogy, elevation, morphology, etc. in the identification and interpretation of lunar geologic map units. These products will be placed online at the above Web site as resources for prospective lunar geologic mappers.

References: [1] Gaddis et al., 2005, LPS XXXVI, \#2021. [2] Gaddis et al., 2005, Abst. Plan. Mappers Mtg., USGS OFR 2005-1271. [3] Gaddis et al., 2005, GSA Ann. Mtg., Abs. 514-4. [4] Shoemaker and Hackman, 1962, Symp. 14 IAU, 289. [5] Schmitt et al., 1967, USGS I-515. [6] Wilhelms and McCauley, 1971, USGS I-703. [7] Gaddis et al., 2006, LPS XXXVII, \#2135. [8] Skinner et al., this volume. [9] Hawke et al., 2006, LPS XXXVII, \#1133. [10] Hawke et al., this volume. [11] Weller et al., 2006, LPS XXXVII, \#2143. [12] Eliason et al. 1999, PDS_CL_4001 to _4078. [13] Gaddis et al., 2005, NIR PDS archive, in prep. [14] Lucey et al., 2000, JGR 105, 20377. [15] Wilcox et al., 2005, JGR-P 110, E11001 [16] Lawrence et al., 2006, LPS XXXVII, \#1925. [17] Archinal et al., 2006, LPS XXXVII, \#2310. [18] Wilhelms, 1972, USGS Interagency Report: Astrogeology 55, 36 pp. [19] Wilhelms, 1987, USGS Prof. Paper 1348, 302 pp. [20] Hiesinger et al. 2003, JGR 108(E7). [21] North American Stratigraphic Code 1983, AAPG Bull. 67, 841-875. 
THE COMPOSTION AND ORIGIN OF COPERNICUS RAYS: IMPLICATIONS FOR THE COPERNICAN-ERATOSTHENIAN BOUNDARY. B.R. Hawke ${ }^{1}$, T.A. Giguere ${ }^{1,2}$, L.R. Gaddis ${ }^{3}$, B.A. Campbell $^{4}$, D.T. Blewett ${ }^{5}$, J.M. Boyce ${ }^{1}$, J.J. Gillis-Davis ${ }^{1}$, P.G. Lucey ${ }^{1}$, C.A. Peterson ${ }^{1}$, M.S. Robinson ${ }^{6}$, and G.A. Smith ${ }^{1},{ }^{1}$ Hawaii Institute of Geophysics and Planetology, University of Hawaii, Honolulu, HI 96822, ${ }^{2}$ Intergraph Corporation, P.O. Box 75330, Kapolei, HI 96707, ${ }^{3}$ U.S. Geology Survey, Astrogeology Program, 2255 N. Gemini Drive, Flagstaff, AZ 86001, ${ }^{4}$ Center for Earth and Planetary Studies, National Air and Space Museum, Washington, D.C. 20560, ${ }^{5}$ NovaSol, 733 Bishop Street, Honolulu, HI 96813, ${ }^{6}$ Center for Planetary Science, Northwestern University, Evanston, IL 60208.

Introduction: The nature and origin of lunar rays have long been the subjects of major controversies. We have been investigating the origin of lunar crater rays in support of the new Lunar Geologic Mapping Program. In an effort to better understand the processes responsible for the formation of lunar rays, we have utilized a variety of remote sensing data to study selected rays. Clementine UV-VIS images were used to produce high-resolution $\mathrm{FeO}, \mathrm{TiO}_{2}$, and optical maturity (OMAT) maps for the various rays utilizing the methods presented by Lucey et al. [1, 2]. Near-IR spectra and 3.8- and 70-cm radar maps were also utilized $[3,4]$. Our preliminary finding resulted in a model for lunar ray formation [5, 6]. It was found that lunar rays are bright because of compositional contrast with the surrounding terrain, the presence of immature debris, or some combination of the two. The purpose of this report is to present the results of studies of Copernicus rays and to assess the implications for the calibration of the lunar stratigraphic column.

The Origin of Copernicus Rays in Mare Imbrium: Copernicus is a large bright-rayed crater, $93 \mathrm{~km}$ in diameter, located at $9.5^{\circ} \mathrm{N}, 20.0^{\circ} \mathrm{W}$ on the lunar nearside, and has long been used as a stratigraphic marker for lunar geology $[7,8,9]$. Continuous ejecta deposits occur up to a crater diameter away from the rim crest of Copernicus, while the ray system extends radially for more than $500 \mathrm{~km}$ [9]. We have investigated the Copernicus rays that extend north across the surface of Mare Imbrium with particular emphasis on four major rays. Two of these rays (Rays 1 and 2) extend north of Copernicus, and two (Rays 3 and 4) extend to the northeast. The albedo of the rays varies from moderate to high, and all exhibit numerous secondary craters which range in diameter from $200 \mathrm{~m}$ to 7.0 $\mathrm{km}$. Many of the secondaries occur in chains or clusters that exhibit characteristic $\mathrm{V}$ structures or herringbone patterns. It has been demonstrated that herringbone patterns are formed by the interference of ejected materials during the near-simultaneous impact of secondary-forming projectiles $[9,10]$. In the secondary crater clusters, the downrange members of the clusters are commonly mantled by ejecta or debris surges generated by the uprange secondaries.
The rays north of Copernicus (Rays 1 and 2) exhibit moderate to strong returns in the $3.8-\mathrm{cm}$ depolarized radar image mosaic. The highest values are associated with secondary crater clusters. These areas have greater abundances of 1 - to 40 -cm-sized fragments in the upper $0.5 \mathrm{~m}$ of the regolith. Portions of Rays 1 and 2 exhibit slightly enhanced backscatter in the depolarized $70-\mathrm{cm}$ radar image. The strongest enhancements are associated with secondary crater clusters. These enhancements have an excess of meter-sized blocks within 5-10 m of the surface.

The Copernicus rays in Mare Imbrium exhibit lower $\mathrm{FeO}$ and $\mathrm{TiO}_{2}$ values than do the adjacent mare deposits. The background mare flows have $\mathrm{FeO}$ values that range between 17 and 19 wt.\% and $\mathrm{TiO}_{2}$ concentrations that range between 4 and 6 wt.\%. The rays north of Copernicus have $\mathrm{FeO}$ abundances that vary from 12 to $16 \mathrm{wt} . \%$ and $\mathrm{TiO}_{2}$ values that range from 2 to 4 wt.\%. The $\mathrm{FeO}$ and $\mathrm{TiO}_{2}$ concentrations generally show a positive correlation with the albedo values exhibited by the ray surfaces. $\mathrm{FeO}$ abundances generally decrease along a given ray as a function of distance from Copernicus. The measured $\mathrm{FeO}$ value (8.0 wt.\%) for the Copernicus ejecta blanket can be used to calculate the amount of highland-rich primary ejecta in the rays north of Copernicus. The calculated abundances of primary ejecta range from $20 \%$ to $60 \%$.

The optical maturity (OMAT) images of the Copernicus rays indicate that relatively high OMAT values are associated with secondary crater chains and clusters. The highest values are exhibited by steep slopes on the crater interiors. Apparently, downslope movement on the interior crater walls constantly adds fresh material to the regolith. Ray surfaces away from the interiors of secondary craters display much lower OMAT values. These OMAT values are slightly higher than those exhibited by fully mature background mare surfaces near the rays. The rays of Copernicus in Mare Imbrium have not reached full optical maturity.

Several faint rays from the crater Eratosthenes were identified in Mare Imbrium. These rays exhibit lower $\mathrm{FeO}$ and $\mathrm{TiO}_{2}$ values than do the adjacent mare units and are fully mature.

In summary, the Copernicus rays in Mare Imbrium display relatively low $\mathrm{FeO}$ and $\mathrm{TiO}_{2}$ values 
because of the presence of variable amounts of highland-rich primary ejecta. The rays exhibit relatively low OMAT values except for areas with secondary crater clusters. Still, the rays are not fully mature. The Copernicus rays are bright largely due to contrast in albedo between the ray material containing highland-rich primary ejecta and the adjacent dark mare surfaces. Only in the vicinity of secondary crater clusters and chains does the presence of immature, high-albedo material make a significant contribution to the brightness of the rays.

Implications for the CopernicanEratosthenian Boundary: The working distinction between the Eratosthenian (E) and Copernican (C) Systems is that Copernican craters have visible rays whereas Eratosthenian-aged craters do not [7, 11, 12]. Since compositional rays can persist for $3 \mathrm{Ga}$ or more, the mere presence of bright rays is not a reliable indicator that a crater was formed during the C Period [6, 9, 13, 14, 15]. It is clear that a new method is required to distinguish $\mathrm{C}$ from E-aged craters. It has been suggested that the OMAT parameter be used to define the C-E boundary [6, 14, 15]. With increasing age, the OMAT values for ejecta and rays decrease and eventually become indistinguishable from the background value, which is the optical maturity index saturation point [2, 15]. The time required for a fresh surface to reach the optical maturity index saturation point could be defined as the Copernican Period. Surfaces that have reached full optical maturity would then be of Eratosthenian (or greater) age. Grier and co-workers $[14,15]$ noted that if the ejecta of Copernicus were slightly more mature, it would be indistinguishable from the background in an OMAT image. Our results for the Copernicus rays in Mare Imbrium are consistent with these findings. Hence, the saturation of the optical maturity index may occur at about 0.8 Ga which is the commonly accepted age of Copernicus [16, 17, 18].

A Reevaluation of Lunar Crater Ages: Because of the new definition of the C-E boundary, we have investigated the rays associated with a number of lunar craters. Our purposes were to determine the compositions and maturity states of the rays and to assess the ages of the parent craters in light of the new criteria.

Aristillus and Autolycus are located NW of the Apollo 15 site. Both have been mapped as Copernican craters based on the presence of rays [8, 12]. The high-albedo rays of Aristillus and Autolycus contain highland material and are bright because of compositional contrast with the surrounding mare terrain. The rays and ejecta of both craters have reached full optical maturity. Hence,
Aristillus and Autolycus are older than Copernicus and should be mapped as Eratosthenian-aged craters.

Taruntius, O’Day, and Eudoxus have been mapped as Copernican-aged craters [8, 12]. Our results indicate that the rays associated with these craters are compositional rays. They are optically mature and appear bright only because they contain highland debris. These craters are older than Copernicus and should be mapped as Eratosthenianaged craters.

Taruntius $\mathrm{H}$ and $\mathrm{P}$ are located SE of Taruntius. Since these small craters lack well-defined rays, they are mapped as Eratosthenian craters [19]. The OMAT image of these craters shows that their ejecta deposits are immature. They are younger than Copernicus and should be assigned a Copernican age.

Pytheas has been mapped as a Copernican-aged crater [8, 12]. Some portions of the Pytheas ejecta deposit exhibit low OMAT values and appear to be fully mature. Other portions of the ejecta blanket have higher OMAT values. The cause of this difference is the subject of a continuing investigation.

References: [1] Lucey P. et al. (2000) J. Geophys. Res., 105, 20,297. [2] Lucey P. et al. (2000) J. Geophys. Res., 105, 20,377. [3] Zisk S. et al. (1974) Moon, 10, 17. [4] Campbell B. and Hawke B. (2005) J. Geophys. Res., 110, E09002. [5] Hawke B. et al. (2006) LPSC 37, \#1133. [6] Hawke B. et al. (2004) Icarus, 170, 1. [7] Shoemaker E. and Hackman R. (1962) The Moon-Sym. 14 of the I.A.U., 289. [8] Wilhelms D. and McCauley J. (1971) U.S.G.S. Map I-703. [9] Pieters C. et al. (1985) J. Geophys. Res., 90, 12,393. [10] Oberbeck V. and Morrisson R. (1973) Proc. Lunar Sci. Conf., 4 ${ }^{\text {th }}, 107$. [11] Ryder G. et al. (1991) Geology, 19, 143. [12] Wilhelms D. (1987) U.S.G.S. Prof. Pap., 1348. [13] McEwen A. et al. (1993) J. Geophys. Res., 98, 17,207. [14] Grier J. and McEwen A. (2001) Accretion of Extraterrestrial Material Throughout Earth History, 403. [15] Grier J. et al. (2001) J. Geophys. Res., 106, 32,847. [16] Eberhardt P. et al. (1973) Moon, 8, 104. [17] Bogard D. et al. (1994) GCA, 58, 3093. [18] Stoffer D. and Ryder G. (2001) Space Sci. Rev., 96, 9. [19] Olson A. and Wilhelms D. (1974) U.S.G.S. Map I-837. 
PROGRESS ON MAPPING THE COPERNICUS 1:2,500,000-SCALE QUADRANGLE ON THE MOON: IMPACT CRATER FACIES AND MINERALOGIES. J.A. Skinner, Jr., L.R. Gaddis, and K. L. Tanaka. Astrogeology Team, U.S. Geological Survey, Flagstaff, AZ 86001 (jskinner@usgs.gov).

Introduction: The first systematic lunar geologic maps were completed at $1: 1 \mathrm{M}$ scale for the lunar near side during the 1960's using telescopic and Lunar Orbiter (LO) photographs [1-3]. Later, global mapping of the Moon was accomplished at 1:5 M scale [4-9], and smaller scale maps were made for sites of 'scientific interest' (including the Apollo landing sites) using orbital and in situ data [e.g., 10]. Geologic mapping of the Copernicus crater (dia. $95 \mathrm{~km}$ ) region was performed by Shoemaker and Hackman [11], Schmitt et al. [1], and Howard [10]. Numerous topical studies have since considered the origin, distribution, and composition of geologic units within this region [e.g., 12-14].

Here we describe progress in the pilot lunar mapping project, which not only addresses the geologic units and history of the Copernicus quadrangle $\left(0-30^{\circ} \mathrm{N}, 0-45^{\circ} \mathrm{W}\right)$ but is also intended to evaluate the utility of existing data and outline the processes and precedents that should be implemented in future systematic mapping. Following our reconnaissance-level mapping, we now focus our efforts on detailed delineation and discrimination of geologic units. Our current emphasis is on integrating color and mineralogic information with "classical" morphogeologic crater units to better discriminate impact-related materials and facies. This approach is relevant because the region contains type localities for crater-related units and major stratigraphic divisions. Our mapping is guided by recent characterization of the Copernican-Eratosthenian lunar stratigraphic boundary using Clementine-derived optical maturity (OMAT) data [e.g., 15].

Geologic Setting: The Copernicus quadrangle is dominated by high-albedo units of the young $(\sim 0.8$ $\mathrm{Ga}$ Copernicus crater. These are superimposed on older basin rim and ejecta units of Imbrium basin (highlands of Montes Carpatus), as well as old or intermediate-aged highlands, mare, pyroclastic and impact crater (e.g., Eratosthenes, dia. $58 \mathrm{~km}$ ) units. Mapped geologic units within the quadrangle include the oldest, Lower Imbrian materials of Imbrium basin (Alpes and Fra Mauro Fms.), Upper Imbrian mare basalts, cones, dark-halo craters and pyroclastic deposits (Mare Insularum, Sinus Aestuum, and SE Mare Imbrium), Eratosthenian mare basalts (central Mare Imbrium) and crater materials, and young Copernican impact and related deposits.

Data: We processed, orthorectified, and coregistered data using image processing (ISIS) and GIS (ArcMAP) software. All digitization was completed in an ESRI geodatabase format to simplify data compilation, vector attribution, topological cleaning, interlayer analyses and data sharing. Basemaps include a LO-IV photomosaic $(60 \mathrm{~m} / \mathrm{px}$; [e.g., 16]),
Clementine 5-band UVVIS (100 m/px, [17]) and 6band NIR data $(500 \mathrm{~m} / \mathrm{px},[18])$ and derived maps of iron [19] and titanium, Clementine-derived topographic data [20], Earth-based $3.8 \mathrm{~cm}$ radar (3.1 $\mathrm{km} / \mathrm{px}$; [21]), and OMAT [19, 22]) data. We also use high $(9 \mathrm{~m} / \mathrm{px})$ and very-high $(1.3 \mathrm{~m} / \mathrm{px})$ resolution LO-IV frames of the Copernicus crater floor, wall, and central peak [16].

Current lunar geologic mapping is performed in the context of previous studies but also takes advantage of new digital data for the Moon. Integration of historical mapping products and more recent investigations is challenging, and requires complementing standard mapping methods and conventions based on morphology, texture, and albedo with mineralogic and lithologic information derived or inferred from Clementine 11-band color and other data.

Mapping Scale and Feature Size: At 1:1M scale [1], Copernicus crater units and features were mapped at sizes down to $2 \mathrm{~mm}(2 \mathrm{~km}$ on the ground), and numerous (but not all) secondary craters were mapped. At 1:2.5M scale, we map features down to $2 \mathrm{~mm}$ in size (5 $\mathrm{km}$ on the ground). Because many of the Copernicus secondary craters are at or just less than $5 \mathrm{~km}$ in size, they will not be identified in our mapping; those greater than $5 \mathrm{~km}$ in size are identified by a symbol. Major secondary crater chains are mapped as discrete units (e.g., feature formerly named Rimae Stadius). Minor secondary scatters and chains are identified by a crater ray pattern. Overlapping rays of Copernicus, Kepler, and Aristarchus craters are not differentiated within the mapped ray patterns. Following the lead of Schmitt et al. [1], we do not discriminate secondary rays, craters, or materials when they superpose primary rim materials of the parent impact.

Crater Units: Geologic units of Copernicus crater include wall, floor, and central peak materials, impact melt deposits, ejecta morphologies, and numerous secondary rays and craters $[1,10,12]$. With Clementine color, particularly derived maps (e.g., $\mathrm{FeO}$ and OMAT) and color-ratio images, we can more accurately map the extent of excavated materials and identify the potential type lithology of material being excavated and redistributed. Objectively balancing criteria for morphologic unit identification with those for color or spectral units has proven to be a challenge.

Morphologic Unit Criteria. "Classical" crater units are divided by crater location (e.g., rim, wall, floor) and then subdivided into surface texture and morphology (e.g., hummocky, smooth, radial). The result is a unit symbol (e.g., Ccrh) that designates age (e.g., Copernican age--C), material type (e.g., 
crater-related material--c), unit (e.g., rim material-r), and sub-unit (hummocky--h). Spectral data permit us to advance beyond pure "morphostratigraphic" mapping, allowing units and subunits to be divided by morphology and spectral characteristics. Morphology-dependent units have been described as problematic and not entirely correlative to the emplacement process [23-24]. Thus we avoid naming units based on morphology alone (for example, "Ccrh--Copernican-age, crater unit, rim subunit, hummocky member), opting instead for " $\mathrm{Ccr}_{\mathrm{a}}$ -Copernican-age, crater unit, rim sub-unit, member a". Using this convention, although Copernicus and Kepler craters have correlative morphologic units, they can be discriminated on the basis of their distinctive spectral properties.

Mineralogic Unit Criteria. Clementine data show substantial variation in optical maturity, reflectance, and morphology among deposits from Copernicus and Eratosthenes craters. For example, the northwest crater floor, wall, and ejecta blanket of Copernicus have significantly elevated 750-nm values (herein deemed a proxy for albedo), indicating excavation and redistribution of a bright material. This unit has been mapped as glass-rich, impact melt that ponded on the floor and draped the walls and ejecta [e.g., 10]. These bright regions are inferred to be comprised of a low-iron material excavated from a highlands unit at depth. A broad heterogeneity in color of wall, floor, and ejecta units of Copernicus crater indicates that materials are diverse in composition and, in some locations, were not intimately mixed during crater formation. No thorium enrichment is observed for Copernicus [e.g., 25], so a local 'KREEP-rich' rock unit is not likely to be present. Eratosthenes crater, which partly overlies highlands units of Imbrium basin rim deposits, shows a comparable but more subdued color variation, suggesting that the northernmost ejecta may contain materials from excavated pre-Imbrium (Nectarian) basement rocks.

Color data also provide an ability to distinguish between craters that have penetrated through impact ejecta into underlying mare basalts (i.e., darkhalo craters such as Copernicus $\mathrm{H}$ ) and those that have penetrated further to the deepest highlands units. Such craters provide information on the stratigraphy, thickness, and distribution of underlying geologic units. Derived OMAT data have also allowed us to re-evaluate relative ages of craters in this region and to assign new, Eratosthenian (older) ages to craters Aristillus, Autolycus, Taruntius, O'Day, Eudoxus and possibly Pytheas [15].

The integration of Clementine color data means that we must modify and adapt previous mapping conventions. For example, we divide materials that have distinct morphologic textures, stratigraphic (cross-cutting) relationships, and spectral characteristics into distinct geologic units. When color or spectral signatures vary among units within a single formation, a ruled and dashed pattern is used to indicate subdivided units. To avoid overlapping patterns, we group key mineralogic characteristics together when possible. Units with comparable ranges of iron, titanium, or optical maturity values can be grouped together and indicated with unit patterns (e.g., "low OMAT", "low Fe", "high TiO2"), in much the same way ruled and dashed patterns were used by Schmitt et al. [1] to discriminate three albedo ranges (e.g., high, medium, and low). Though Clementine raster maps allow us to quantify spectral unit characteristics, we use this information primarily as a supplement to geologic observations and measurements.

Plans: We will present a map for review within the project team by the end of CY06. During map review, we will complete a Lunar Geologic Mapper's Handbook that will (1) address data specifics (e.g., instrumentation, processing, projection, limitations), (2) outline stratigraphic and unit precedent, and (3) explore methods for hard-copy presentation (e.g., correlation of map units). We intend to have the Handbook rigorously reviewed by a host of planetary geologists whose combined experience and expertise in lunar and planetary science will help pave the way for the complete, systematic $1: 2.5 \mathrm{M}$-scale geologic mapping of the lunar surface.

References: [1] Schmitt et al., 1967, USGS I515 (LAC-58). [2] Wilhelms and McCauley 1971, USGS I-703. [3] Shoemaker and Hackman, 1962, Symp. 14 IAU, 289. [4] Wilhelms and McCauley, 1971, USGS I-703. [5] Lucchitta, 1978, USGS I1062. [6] Wilhelms et al., 1979, USGS I-1162. [7] Wilhelms and El-baz, 1977, USGS I-946. [8] Scott et al., 1977, USGS I-1034. [9] Stuart-Alexander, 1978, USGS I-1047. [10] Howard, 1975, USGS I840. [11] Shoemaker and Hackman, 1962, Symp. 14 IAU, 289-300. [12] Pieters et al., 1985, JGR 90, 12393-12413. [13] Gaddis et al., 1985, Icarus 61, 461-489. [14] Zellner et al., 2002, JGR 107. [15] Hawke et al., this volume. [16] Weller et al., LPSC 37. [17] Eliason et al. 1999, PDS Vol. USA_NASA_PDS_CL_4001 to 4078. [18] Gaddis et al., 2006, PDS archive (in prep.). [19] Lucey et al., 2000, JGR 105, 20377-20386. [20] Archinal et al., LPSC 37. [21] Zisk et al., 1974, The Moon, 1750. [22] Wilcox et al., 2005, JGR 110. [23] Hansen 2000, EPSL 176, 527-542. [24] Tanaka et al. 2005, USGS SIM 2888, 1:15 M scale. [25] Gillis and Jolliff, 1999, New Views of the Moon II. 
GEOLOGIC MAPPING OF HIGHLAND/LOWLAND BOUNDARY ZONES: EASTERN HELLAS PLANITIA AND DEUTERONILUS MENSAE, MARS. David A. Crown, Leslie F. Bleamaster, III, and Frank C. Chuang, Planetary Science Institute, 1700 E. Ft. Lowell Rd., Suite 106, Tucson, AZ 85719, crown@psi.edu.

Introduction: Geologic mapping investigations of Hellas Planitia at the eastern margin of Hellas basin and of Deuteronilus Mensae at the northern margin of Arabia Terra provide new constraints on the styles and timing of the diverse processes that have shaped the complex geologic records preserved in these highlandlowland boundary zones. Current mapping studies build on previous geologic mapping in eastern Hellas [1-10] and recent analyses of debris aprons in eastern Hellas and along the dichotomy boundary [11-13].

Eastern Hellas Planitia: This map area includes parts of Dao and Harmakhis Valles and their floor deposits, possible remnants of basin rim materials, dissected and channeled plains, and deposits associated with the Hellas basin floor. Following the mapping precedents of $[3,8]$, materials in MTM -40277, -45277, and -45272 (and -40272 [8]) quadrangles have been divided into two major geologic assemblages: the Hellas rim assemblage and the Hellas floor assemblage. The contact between these assemblages occurs near the -5800 meter topographic contour. At $1: 5 \mathrm{M}$ scale, materials above $-5800 \mathrm{~m}$ were mapped as the Hesperian/Noachian dissected unit, member 1; below $-5800 \mathrm{~m}$, materials were mapped as the Hesperian smooth interior unit [3]. Mapping at 1:1M scale by Price [8] subdivided the dissected unit into Hesperian smooth plains (unit Hps) and Hesperian/ Noachian hummocky plains (unit HNh).

Hellas rim assemblage. Two areally expansive units (units HNh and Hps) surround the distal portions of the Dao and Harmakhis Valles canyon systems. Using THEMIS IR and VIS data, we have evaluated the contacts of units Hps and HNh mapped by Price [2] and have extended these unit boundaries from MTM -40272 to the rim/planitia boundary. Hummocky plains (unit HNh) display 10s to 100s of meters of relief and appear to be exposed by removal of the upper smooth plains surface (by either down cutting from channels, scarp retreat and aeolian erosion, and/or collapse from loss of volatiles). Smooth plains (unit Hps) are correlated with the locations of small-scale surface channels, which may be the first stage in canyon development and hummocky plains exposure. It is unclear if the channels are responsible for emplacing the smooth plains (i.e., bank-full deposits) or channels cut the smooth plains and are only preserved within them; most likely both circumstances exist. The larger, more mature, canyon segments of Dao and Harmakhis Valles also dissect the rim assemblage; the lower reaches of Dao Vallis preserve several episodes of channel/canyon development showing abandoned truncated channels (units ch1 and ch2). Where the canyons are wide and more fully developed, Amazonian/Hesperian valley fill superposes their floors (units vd and vh).

Using MOC images, we systematically searched the map region for layered materials; results indicate that finely-layered outcrops are concentrated along the scarp that defines the eastern edge of the basin.
Outcrops are exposed in locally high standing mesas, knobs, and surfaces near $-5700 \mathrm{~m}$ within hummocky plains. Consistent elevations and spatial associations among unit contacts of these layered deposits suggest that the isolated layered outcrops most likely represent remnants of a once laterally continuous deposit of the smooth plains (unit Hps) that was part of a more widespread depositional shelf in eastern Hellas [14].

Hellas floor assemblage. Hellas floor materials are moderately to heavily cratered, deformed by polygonal wrinkle ridges, and are locally dissected by the farthest extensions of Dao and Harmakhis Valles. With the exception of a lobe extending from the mouth of Dao Vallis (unit vt), there is a general lack of distinct depositional margins/contacts in the vicinity of channel and canyon mouths that cross the rim/floor assemblage contact. This suggests that eastern Hellas floor materials 1) are far reaching deposits from Dao and Harmakhis Valles with contacts west of the map area, 2) are not comprised of significant materials delivered by Dao and Harmakhis Valles, or 3) that both the floors of the canyons and Hellas have undergone significant Amazonian resurfacing (mass movements and aeolian infill), which has masked any original genetic and/or temporal relationships between canyon floor and Hellas floor materials.

Near the mouth of Harmakhis Vallis, relatively deep sinuous depressions extend from the mouth of Harmakhis Vallis and meander around high standing plateaus. These depressions do not preserve primary channel features but do maintain a characteristic planform shape indicative of fluvial processes, supporting hypothesis 3 as described above. The subdued topography of these depressions and the surrounding plateaus suggests burial by meters to $100 \mathrm{~s}$ of meters of material. The deepest portions of these depressions exhibit the smoothest materials, perhaps indicating the greatest degree of burial (units bfs and bfh). These farthest extensions of Harmakhis Vallis may or may not represent ancient surface connections between the Harmakhis head valley and its terminus. The plateaus in this region preserve trends consistent with wrinkle ridge trends to the south of the sinuous depressions. There is no topographic expression of any wrinkle ridge across the depressions, suggesting that topography associated with the wrinkle ridges and plateaus was established prior to the excavation of the channel-like features. Thus the surfaces of the plateaus and the plains to the south most likely represent the same surface (unit sia).

South of this plateau region are several large craters with commingled ejecta blankets. Some ejecta blankets display radial striations and lobate margins. A variety of degradation states are evident, consistent with various ages of the impact events; however, the exposed surface is dominated by armored ejecta blankets with few superposed pristine craters suggesting that this surface was potentially buried and has since been exhumed in a relatively uniform manner. Several crater rims merge with both 
pronounced and subdued topography associated with the regional wrinkle ridges, making this region older than the deformation, and potentially the oldest area within the map area.

In the SE corner of the map area, the division between the rim and floor assemblages is not as clear as it is expressed as a much less pronounced facies transition. The rim to floor gradient is more gradual than the sharp depositional shelf margin in the north; however, the $-5800 \mathrm{~m}$ contour still marks a morphologic change. Ridge trends trace across this gradational boundary, but to the east of the contour, the surface is smooth and displays superposed channels (unit pc), whereas the west lacks channels and contains many small to medium-sized craters (unit sia).

Deuteronilus Mensae: MTM 35337, 40337, and 45337 quadrangles contain the transition from Arabia Terra highlands to lowland plains of Acidalia Planitia. Deuteronilus Mensae as a whole has been included in previous mapping at $1: 5 \mathrm{M}$ [15] and $1: 15 \mathrm{M}$ scales [1617], and McGill [18] mapped a N-S swath of MTM quadrangles to the east. MTM quadrangle 35337 consists of cratered terrain exhibiting $\sim 8$ craters $\geq 15$ $\mathrm{km}$ in diameter, including the $125 \mathrm{~km}$-diameter crater Cerulli. Large craters show a range of preservation states but are mostly moderately to highly degraded. MTM quadrangles 40337 and 45337 contain the transition from relatively continuous highland surfaces into the fretted terrain where uplands are preserved in mesas surrounded by low-lying plains and debris aprons. Parts of fretted terrain valley systems (including Mamers Valles), the large low-lying expanse containing Deuteronilus Colles, and the angular mesas and surrounding lowlands of Deuteronilus Mensae proper are also included. Crater Lyot is located to the NE and its ejecta should have at one time covered the area exposed in MTM 45337. Parker et al.'s [19] analysis of Deuteronilus Mensae to the west suggests the presence of two gradational boundaries that may be associated with ancient Martian northern oceans.

From analyses of Viking Orbiter, THEMIS IR and VIS, and MOC images coupled with MOLA topography, preliminary mapping of MTM 35337, 40337, and 45337 quadrangles has been completed. In the map area, the continuous highland terrain of northern Arabia Terra has been divided into two units (plateau material and dissected plateau material) based on the degree of modification by fluvial activity in the form of small, sinuous channels. Plateau material exhibits several large elongated depressions that contain blocks of the surrounding materials, suggesting the initial stages of surface collapse above a volatilerich zone. Numerous craters are evident within the highland terrains, often with multiple lobes of ejecta. The materials associated with Cerulli crater are mapped separately, given their large areal extent; radial grooves, secondary crater fields, sinuous channels, and small superposed impact craters are shown. Remnants of the highland plateau are preserved to the north as individual and clustered polygonal mesas, typically with flat upper surfaces. Division into lower and upper mesa materials is based on consistent differences in albedo and elevation, presumably reflecting stratigraphic layers within the highland plateau. Lowlying materials surrounding mesa materials have been mapped as mottled, knobby, and smooth plains. Deuteronilus Colles, interpreted to be the eroded remnant of a crater interior structure, includes individual and clustered, irregularly-shaped, rounded knobs ranging from 100s of meters to a few kilometers across (Deuteronilus Colles material) and smooth to hummocky deposits with lobate margins adjacent to knobs (Deuteronilus Colles apron material). Numerous debris aprons are apparent in the central and northern parts of the map area. These occur as smooth lobate deposits that surround and extend from the bases of mesas, knobs, degraded crater rims, and fretted valley walls. The surfaces of debris apron material often have lineations parallel or transverse to the apparent flow direction. Multiple overlapping aprons in a given locality are common. Apron surface slopes in the map area are gentle, ranging from 0.4 to $6.6^{\circ}$. Debris apron materials clearly post-date the formation of mesas and appear to also post-date formation of the low-lying plains and medium to large impact craters in the region.

In addition to the debris aprons, there is additional evidence for young resurfacing in the region, at least on a local basis. Smooth fill material, observed between blocks of plateau material in collapse depressions and within the floors of impact craters, is interpreted to be debris resulting from complete breakdown of collapsed blocks. Hummocky fill material consists of small knobs and associated smooth deposits with lobate margins on the floors of collapse depressions and may represent a less complete state of degradation. Grooved fill material exhibits a series of concentric surface lineations and occurs in crater interiors (i.e., concentric crater fill). The surface lineations observed on debris aprons and certain fill deposits are consistent with a volatile-rich substrate during at least the later stages of the geological history of the region.

References: [1] Crown D.A. et al. (1992) Icarus, 100, 125. [2] Mest S.C. and Crown D.A. (2001) Icarus, 153, 89-110. [3] Leonard G.J. and Tanaka K.L. (2001) USGS Geol. Invest. Ser. Map I-2694. [4] Tanaka K.L. and Leonard G.J. (1995) JGR, 100, 5407-5432. [5] Greeley R. and Guest J.E. (1987) USGS Geol. Invest. Ser. Map I-1802B. [6] Mest S.C. and Crown D.A. (2002) USGS Geol. Invest. Ser. Map I-2730. [7] Mest S.C. and Crown D.A. (2003) USGS Geol. Invest. Ser. Map I-2763. [8] Price K.H. (1998) USGS Misc. Invest. Ser. Map I-2557. [9] Mest S.C. and Crown D.A. (2005 in press) USGS. [10] Crown D.A. and Greeley R. (2005 in USGS edit) USGS. [11] Pierce T.L. and Crown D.A. (2003) Icarus, 163, 46-65. [12] Mangold N. (2003) JGR, 108, doi: 10.1029/ 2002JE001885. [13] Chuang F.C. and Crown D.A. (2005) Icarus, 179, 24-42. [14] Crown D.A. et al. (2005) JGR, 110, E12S22. [15] Lucchitta B.K. (1978) USGS Misc. Invest. Series Map I-1065. [16] Greeley R. and Guest J.E. (1987), USGS Misc. Invest. Series Map I-1802-B. [17] Tanaka K.L. et al. (2005) USGS Scientific Invest. Series Map I-2888. [18] McGill G.E. (2002) USGS Geol. Invest. Ser. Map I-2746. [19] Parker T.J. et al. (1989) Icarus, 82, 111-145. 
MAPPING MARGARITIFER TERRA: MTMS -15017, -20002, -20007, -20017, -20022, -25002, -25007. C. M. Fortezzo $^{1,2}, \mathrm{~K}$. K. Williams ${ }^{1}$, and J. A. Grant ${ }^{1}$, ${ }^{1}$ Center for Earth and Planetary Studies, National Air and Space Museum, Washington, DC, 20013-7012, №rthern Arizona University, Flagstaff, AZ, 86001. cfortezzo@si.edu

Introduction: As part of a continuing campaign to better understand the relationship between valleys and resurfacing events through mapping, we are mapping seven 1:500,000-scale MTM quads in the Margaritifer Terra region. Results from this mapping will also help constrain the role and extent of past water in Margaritifer Terra. The MTMs are grouped in two different areas (Figure 1, red boxes with black text) within the region and compliment the completed mapping in four quads (Figure 1, red boxes with hatch pattern) that are currently in the review process [1-4].

Three western quads focus on Jones crater and the Himera, Samara and Loire Valles systems (central portion of figure 1). The four eastern quads focus on the headward regions of Paraná Valles and the valleys on the western flank of Newcomb crater (southeast area of Figure 1).

Datasets: For these maps, we used MDIM 2.1 and MOLA 128 pix/deg datasets as the initial mapping base. In addition, we processed THEMIS daytime and nighttime infrared images and overlaid both sets on MDIM 2.1 and used them as a mapping base with $~ 95 \%$ coverage. THEMIS daytime and nighttime infrared images were processed using the ISIS-based THEMIS processing website (themproc.mars.asu.edu) and overlain in ArcMap. Regional-scale map bases are supplemented with GIS hotlinked THEMIS visible and MOC narrow angle images where available.

Methods: We have imported and registered all pertinent raster and vector data using ESRI's ArcMap GIS software. Using this digital environment, we have begun digitizing lines (e.g., contacts, structures, etc.) and polygons (e.g., units and craters). Arc extensions provide robust tools for (1) analyzing spatial relationships across multiple data layers, (2) attributing and updating digital linework, (3) building and analyzing vector topologies, and (4) importing new data as they are released. To inspect and quantify stratigraphic relations, we are compiling crater counts in ESRI's ArcView GIS software to make use of crater counting tools [5] specifically developed for planetary mappers [6].

Current Work: Work on the seven quads began by concentrating on the Newcomb-Paraná area

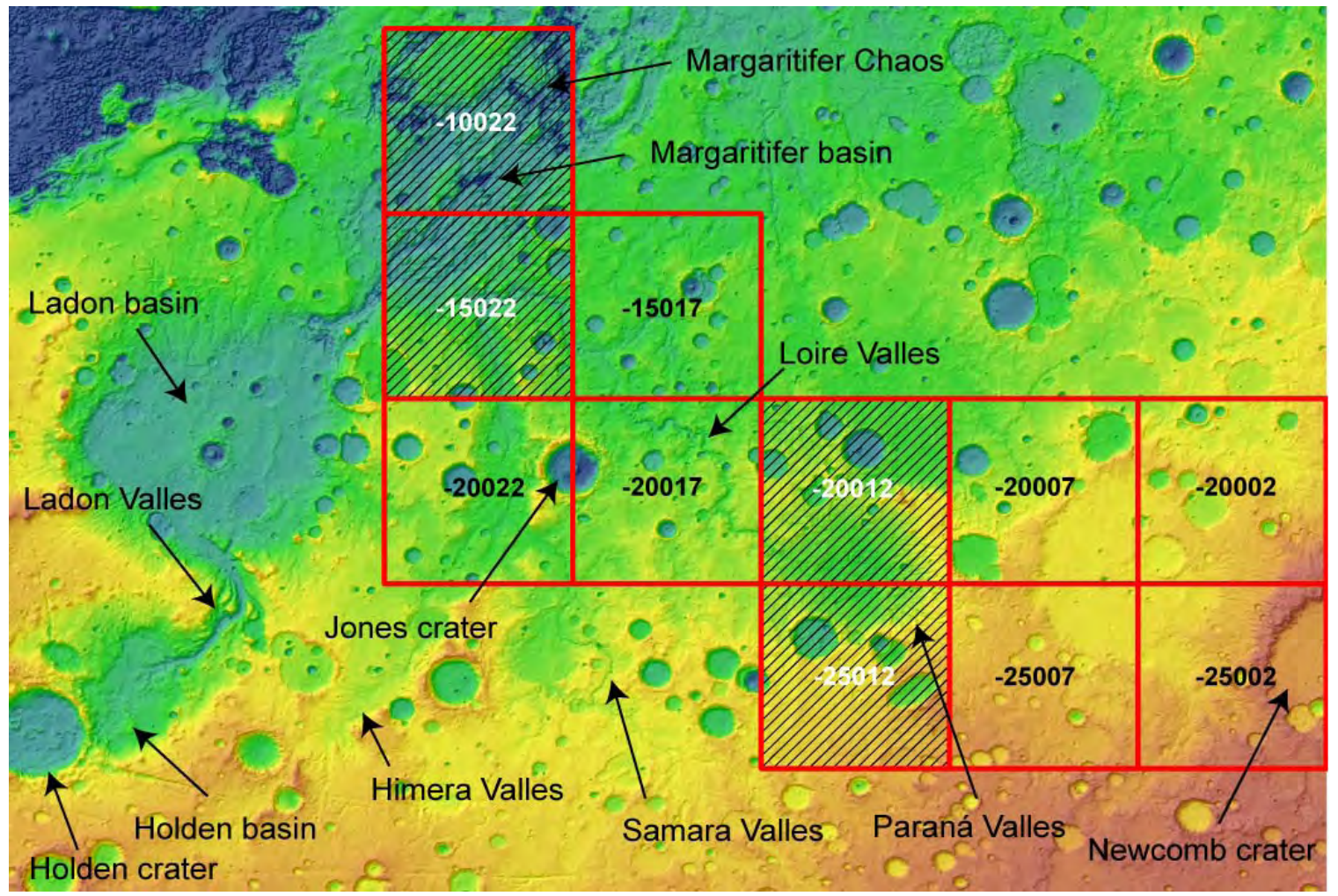

Figure 1: Shaded relief overlain by MOLA 128 pix/deg of Margaritifer Terra. Arrows point to the locations of prominent features. The red boxes indicate MTM quads. Red boxes with black numbers are the 7 quads currently being mapped and boxes with a hatch pattern and white numbers indicate quads submitted for review. 
(MTMs -20002, -20007, -25002, and -25007; Figure 3 ) in order to determine the relative ages of resurfacing events in upper Paraná Valles and to examine how valleys either incise or are mantled by resurfacing deposits within the Newcomb-Paraná region.

The Jones crater area (MTMs -15017, -20022, and -20017; Figure 2) covers an L-shaped area from Himera Valles, around Jones crater, to Loire Valles (Figures 1 and 2). Current work in this area involves counting craters and demarcating initial units.

Future Work: For both areas, geologic linework advances as the science tasks are started.

In the Jones crater area, review of Viking Orbiter images led to the hypothesis that the drainage history of the Jones-Loire area may have been affected by emplacement of Jones crater [7]. Ejecta from Jones crater partially buries parts of Samara and Loire Valles and totally obscures portions of Samara Valles [7]. We will test the hypothesis that a second order pathway once connected Samara Valles with Loire Valles east of the third ring of the Ladon basin using higher resolution MOC and THEMIS images, MOLA topography and the 1:500,000 map.

In the Newcomb-Paraná area, crater counting techniques designed for calculating the ages of narrow, linear features $[8,9]$ will be used to establish comparative ages of the valley networks relative to each other. This analysis will be performed on the Paraná Valles network and on the network on the western flank of Newcomb crater, and the results of each area will be compared to determine their ages relative to each other. We will compute the cumulative crater densities for sub-basins within the valley networks and compare them against each other to further constrain the role and persistence of water in the region.

Figure 2: THEMIS daytime infrared image mosaic of the L-shaped Jones crater area. Gaps in the dataset are areas where there is currently no released THEMIS daytime IR coverage.

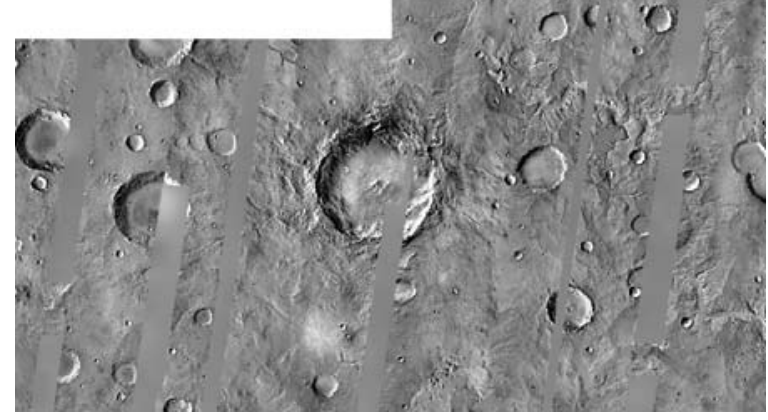

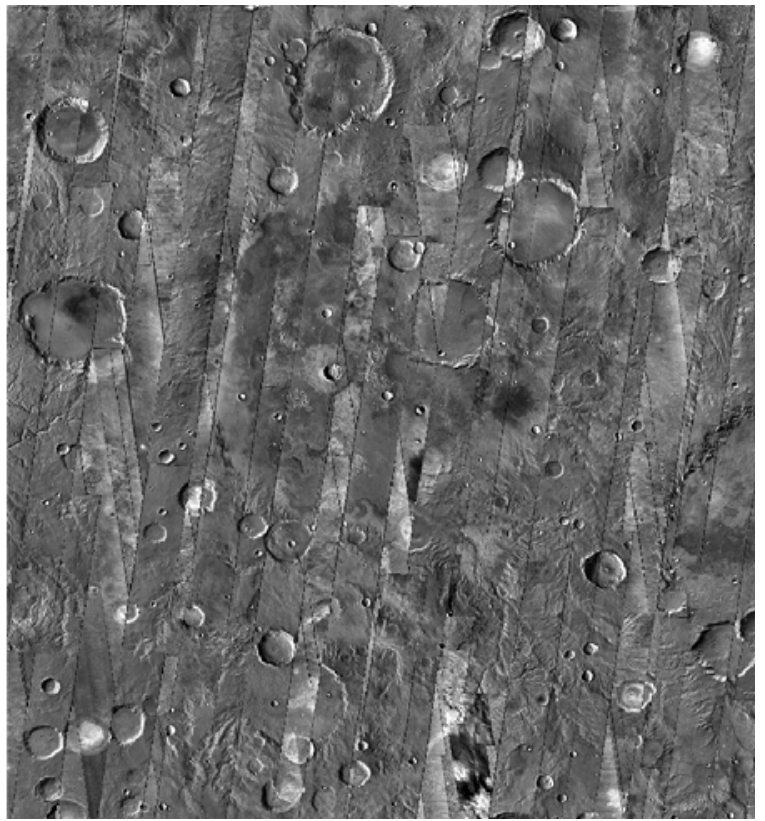

Figure 3: THEMIS daytime and nighttime infrared image mosaic of the Newcomb-Paraná area.

If the results of crater counts show that valley networks formed simultaneously, it may suggest that groups of basins and sub-basins over a region are related, suggesting an areally extensive period of water-driven erosion. However, Paraná Valles and the valley network on the west flank of Newcomb crater do not currently display linked valleys at the surface, but it is possible that they were linked hydrologically in the past. One possible scenario is that the valley networks could have been connected when they were active but evidence of their connection is obscured by later resurfacing events (i.e. volcanic resurfacing or crater impactslejecta). The second scenario is that the valleys are not linked at the surface but are linked by a groundwater network. This hypothesis will be tested by attempting to create a groundwater flow model using discharge rates from active sapping systems on Earth and scaling the model with Martian physical properties.

References. [1] Grant J.A. and D.A. Clark (2002) Planetary Mappers Meeting (abst.). [2] Williams, K.K. and J.A. Grant (2003) Planetary Mappers Meeting (abst.). [3] Fortezzo, C.M. and J.A. Grant (2004) Planetary Mappers Meeting (abst.). [4] Grant, J.A., K.K. Williams, and C.M. Fortezzo (2005) Planetary Mappers Meeting (abst.). [5] Hare, T. et al. (2006) LPSC XXXVII, 2398 (abst.). [6] Barlow, N. (2006) LPSC XXXVII, 1337 (abst.). [7] Grant, J.A. (1987) NASA Tech, Memo., 89871, 1-268. [8] Tanaka, K.L. (1982) NASA Tech. Memo., 85127, 123-125. [9] Wichman, R. and P.H. Schultz (1987) NASA Tech. Memo., 89810, 474-475. 
GEOLOGIC MAPPING OF OLYMPUS MONS CALDERA, MARS, AT 1:200K. Peter J. Mouginis-Mark, HIGP/SOEST, University of Hawaii, Honolulu, HI 96822

A 1:200K geologic map of Olympus Mons caldera will be produced, using both THEMIS VIS and HRSC images. By mapping each of the other craters within the caldera, we will be able to examine the possible differences in intra-caldera activity at different times in the evolution of the caldera. Understanding the spatial distribution of the tectonic and volcanic features within Olympus Mons caldera via the new map will have importance for future research efforts that will either be proposed by us to PG\&G or MDAP, or by others who could use the map for input data for thermal models that explore the longevity of the magma source (e.g., Wilson et al., 2001).

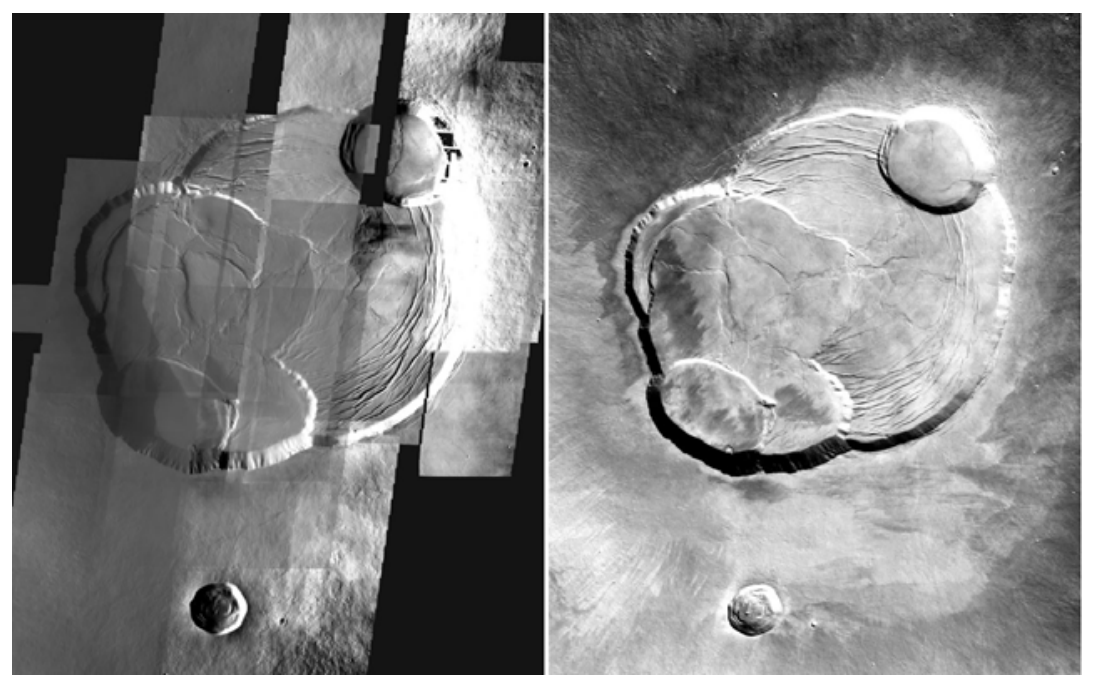

Figure 1: Base-maps of the coverage for Olympus Mons caldera that we have assembled for this mapping effort. At left is a mosaic of 15 individual THEMIS VIS images at a resolution of $18 \mathrm{~m} / \mathrm{pixel}$. At right is the Mars Express coverage provided by orbit 037. These two images will serve as the geodetic control for all of the GIS layers that are produced under this mapping effort.

\section{Progress in Year 1}

1) We have assembled the map base from the THEMIS VIS images, co-registered these images with the Mars Express data (Figure 1), and converted these images to the mapping projection. The two data sets provide complimentary coverage of the caldera by virtue of the higher spatial resolution of the Mars Express scene and the more suitable (i.e., lower) sun angle of the THEMIS data. All of the GIS data products to be generated during this mapping will be referenced to this image data base.

2) Initiate investigations of secondary craters on the caldera floor as a precursor to the development of crater counts based on the available MOC images. This is an important precursor to the development of a chronology for the collapse events that now form the six main craters that comprise the caldera. We are particularly concerned about this relative timing of the caldera collapse events in the light of the results from Mars Express (Neukum et al., 2004) that propose a sequence of collapse that is contrary to the stratigraphic sequence of the craters. To this end, part of our work in Year 1 has been to examine all of the MOC images of the caldera floor to identify probable secondary 
craters from the $14 \mathrm{~km}$ diameter impact crater on the southern rim. The results from our search are shown in Figure 2.

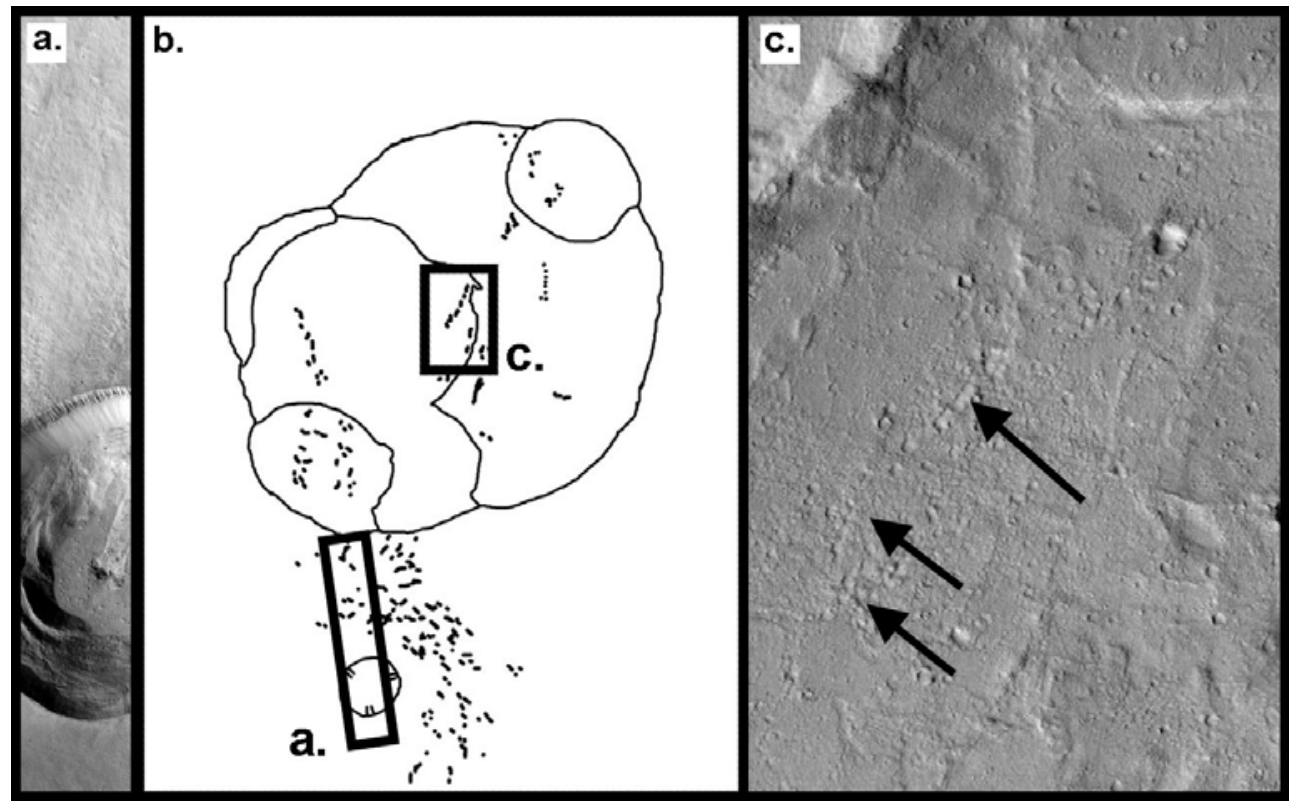

Figure 2: Distribution of secondary craters from the impact crater Pangboche (name provisionally approved by the IAU) to the south of the caldera rim (shown "a" at left). Preliminary mapping conducted under this effort ("b") shows that these secondary craters extend across most of the caldera floor and are most likely responsible for the old ages inferred by Neukum et al. (2004). Center image shows the locations of these secondary craters and the locations of the two MOC images. At right ("c") the arrows identify some of the larger clusters of secondary craters. a) Part of MOC image E0701134; c) part of MOC image R0700514.

\section{Plans for Year 2}

a) Conduct the crater counts, discounting the secondary craters shown in Figure 2 in order to derive a relative chronology for the caldera collapse events.

c) Complete a draft geologic map of the entire Olympus Mons summit area, and submit this map to the U.S. Geological Survey for preliminary review.

d) Publish a research paper (either in JGR-Planets or Icarus) on the similarities and differences between caldera subsidence at the different craters within the Olympus Mons caldera.

e) Start to write the accompanying map text. It is not yet known if we will just have text on the side of the formal map, or whether there will be sufficient information to make this a supplement to the map.

f) Explore options for the production of supplemental map materials, such as slope and aspect maps from MOLA.

\section{References}

Neukum, G. and 10 others (2004). Recent and episodic and glacial activity on Mars revealed by the High Resolution Stereo Camera. Nature 432: 971 - 979.

Wilson, L., E.D. Scott and J.W. Head (2001). Evidence for episodicity in the magma supply to the large Tharsis volcanoes. J. Geophys. Res. 106: 1423 - 1433. 
1:200K GEOLOGIC MAPPING OF THE MARTIAN IMPACT CRATER TOOTING. Peter J. Mouginis-Mark, HIGP/SOEST, University of Hawaii, Honolulu, HI 96822

Impact craters provide crucial information on the subsurface structure of the target material, as well as insights into the cratering process. In the case of impact craters on Mars, the three-dimensional structure of a crater is particularly important as it may provide evidence for spatial or temporal variations in the distribution of volatiles. Mouginis-Mark et al. [2003] identified a $29 \mathrm{~km}$ diameter crater at $23.2^{\circ} \mathrm{N}, 207.8^{\circ} \mathrm{E}$ that meets many of the criteria for having formed in the very recent past. This crater (Fig. 1), provisionally named "Tooting", lies to the west of the Olympus Mons aureole, and formed in relatively young lava flows from the volcano. Analysis of Tooting crater not only provides information on the original geometry of large impacts on Mars, but also enables the original morphology of the crater cavity and ejecta layers to be examined. We have just started a new 1:200K geologic map of Tooting crater in order to better understand the geologic history and spatial distribution of units. A 1:1M map of the secondary crater field of Tooting will also be produced. In this way, we hope that our maps will further the understanding of the morphology of a very fresh, large, impact crater on Mars in much the same way that the map of the crater Copernicus [Howard, 1975] promoted a better understanding of fresh large lunar craters. We have three goals for this mapping:

1) Mapping the secondary crater field: Tooting has a large number of secondary craters that are located right next to the distal rampart of the ejecta lobes (indeed, it seems highly likely that some secondaries are buried by the ejecta lobes). This distribution of secondaries is strikingly different from that of Zunil where most of the secondaries are at large radial distances from the primary [McEwen et al., 2005], and so we hope that by producing a 1:1M scale map of the secondary crater field of Tooting we will be able to document the proximal segment of a large secondary crater population.

2. Geology of the crater cavity: Understanding the pristine geology of any impact crater on Mars that is several tens of kilometers in diameter has great value by virtue of the fact that it sets a benchmark against which other, older and more degraded, craters can be compared. We believe that we can identify several features within Tooting that set such constraints for the impact cratering process on Mars. These features include: (a) blocks on the crater floor that may be segments of a large central peak; (b) impact melt sheets on the southern portion of the floor; and (c) lobes of material that may be impact melt on the southern outer rim. The possible identification of impact melt is particularly intriguing as numerical models for the effects on volatiles on Mars would predict that melt would be rapidly destroyed during the cratering process (Kieffer and Simonds, 1980).

3. Mode of ejecta emplacement: Topographic information for Tooting crater will also be included in the new map, enabling the distribution of geomorphic features seen in THEMIS and MOC images to be compared with the MOLA elevation and local slope information. This will be particularly important for the analysis of ejecta thickness and the geometry of the crater cavity. 

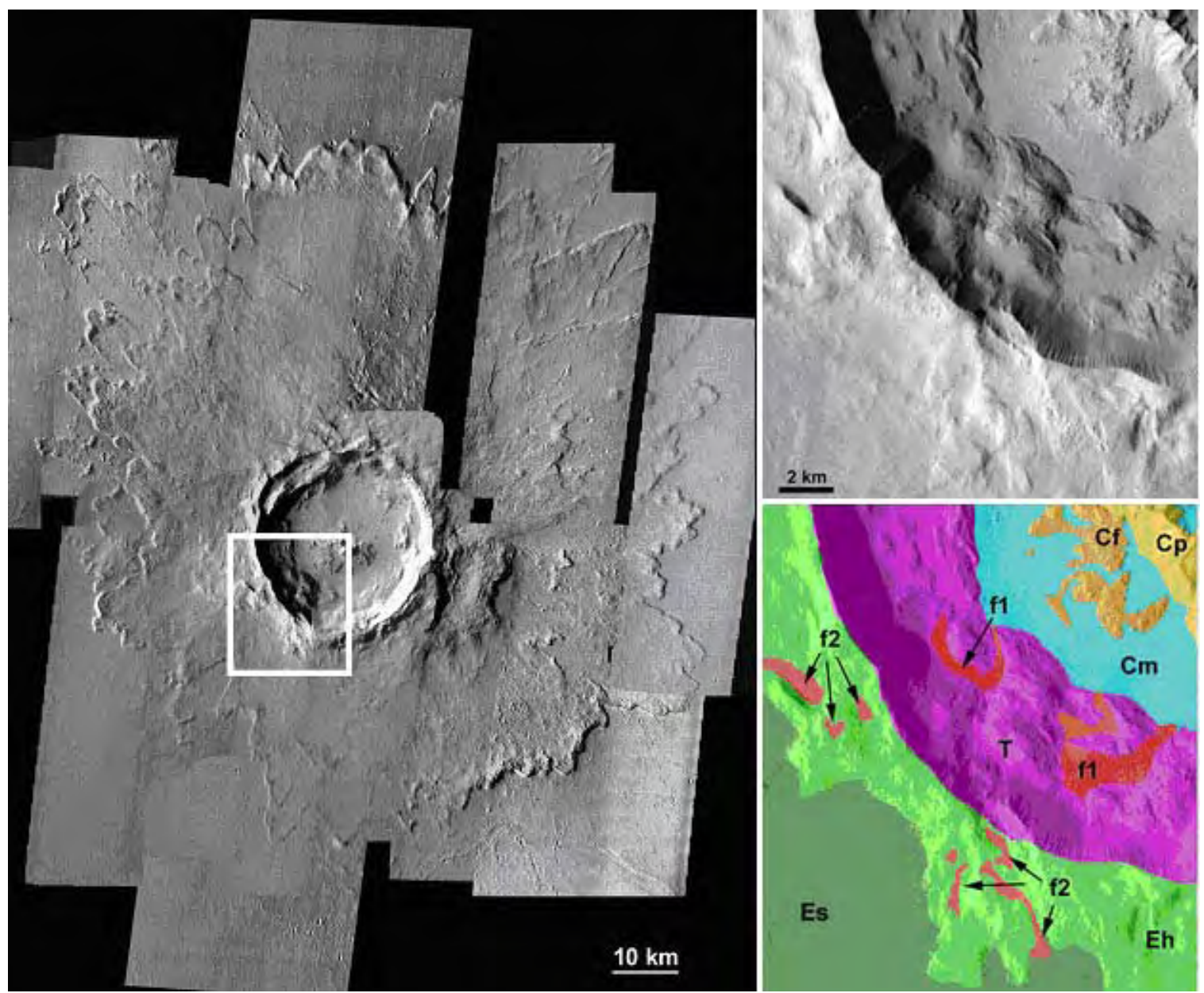

Figure 1 (left): Uncontrolled photomosaic of all the THEMIS VIS and daytime IR images of Tooting crater. Even at this scale, it is evident that not all of the ejecta had the same flow properties, as evidenced by the blocky nature of the deposit to the east of the rim crest. The white box delineates the area of coverage shown in Fig. 2. Figure 2 (right, top and bottom): Preliminary geologic map of the southwestern floor and rim of Tooting crater (at bottom right), mapped from THEMIS image V01990003 (at top right). Units are as follows: "Cp" - Central peak; "Cf" - hummocky crater floor; "Cm" - melt sheet on crater floor; "T" - terraces; "f1" - lobate flows on inner wall, interpreted to be impact melt comparable to that seen on the Moon [Hawke and Head, 1977]; "Eh" - hummocky ejecta on outer rim; "Es" - smooth ejecta on outer rim; "f2" - lobate flows on exterior rim, interpreted to be impact melt.

\section{References}

Hawke, B.R. and J.W. Head (1977). Impact melt on lunar crater rims. In Impact \& Explosion Cratering (D.J. Roddy, R.O. Pepin and R.B. Merrill, editors), pp. 815 - 841, Pergamon Press, N.Y.

Howard, K.A. (1975). Geologic Map of the Crater Copernicus. U.S. Geological Survey Map I-840.

Kieffer, S.W. and C.H. Simonds (1980). The role of volatiles and lithology in the impact cratering process. Rev. Geophys. Space Phys. 18: 143 - 181.

McEwen, A., and 8 others (2005). The rayed crater Zunil and interpretation of small impact craters on Mars, Icarus, 176, 351-381.

Mouginis-Mark, P.J., J.M. Boyce, V.E. Hamilton, F.S. Anderson (2003). A very young, large, impact crater on Mars. Int. Mars Conference VI (abstract \#3004). 
GEOLOGIC MAPPING RESULTS OF THE OLYMPIA CAVI REGION OF MARS (MTM 85200): UNITS AND HISTORY. J. A. Skinner, Jr. and K. Herkenhoff, Astrogeology Team, U.S. Geological Survey, 2255 N. Gemini Drive, Flagstaff, AZ 86001 (jskinner@usgs.gov).

Introduction. The north polar plateau of Mars contains geologic units that record some of the most recently active processes on the surface of the planet [1-3]. New, 1:500K-scale geologic mapping of MTM 85200 provides detailed insight into the units and history of the polar plateau, including the evolution of deeply-exposed, low albedo basal materials and repetitive deposition and planation of the uppermost dust-ice units.

MTM 85200 includes dunes of Olympia Undae, the wide troughs and deep depressions of Olympia Cavi (provisional name [pers. comm. J. Blue, USGS]), and the narrow, spiral troughs of Boreales Scopuli. A $>1000 \mathrm{~m}$ high sinuous scarp located at $\sim 85^{\circ} \mathrm{N}$ (herein termed the boreal scarp) elevates higher latitude spiral troughs above the lower latitude rugged troughs, scarps, and dune fields and is a major physiographic and geologic feature within the quadrangle.

Datasets and Methods. Primary base maps included (1) the Mars Global Surveyor (MGS)-borne Mars Orbiter Laser Altimeter (MOLA) $231 \mathrm{~m} /$ pixel digital elevation model (DEM) and related products, and (2) a Viking Orbiter $2(\mathrm{VO} 2)$ summer $1978\left(\mathrm{~L}_{\mathrm{s}}\right.$ between 134 and 137) image mosaic. Mars Odyssey-borne Thermal Emission Spectrometer (THEMIS) visual range and Mars Express-borne High Resolution Stereo Camera (HRSC) image mosaics supplemented the primary map bases. Internet hotlinked MGS Mars Orbiter Camera (MOC) narrow-angle and THEMIS visual range image footprints provided fundamental access and visualization of all available high resolution images. Data were coregistered, rendered, and analyzed using ESRI's ArcMap GIS software package.

Geologic units. The map units, structure, and symbology represented in our MTM 85200 geologic map represents a concerted effort to correlate (where plausible) the results from recently completed [4] and ongoing [5] geologic map efforts and recent topical studies [6-9] of the north polar plateau and surrounding regions. We present our map units as belonging to the Borealis geologic map province, as defined by [4]. Though we observed two craters in the polar sequences, their paucity precludes crater-age determination; relative ages presented herein are postulated based on geological context.

Olympia Cavi units. The Olympia Cavi dominate the polar plateau south of the boreal scarp and include wide $(>15 \mathrm{~km})$ and deep $(>500 \mathrm{~m})$ troughs and depressions. We discriminate three geologic units that crop out within the Olympia Cavi. The Early Amazonian units form the lowest elevation and stratigraphically oldest exposures within the map boundary. These units, which form rug- ged outcrops in southwest-facing trough walls, dip shallowly $\left(<2^{\circ}\right.$, where measurable) to the south. The older of these two units (Olympia Cavi 1 unit--ABoc ) consists of an upward gradation of massive to thickly-bedded materials with moderate to low albedo. The unit occurs between -4200 and $-4800 \mathrm{~m}$ elevation and ranges in apparent thickness from $\sim 100$ to $\sim 350 \mathrm{~m}$.

The younger, immediately superposed unit (Olympia Cavi 2 unit-- $\mathrm{ABoc}_{2}$ ) includes thickly-bedded materials with low to very low albedo and intercalated, thin, highalbedo layers. Unit $\mathrm{ABoc}_{2}$ occurs between -4200 and $4800 \mathrm{~m}$ elevation and ranges in apparent thickness from $\sim 50$ to $\sim 300 \mathrm{~m}$. The $\mathrm{ABoc}_{1}-\mathrm{ABOc}_{2}$ contact ranges between -4350 to $-4700 \mathrm{~m}$ elevation. Some diffuse unconformities separate the units, though in other locations an absent or subdued contact may suggest an upward gradation between units.

The Late Amazonian Olympia Cavi 3 unit $\left(\mathrm{ABoc}_{3}\right)$ is the youngest of the cavi units and drapes unit $\mathrm{ABoc}_{1}$ on trough floors and at the base of the pole-facing trough walls. The unit is only identified south of the boreal scarp. In MOC images, unit materials are exposed in a "swirled" pattern that fills shallow depressions within underlying units and forms topographically smooth, moderate albedo deposits at the base of pole-facing trough walls.

Olympia Undae units. The Olympia Undae extend from $120^{\circ}$ to $240^{\circ} \mathrm{E}$ longitude and are comprised of dune fields and subjacent materials. We discriminate two units within the Olympia Undae. The older unit (Olympia Undae 1 unit-- $\mathrm{ABou}_{1}$ ) forms a $20-\mathrm{km}$-wide band between the margins of the polar plateau and the overlying erg. The surface of unit $\mathrm{ABou}_{1}$ generally consists of highalbedo, linear swales (300 to $600 \mathrm{~m}$ spacing and 10's of meters amplitude) oriented concentric to the polar plateau and perpendicular to the regional wind direction [10]. Unit ABou $_{1}$ pre-dates the younger layered deposits (described below) and may be equivalent in age or older than the older layered deposits.

The younger unit (Olympia Undae 2 unit-- $\mathrm{ABou}_{2}$ ) covers unit $\mathrm{ABou}_{1}$ and consists of low-albedo barchan dunes, which indicate easterly winds. The unit is also mapped near the western margins of the wide troughs and depressions of the Olympia Cavi. Dune forms have similar low albedo, are spatially associated with, and onlap unit $\mathrm{ABoc}_{2}$ suggesting it is a source for the aeolian unit.

Planum Boreum units. The north polar plateau is dominated by layered deposits exposed in the uppermost sections of Olympia Cavi south of the boreal scarp and 
within the entire south-facing trough walls and floors of Boreales Scopuli north of the boreal scarp. We divide the layered deposits into two units, roughly equivalent to the upper and lower layered deposits described by [9]. The Planum Boreum 1 unit (unit $\mathrm{ABb}_{1}$ ) consists of thick $(>10 \mathrm{~m})$ beds with multiple, alternating high and low albedo layers. The unit erodes into scalloped alcoves, particularly at lower latitude and elevation. Angular unconformities are common within unit $\mathrm{ABb}_{1}$, with most observed proximal to the boreal scarp and at trough terminations. The Planum Boreum 2 units drape the lower layered sequences and are divided into lower and upper members. The lower member (Planum Boreum 2a unit-$\mathrm{ABb}_{2 \mathrm{a}}$ ) consists of thin layers positioned above a subtle unconformity that is not always present. Layers have lobate margins and distinctive alternating high/low and speckled albedo patterns. The upper member (Planum Boreum $2 b$ unit-- $\left.A B b_{2 b}\right)$ is the equivalent of polar ice of previous maps (e.g., unit Api of [3]). Our extent is based on a VO2 mosaic of images acquired during late Martian summer of 1976. We map unit $\mathrm{ABb}_{2 \mathrm{~b}}$ as draping (in some instances) both Planum Boreum 1 and 2a units. We use a buried contact to represent the relationship of the 1976 ice extent with underlying layered deposits, as observed in MOLA, MOC, and THEMIS data.

Geologic history. During the Early Amazonian, the Olympia Cavi 1 and 2 units were emplaced, forming the base of the polar plateau and burying volatile-rich materials and mantles of the Vastitas Borealis (VB) units [4]. The polar basal units may extend no deeper than -4800 $\mathrm{m}$ elevation based on the average elevation of the surrounding VB units. The Olympia Cavi 1 unit was emplaced through the accumulation of fine-grained materials, perhaps related to the erosion of the Scandia region materials [9], Chryse outflow sediments, volcanic materials and/or the emplacement of ice-rich surface mantles. We interpret the massive to thickly-bedded character of these materials to reflect post-emplacement (and perhaps repetitive) climate oscillations that desiccated volatilerich strata, resulting in compaction and disruption of internal layers. The Olympia Cavi 1 unit was subsequently eroded into irregular mountains and hillocks $<500 \mathrm{~m}$ in height based on unit thickness and the irregular contact with overlying materials. Broad-scale trough orientation may date to the Early Amazonian scouring of the Olympia Cavi 1 unit. Accumulation of thick, dark deposits both against and above eroded Olympia Cavi 1 unit vestiges formed the Olympia Cavi 2 unit. Geologically recent dune sources from this unit suggest that it is made up (in part) of sand-sized material; finer-grained material may have accumulated at higher elevations to form apparent gradational material boundaries with the eroded, underlying Olympia Cavi 1 unit. Both Olympia Cavi units were subsequently subjected to aeolian scour- ing and devolatilization, where disaggregated lithic particles may have been re-distributed into lower latitudes as (1) sand sheets through surface saltation and (2) surface mantles through atmospheric fall-out. Though we cannot yet discriminate discrete erosional events within the mapped sequences, the Olympia Cavi units likely represent multiple accumulation-degradation events that occurred throughout the Amazonian. Accumulation of ice and non-volatile material as both layered deposits and migrating sand sheets during periods of low solar insolation may have been followed by devolatilization, compaction, and erosion during periods of high solar insolation.

During the Late Amazonian, the Olympia Undae 1 unit was emplaced, perhaps as an early (and since planated and partly buried) sequence of layered deposits (as suggested by [11]). Alternatively, the unit may postdate the Planum Boreum 1 unit. During the latest major decrease in solar insolation (estimated at $\sim 5 \mathrm{Myr}[9,12]$ ), the Planum Boreum 1 unit was emplaced as thick sequences of dust and ice layers, where unconformities record periodic erosion perhaps related to orbital changes, volcanic activity at lower latitudes, or other causes. These events were of insufficient intensity/longevity to destroy the entire unit. Surface erosion may have been concentrated along pre-existing surface swales and troughs based on observed angular unconformities at trough terminations. During the most recent high obliquity cycle (estimated at $\sim 20 \mathrm{Kyr}[9,12]$ ), the Planum Boreum 1 unit was severely scoured and quickly followed by a resumption of dust-ice deposition to form the Planum Boreum 2 units. The latitudinal variation of the seasonal frost boundary records alternating periods of surface scour and surface deposition, as reflected by the overlapping nature of unit $\mathrm{ABb}_{2 \mathrm{~b}}$ on underlying upper and lower layered deposits.

Further work. We are finalizing map text and will submit the map for review by the end of summer 2006. In addition, we have submitted an abstract to the $4^{\text {th }}$ International Conference on Polar Science and Exploration (Oct 2-6, 2006) to present the results concerning the most recent geologic evolution of MTM 85200 units.

References. [1] Cutts et al. (1976) Science 194, 1329-1337. [2] Thomas P. et al. (1992) in Mars, pp. 767-795. [3] Tanaka and Scott (1987) USGS I-1802-C. [4] Tanaka et al. (2005) USGS SIM 2888, 1:15M scale. [5] Tanaka et al. (2006) LPSC XXXVII abs. \# 2344. [6] Byrne and Murray (2001) JGR 107, doi:10.1029/ 2001JE001805. [7] Kolb and Tanaka (2001) Icarus 154, 22-39. [8] Fishbaugh and Head (2005) Icarus 174, 444474. [9] Tanaka (2005) Nature 437, 991-994. [10] Tsoar et al. (1979) JGR 84, 8167-8180. [11] Fishbaugh and Head (2000) JGR 105, 22,455-22,486. [12]Laskar et al. (2002) Nature 419, 375-377. 
GEOLOGIC MAPPING AND STRATIGRAPHY OF NORTH POLAR DEPOSITS ON MARS: PRELIMINARY RESULTS. K.L. Tanaka ${ }^{1}$, K.F. Mullins ${ }^{1}$, J.A. Skinner, Jr. ${ }^{1}$, J.A.P. Rodriguez ${ }^{2}$, and C.M. Fortezzo ${ }^{1,3}$; ${ }^{1}$ Astrogeology Team, U.S. Geological Survey, Flagstaff, AZ 86001 (ktanaka@usgs.gov); ${ }^{2}$ Dept. Earth and Planetary Sci., U. Tokyo, Tokyo, Japan; ${ }^{3}$ Dept. of Geology, Northern Arizona U., Flagstaff, AZ.

Introduction: We report on preliminary results of detailed photogeologic mapping at 1:5,000,000 scale of parts of the north polar region on Mars that expose key geologic elements and relationships. Our goal is to better understand the interplay of local stratigraphy, $\mathrm{H}_{2} \mathrm{O}$ ice and $\mathrm{CO}_{2}$ frost, climate, and insolation and eolian processes in the development and modification of north polar stratigraphy and geomorphology. At present, extensive data sets for the north polar region include a MOLA DEM at $115 \mathrm{~m} /$ pixel resolution and thousands of THEMIS VIS and IR, HRSC, and MOC wide- and narrow-angle images acquired at various times. TES and THEMIS data provide useful albedo and thermophysical information.

The Rupes Tenuis unit: Much of the basal part of Planum Boreum within and west of Chasma Boreale consists of nearly horizontally bedded strata of possibly Early Amazonian age [1] exposed on the floor of Chasma Boreale and along and above parts of Rupes Tenuis [1]. This prominent scarp runs from the southwest margin of Chasma Boreale westward to $\sim 240^{\circ} \mathrm{E}$. and rises hundreds to $\sim 1000 \mathrm{~m}$ above Vastitas Borealis and $\sim 600 \mathrm{~m}$ above the floor of Chasma Boreale. We name the basal strata of Planum Boreum the Rupes Tenuis (RT) unit.

Along Rupes Tenuis, the RT unit forms most of the thickness of Planum Boreum but is partly buried by younger layered deposits and mantle material that obscures its morphology (THEMIS V05209008). RT is crowned at $287^{\circ} \mathrm{E}$. by two massive layers having a combined thickness of $\sim 100 \mathrm{~m}$ and whose eroded margins include circular to elongate knobs mostly $<1 \mathrm{~km}$ across. The massive layers appear to dip gently westward. Below these, about 20 layers (and/or layer sequences) totaling $<850 \mathrm{~m}$ can be discriminated in better exposures, but they generally cannot be traced continuously for more than several kilometers. These beds appear to have somewhat uneven thicknesses. Locally, scarps cut across the beds and may result from faulting. The unit thins westward and cannot be traced with certainty west of $\sim 242^{\circ} \mathrm{E}$.

For the Chasma Boreale floor platform, the RT unit is reduced to 10 layers totaling 200 to $350 \mathrm{~m}$ in thickness [2]. MOC images (e.g., R2300500 and S0100879) indicate minor faulting, tilting, and fracturing and local burial by thin layered material.

None of these better exposures of the RT unit display dunes emanating from them and thus the unit does not make up part of the dark platy deposit described as forming the base of the Olympia Undae unit below. Rather, the RT unit may result from erosion and redeposition of materials generated by mud volcanism from the Scandia Tholi, Cavi, and Colles region, covering $\sim 1.5 \times 10^{6} \mathrm{~km}^{2}$ of surrounding plains and averaging $100 \mathrm{~m}$ in thickness [2]. This reworking may have involved the adherence of fine-grained particles to polar surface ice. Rapid erosion of the RT unit ensued, perhaps resulting in much of the present form of the deposits. Subsequent stabilization of these deposits permitted the accumulation of the presently observed Early Amazonian crater population.

Amazonian craterforms-Implications for paleomantles: Based primarily on MOLA data, >1800 craterforms have been identified in the northern plains characterized by elevated interior floors and highstanding, horizontal to gently sloping, modified ejecta blankets [1,3]. The observed craterforms may be indicative of impact-armored mantle material, which was subsequently removed where unarmored, leaving a perched (pedestal) crater. The distribution of these craterforms throughout the northern plains suggests that mantles were often present and in flux following formation of the Vastitas Borealis units [1]. Pedestal craterforms are also evident on the RT unit where exposed on Planum Boreum, including within Chasma Boreale, indicating that thick, Planum Boreumcentered layered deposits like the PB1 unit described below have been absent during much of the Amazonian [2]. Here, we refer to these inferred lowland mantles as the Vastitas Borealis paleomantle (VBP) unit.

The Olympia Undae unit: The dark north polar ergs of Olympia, Abalos, and Hyperboreae Undae mapped as the Olympia Undae (OU) unit [1] consist of dunes tens to hundreds of meters wide of varied form and areal coverage. The dunes are generally superposed on a moderately dark surface marked locally by fine ripples ( $>15 \mathrm{~m}$ in wavelength; e.g., MOC R0100086), which are oriented perpendicular to the wind direction indicated by barchan dune orientations. Locally, the dark surface includes broader undulations $\sim 100$ to $300 \mathrm{~m}$ in wavelength. The dunes emerge from beneath layered sequences mapped as Planum Boreum unit 1 (PB1) [1] where an uneven dark layer is locally detected (e.g., MOC E0201976). The dark layer may be buried dune material. The dunes are also partly buried by thin, bright deposits, mapped as the PB2 unit, as 
well as by young mantle deposits. The interdune ripples may be similar in age to the dunes, postdating the dark undulating material in places (e.g., MOC S0100668). In scalloped depressions along the margin of Planum Boreum, the dark material underlying the dunes and PB1 unit has a layered, platy appearance [4] and is locally buried by patches of possibly PB2 unit (e.g., MOC R0100728). Thus the OU unit consists of (1) a moderately dark, platy, locally basal member, (2) a very dark, uneven, probably sandy member locally made up of dunes discontinuously overlying the platy member, and (3) dark dunes and less-dark ripples that discontinuously overlie the eroded surface of the platy unit. The platy and dark members formed after the RT and VBP units and prior to PB1 unit. The dark dunes may include both exhumed dunes of the dark member [5] and younger dunes resulting from erosion of the platy and dark members prior to deposition of PB2 and mid-latitude mantle (MLM) [6] units. The interdune ripples may be made up of a non-saltating sand component. A 19-km-diameter crater provisionally named Jojutla at $81.7^{\circ} \mathrm{N}, 190.1^{\circ} \mathrm{E}$ within Olympia Undae likely formed in the midst of the platy unit sequence; the ejecta rests on the Olympia lobe and the crater contains some dark platy layers and dunes.

Formerly, Olympia Undae was interpreted to be underlain by PB1-equivalent layered deposits due to its domical regional shape [7]. However, we see only evidence for the opposite relationship (e.g., MOC E0201976). Overall, it may be that each platy layer, where not cross-bedded, represents an epoch of sandsea migration and accumulation. These deposits then became subdued and modestly indurated during quiescent periods that may have included accumulation of icy layered deposits, which are locally observed in eroded scarps as bright interlayers (e.g., MOC E0201209). The dark upper layer may be the youngest of the sand-sea layers, but for some reason did not become indurated. The upper dune and ripple member is in close spatial association with the platy and dark members, indicating that the dunes have not migrated significantly since erosion of the PB1 unit and the platy and dune members. Also, dunes generally appear not to have migrated since emplacement of the PB2 unit.

Planum Boreum 1 unit. The lower part of this unit locally appears to be dark and may represent lag deposits, whereas upper parts appear to include cyclic albedo sequences [8]. We observe that the lower dark zone begins with darker, thicker beds at the base. We suggest that this may be due to inclusion of higher proportions of wind-blown fines derived from erosion of paleomantles (VDP unit) and materials of the OU unit. Ground-penetrating MARSIS radar echoes across accumulating ice layers of Planum Boreum east of Chasma Boreale suggest low-loss material such as a pure, cold ice [9]. This part of the PB units is farthest from exposures of the OU unit and thus likely freer from reworked OU material. Lower parts of PB1 unit include numerous unconformities, which may result in part from early episodes of trough insolationcontrolled deepening perhaps associated with eolian removal and transfer of dark fines disaggregated from dark layers within the unit $[10,11]$.

Planum Boreum 2 unit: This unit consists of several alternating dark and bright layers and rests unconformably over PB1 and OU units and is potentially stratigraphically equivalent to the mid-latitude mantle (MLM). In troughs of Planum Boreum, it displays a basal dark layer that may be preferentially eroded from the troughs [10]. The surface of the PB2 unit appears rough in MOC images, and locally displays ripples similar in appearance to those associated with the OU unit (e.g., MOC M0000063).

Summary: Our north polar stratigraphic results are preliminary, and we likely will find additional stratigraphic units and relations with further study. However, some key findings are emerging, including: (1) much of Planum Boreum is long-lived, consisting of the evenly layered, moderately deformed and cratered, and heavily eroded Rupes Tenuis unit; (2) the circumpolar dunes are derived from platy and dark materials that underlie layered deposits and appear to form sequences (a) underlying Olympia Undae, (b) surrounding parts of Planum Boreum south of Rupes Tenuis and north Olympia Undae, and (c) covering parts of the RT unit on the floor and walls of Chasma Boreale; (3) the Planum Boreum 2 and MLM units may be stratigraphically equivalent; (4) circum-polar dunes generally underlie the PB2 and MLM units and thus appear to be largely inactive; (5) dark veneers appear to be made up of fines eroded from the OU unit and dark layers within the PB units; (6) many PB1 unconformities may be due to episodes of trough lengthening; and (7) Chasma Boreale may largely be the result of katabatic winds along its northwestern marginal scarp, which formed long before the OU and PB units were emplaced above it.

References: [1] Tanaka K.L. et al. (2005) USGS Map I-2888. [2] Tanaka K.L. (2005) Nature 437, 991. [3] Skinner J.A., Jr., et al. (2005) LPSC XXXVII, Abs. \#1476. [4] Byrne S. and Murray B.C. (2002) JGR 107, 5044. [5] Mullins K.F. et al. (2005) LPSC XXXVII, Abs. \#1998. [6] Mustard J.F. et al. (2001) Nature 412, 411. [7] Fishbaugh K.E. and Head J.W. III (2000) JGR 105, 22,455. [8] Milkovich S.M. and Head J.W. (2005) JGR 110, doi:10.1029/ 2004JE002349. [9] Picardi G. et al. (2005) Science. [10] Rodriguez J.A.P. et al. (2005) LPSC XXXVII, Abs. \#1437. [11] Fortezzo C. and Tanaka K.L. (2005) LPSC XXXVII, Abs. \#2277. 
GEOLOGIC MAPPING OF THE MEDUSAE FOSSAE FORMATION ON MARS AND THE NORTHERN LOWLAND PLAINS OF VENUS. J. R. Zimbelman, CEPS/NASM MRC 315, Smithsonian Institution, Washington, D.C., 20013-7012; zimbelmanj@si.edu.

Introduction: This report summarizes the status of mapping projects for both Mars and Venus, supported by NASA grant NAG5-11743 (for which a no-cost extension ends this year). It is anticipated that the three maps discussed below will be submitted to the USGS by the end of the year.

Medusae Fossae Formation (MFF), Mars: Mapping in the eastern portion of MFF was initially undertaken at $1: 500 \mathrm{~K}$ scale by the PI using the best available Viking imaging. However, it soon became apparent that this scale was smaller than was necessary to portray the geologic relationships derived from the images. Mapping was then conducted at 1:4M scale, incorporating the results obtained from the initial study into a broader regional context. As THEMIS daytime IR images became available, it soon became apparent that $1: 4 \mathrm{M}$ scale could not adequately portray the rich detail available from these new data [1]. Somewhat like Goldilocks, we finally settled upon a scale of $1: 2 \mathrm{M}$ as 'just right' in order to take advantage of the information in the daytime IR THEMIS images while also covering a reasonable portion of the planet [2, 3]. This scale also corresponds to the USGS series of Viking-based photomosaics for Mars. ISIS software made it possible to project and mosaic daytime IR THEMIS images in order to make a base image for the mapping. The coverage of released daytime IR images is presently nearly complete within MC 8-SE ( $0^{\circ}$ to $15^{\circ} \mathrm{N}$ lat., $202.5^{\circ}$ to $225^{\circ} \mathrm{E}$ long.), the location for which we have produced a geologic map at 1:2M scale. The mapping results to date have proved helpful in evaluating the history of the global dichotomy in the Amazonis region of Mars [4], strengthened the case for an ignimbrite origin for MFF [5], and in establishing the context for evaluating formation mechanisms potentially active in western portions of MFF [6].

The Gordii Dorsum escarpment is the dominant structural and topographic feature within MC 8-SE (Figure 1). The daytime IR THEMIS images reveal an incredible wealth of detail, due to the combination of a uniform dust cover across the region and the THEMIS daytime IR sensitivity. The new mapping has revealed five distinct subunits for the upper member of MFF and three subunits for the middle member of MFF. Following USGS convention, the coloring of the geologic units is superposed on the base image in a way that allows much of the image detail to 'show through' the color. Unit designations follow after those of the global geologic map [7];

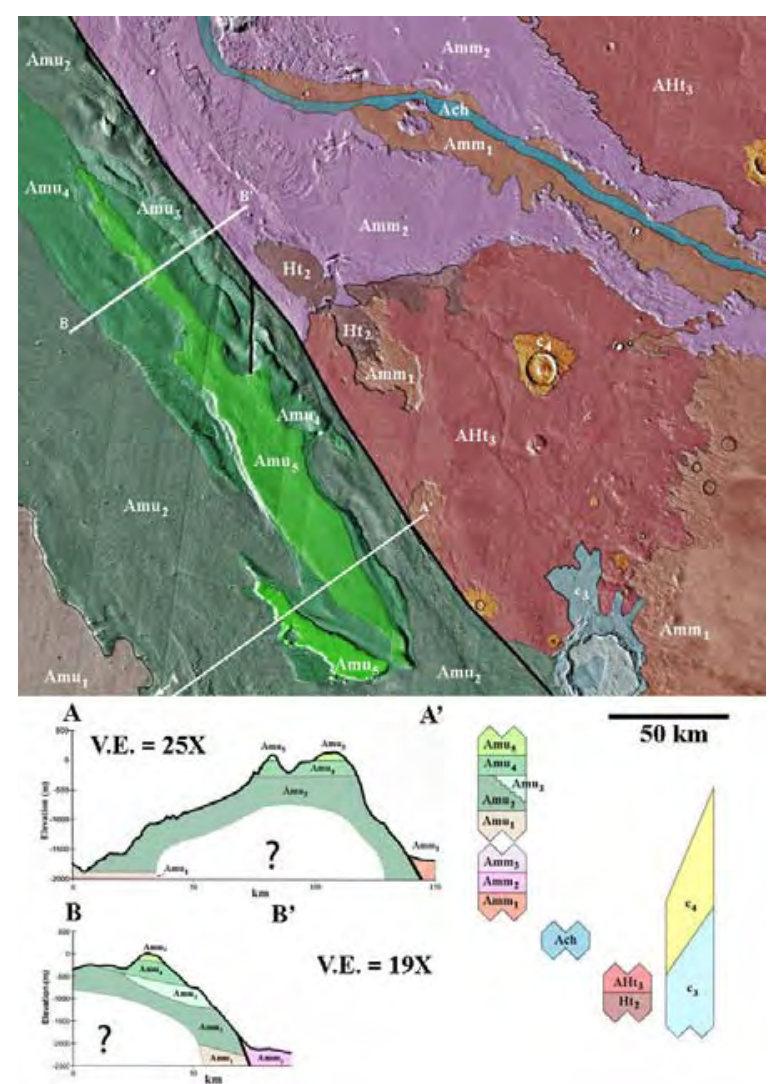

Figure 1. Portion of geologic map for MC 8-SE, centered on the Gordii Dorsum escarpment. Geology is superposed on a base of THEMIS daytime IR images. Stratigraphy and MOLA cross-sections are included below the map.

these units are identified as $\mathrm{Amu}_{1}$ to $\mathrm{Amu}_{5}$ and $\mathrm{Amm}_{1}$ to $\mathrm{Amm}_{3}$ (subscript 1 being the oldest, stratigraphically lowest unit), where ' $A$ ' refers to the Amazonian epoch, the first ' $m$ ' refers to $M F F$ in general, ' $u$ ' refers to the upper (globally defined) member of MFF, and the second ' $m$ ' refers to the middle (globally defined) member of MFF.

The contacts and structures on the map can be easily related to MOLA topography, allowing for unprecedented assessments of the geology in threedimensions (bottom of Figure 1). There is at present no confident way to project the surface contacts to the core of a feature as large as the mound associated with Gordii Dorsum, so the cross-sections include large question marks in their interiors. However, the two cross-sections clearly show that the layering indicated by the subdivisions of Amu is not uniform along the length of Gordii Dorsum. The northernmost cross-section (B to B') has a slight 
easterly dip as compared to the southernmost crosssection (A to A'); a newly identified secondary fault is located between the cross-sections and we conclude that the faulting is likely related to the change in dip. The northernmost section also shows a unit exposed on the eastern side of the topographic mound $\left(\mathrm{Amu}_{3}\right)$ that is not evident on the western side of the topographic mound; this is strong evidence for a significant unconformity within the subunits of Amu.

Northern Lowland Plains, Venus: A 1:5M scale geologic map of the Kawelu Planitia (V-16; $25^{\circ}$ to $50^{\circ} \mathrm{N}$ lat., $240^{\circ}$ to $270^{\circ} \mathrm{E}$ long.) region of the northern lowland plains of Venus has been reviewed through the USGS, and is in final preparation for resubmission. Substantial revisions to the plains stratigraphy took place following the submission of the map; Figures 2 and 3 illustrate the V-16 map units and their relative stratigraphy, respectively. The primary science result derived from the mapping is a detailed stratigraphy identified for lava flows from several volcanic centers around the Sekmet Mons volcano [8], which should be valuable in evaluating hypothesized modes of emplacement for the plains. Geologic mapping of the Bellona Fossae (V-15; $25^{\circ}$ to $50^{\circ} \mathrm{N}$ lat., $210^{\circ}$ to $240^{\circ} \mathrm{E}$ long.) region [9] (Figure 4), immediately west of the Kawelu Planitia map, has continued in parallel with the evolution of the $\mathrm{V}-16$ stratigraphy. Complex interfingering of lava flows around Sekmet Mons [8] extends into the eastern portion of $\mathrm{V}-15$, but the remainder of the quadrangle is relatively simpler than that in $\mathrm{V}-16$. The PI was also assigned the Ulfrun Regio map (V-27; $0^{\circ}$ to $25^{\circ} \mathrm{N}$ lat., $210^{\circ}$ to $240^{\circ} \mathrm{E}$ long.), but it will now be made available for future mapping by other researchers.

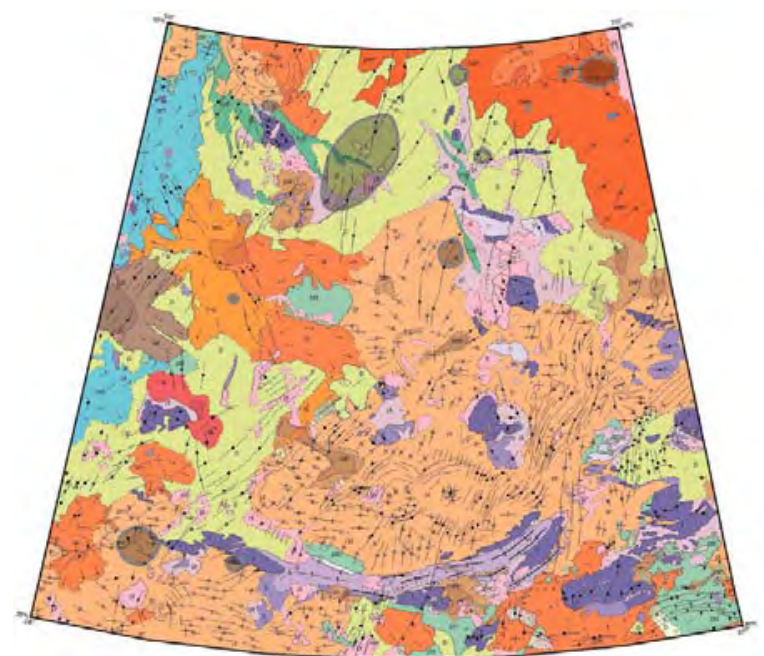

Figure 2. Geologic map of V-16 (Kawelu Planitia).

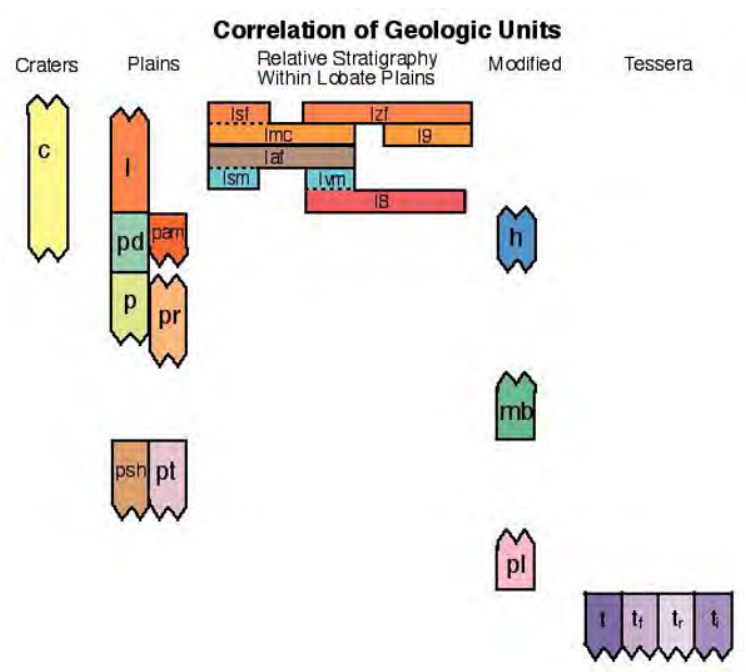

Figure 3. Stratigraphy of map units in V-16 (Fig. 2).

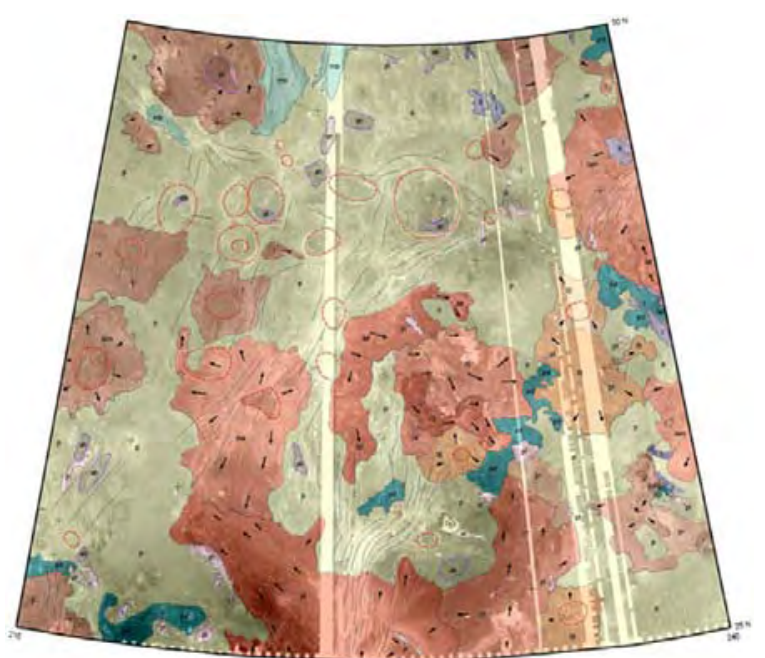

Figure 4. Geologic map of V-15 (Bellona Fossae), over SAR image base.

REFERENCES: [1] Zimbelman J.R. et al. (2003) LPS 34, Abs. \#1390. [2] Shockey K.M. et al. (2004) LPS 35, Abs. \#1539. [3] Shockey K.M. and Zimbelman J.R. (2005) LPS 36, Abs. \#1799. [4] Irwin R.P. et al. (2004) JGR 109, E09011, 10.1029/2004JE002248. [5] Zimbelman J.R. (2003) GSA Abs. Prog. 35(6), 128. [6] Burr D.M. et al. (2006) LPS 37, Abs. \#1367. [7] Scott D.H. and Tanaka K.L. (1986) USGS Map I-1802-A. [8] Zimbelman J.R. (2003) JGR 108, E5, 10.1029/2002JE001965. [9] Zimbelman J.R. (2004) Planetary Geology Mappers Meeting Abstracts, ZIMBELMAN2004PGM.PDF, USGS. 